UNIVERSIDADE DE SÃO PAULO

ESCOLA DE ENFERMAGEM

VITOR HUGO AMENDOLA MARQUES

PRÁTICA PROFISSIONAL DOS ENFERMEIROS

DA ESTRATÉGIA SAÚDE DA FAMÍLIA

NOS GRUPOS DE CAMINHADA DE SÃO PAULO

SÃO PAULO

2010 


\section{PRÁTICA PROFISSIONAL DOS ENFERMEIROS \\ DA ESTRATÉGIA SAÚDE DA FAMÍLIA \\ NOS GRUPOS DE CAMINHADA DE SÃO PAULO}

Dissertação apresentada à Escola de Enfermagem da Universidade de São Paulo para a obtenção do título de Mestre em Ciências

Área de concentração: Cuidado em Saúde

Orientadora: $\operatorname{Prof}^{a} \operatorname{Dr}^{a}$ Anna Maria Chiesa 
AUTORIZO A REPRODUÇÃO E DIVULGAÇÃO TOTAL OU PARCIAL DESTE TRABALHO, POR QUALQUER MEIO CONVENCIONAL OU ELETRÔNICO, PARA FINS DE ESTUDO E PESQUISA, DESDE QUE CITADA A FONTE.

Assinatura:

Data:

Catalogação na Publicação (CIP)

\section{Biblioteca "Wanda de Aguiar Horta"}

Escola de Enfermagem da Universidade de São Paulo

Marques, Vitor Hugo Amendola

Prática profissional dos enfermeiros da estratégia saúde da família nos grupos de caminhada de São Paulo. / Vitor Hugo

Amendola Marques . - São Paulo, 2010.

$88 \mathrm{p}$.

Dissertação (Mestrado) - Escola de Enfermagem da Universidade de São Paulo.

Orientadora: $\operatorname{Prof}^{\mathrm{a}} \operatorname{Dr}^{\mathrm{a}}$ Anna Maria Chiesa

1. Promoção da saúde 2. Atividade física 3. Prática profissional 4. Enfermeiros 5. Saúde da Família I. Título 


\section{FOLHA DE APROVAÇÃO}

Nome: Vitor Hugo Amendola Marques

Título: Prática profissional dos enfermeiros da Estratégia Saúde da Família nos grupos de caminhada de São Paulo

Dissertação apresentada à Escola de Enfermagem da Universidade de São Paulo para a obtenção do título de Mestre em Ciências

Área de concentração: Cuidado em Saúde

Aprovado em:

1

1

\section{Banca Examinadora}

Prof. Dr.

Instituição:

Julgamento: Assinatura:

Prof. Dr.

Instituição:

Julgamento:

Assinatura:

Prof. Dr.

Instituição:

Julgamento: Assinatura: 


\section{Palavras sem história..., são só palavras...}

Filho do meio de mãe solteira, desde a infância tive o sonho de ser atleta e, como muito bem diz o verso da música do Skank "Quem não sonhou em um dia ser um jogador de futebol". Até hoje lembro da minha primeira bola de "capotão" com a mesma emoção que senti naquela dia, com ela nos meus braços franzinos de criança. Entretanto, minha mãe, calejada pela própria experiência - auxiliar de enfermagem - sempre nos guiou para os estudos com mão pesada e com uma sabedoria que só a vida pode ensinar: "inteligência não é nada sem diploma. Filho meu, não será peão barnabé”. Brincando desde a infância em corredores dos hospitais, cresci cercado pela enfermagem e por estes ensinamentos de minha mãe. Por volta dos 14 anos, tive um duro golpe no sonho de ser jogador - ao tentar ser goleiro de um time aqui da capital, fui informado que era muito baixo para tal e que eu nunca iria conseguir êxito nesta área. Com isso, desisti de ser atleta profissional e me dediquei aos estudos e aos campeonatos amadores de levantamento de peso (basismo). E foi desta forma, com o corpo alterado por anos de treinamento pesado, que eu entrei na Escola de Enfermagem da USP com a cabeça raspada, $120 \mathrm{~kg}$ de músculos distribuídos em um corpo de $1,75 \mathrm{~m}$, assistido as aulas acompanhado com bananas, ovos cozidos e com uma cuia d'água. Um ser estranho até para as minhas atuais compreensões. Moldado pela minha crença - "ESPORTE É SAÚDE" - assistia as aulas sem entender o por que tal associação não ocorria na profissão, o que para mim, sempre pareceu lógico e factível. Passei boa parte da minha vida acadêmica dentro da Atlética e envolto as competições de esporte universitário. No último ano, quando estava prestes a seguir outra linha profissional - psicanálise - um sonho inimaginável aconteceu: área de enfermagem nos esportes para estágio curricular supervisionado e monografia. Engraçado como todos na sala simplesmente associaram tal matéria a minha pessoa e, como se o destino conspirasse a favor, eis que voltei a minha crença - "ESPORTE É SAÚDE". Muito difícil foram os primeiros passos pois, inexperiente buscava um guia e, inclusive a minha professora sempre me respondia: "Vitor, o atleta aqui é você. É você quem deverá fazer esta aproximação entre a enfermagem e o esporte". Desta forma, me formei buscando maneiras de "cumprir com a minha missão" e efetuar esta aproximação e fui trabalhar (aprender) com o cuidado de atletas (IOT e Palmeiras). No curso de formação de Pesquisador em Ciências do Esporte do CELAFISCS, aprendi que a Ciências dos Esportes pode ser vinculada à enfermagem por meio da Promoção da Saúde fato que me levou, em 2003, a procurar minha atual orientadora, professora Dra. Anna Chiesa, que me aceitou em seu grupo de estudos e, até hoje não sei bem o que se passa na cabeça dela quando no meio de suas aulas ou apresentações eu inicio "uma série leve de alongamentos". Com as experiências destes dois grupos de estudos, decidi, junto com outra sonhadora (Gisele Machado) iniciar, em 2004, o Grupo de Estudos em Enfermagem nos Esportes que viria a se tornar, em 2005, na Sociedade Brasileira de Enfermagem nos Esportes. Hoje, ao término deste trabalho e, diante de tantas constatações científicas e experiências vivenciadas, agradeço a vida e a todos os que respeitaram meu jeito e me guiaram neste caminho, ainda em construção, da associação da Enfermagem com o Esporte por meio da Promoção da Saúde pela prática da Atividade Física. Continuarei este caminho inspirado por uma frase, dita em meio a uma conversa que tive com a professora Dra Paulina Kurcgant:"

"Você pode fazer uma escolha na vida: Escolher uma profissão de prestígio ou 


\section{Agradecimentos:}

Agradeço sempre aos Astrais Superiores por direcionarem e iluminarem meu caminho em busca do Bem:

Para você melhorar o mundo, basta se voltar para corrigir suas próprias imperfeições.

À professora Ana Cristina Mancussi e Faro por ter sido a responsável por direcionar meus primeiros passos em busca da Enfermagem nos

Esportes:

Os professores às vezes não tem a noção da influência que eles exercem na vida das pessoas

A toda a "Família CELAFISCS" por ter me adotado e por ter me mostrado que o caminho é difícil, porém não impossível:

Tudo o que há no mundo partiu de um sonho.

A Gisele Machado por caminhar comigo na construção da Enfermagem nos Esportes:

Construir o caminho para os outros trilhar... difícil porém gratificante.

Aos meus alunos, que me ensinaram uma valorosa lição:

A melhor forma de aprender é tentando ensinar:

À professora Anna Chiesa que com carinho, e principalmente paciência, acreditou nos meus sonhos e me conduziu com maestria neste caminho, inimaginável e impossível para muitos:

É lindo poder vivenciar e perceber que o ensino não se faz apenas por palavras. 


\title{
Dedicatória:
}

Dedico este trabalho

Ao meu irmão caçula - Fernando Custódio Pereira:

Tenho certeza, de onde você estiver..., está orgulhoso de mim.

\begin{abstract}
Ao meu irmão mais velho - Miguel Ângelo Marques - exemplo de dedicação e luta em prol dos objetivos que devem nortear o ser humano:

O Julgo sempre começa pelas próprias ações.
\end{abstract}

Ao meu Mestre - Cláudio Rogério Silva - pelo exemplo e influencia na
formação do meu caráter:

Mais parecido com um menino, tenho em você - um pai, um amigo, um irmão...

A todos os meus amigos que presenciaram a transformação de um menino em um homem feito:

E que sabem que na intimidade dos encontros de "pés descalços"... ainda sou um menino.

À minha mãe, que abdicou da própria vida para que os filhos não sofressem o que ela sofreu:

Toda grande conquista é influenciada por grandes líderes. Tenho, em todos os seus ensinamentos feitos com português errado e mão de ferro, a base de todo o meu caráter. Espero poder te orgulhar sempre.

À minha esposa, que teve (e tem) a difícil tarefa de me acompanhar em todos estes caminhos:

FAMzinha..

Contigo, não mudei apenas de nome, mudei em toda a minha condição de ser humano. Sou você e ..., dentro dos teus olhos é que percebo o quanto sou pequeno diante de nosso 


\section{SUMÁRIO}

$\underline{\text { Título }}$

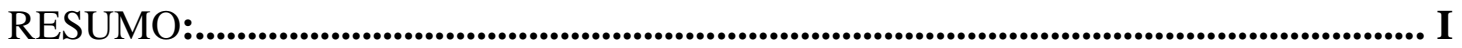

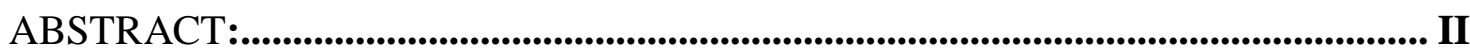

LISTA DE ILUSTRAÇÕES:................................................................................................ III

LISTA DE QUADROS:.................................................................................................... IV

LISTA DE TABELAS:.......................................................................................................V

LISTA DE ABREVIAÇÕES:...............................................................................................VII

1. INTRODUÇÃ̃O................................................................................................01

1.1 Promoção da Saúde..............................................................................................01

1.2 Políticas Públicas e Promoção da Saúde no Brasil............................................ 03

1.3 Atividade Física: Potencial de Promoção de Saúde na Atenção Básica... $\quad 09$

1.3.1 Atividade Física: Histórico mundial..........................................................12

1.3.2 Atividade Física: Histórico nacional...........................................................17

1.3.3 Atividade Física: Histórico municipal...................................................... 20

1.3.4 Atividade Física: Protocolo de prescrição individual para adultos e idosos de ambos os sexos............................................................................23

1.3.5 Atividade Física: Programas de Promoção da Saúde populacional.........................................................................................28

1.3.6 Atividade Física: Incorporação à prática dos enfermeiros................ 33

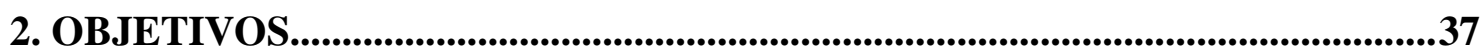

2.1 Objetivo Geral................................................................................................. 37

2.2 Objetivos Específicos................................................................................................... 37 


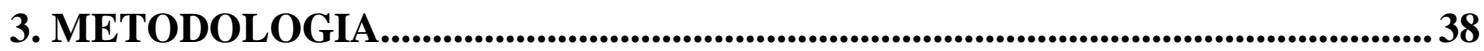

$3.1 \quad$ Tipo de Pesquisa.................................................................................................................38

3.2 Cenário do Estudo....................................................................................................38

3.3 População e amostra do estudo.................................................................................40

3.4 Material e Método..................................................................................................41

3.4.1 Etapas da pesquisa....................................................................................... 41

3.4.2 Descrição dos instrumentos de pesquisa.....................................................43

3.4.3 Tratamento e análise dos dados.............................................................. 46

3.5Aspectos éticos........................................................................................................47

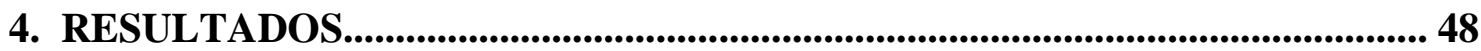

4.1 Caracterização dos grupos de caminhada das equipes de saúde da família da cidade de São Paulo.............................................................................................4 48

4.2 Caracterização dos enfermeiros e de suas práticas nos grupos de caminhada.........................................................................................................50

4.3 Nível de conhecimento dos enfermeiros sobre atividade física para promoção da saúde........................................................................................................ 52

5. DISCUSSÃO

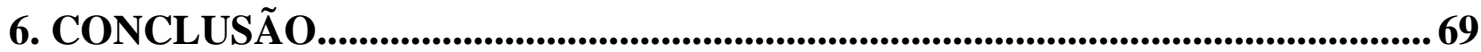

7. REFERÊNCIAS BIBLIOGRÁFICAS................................................................... 72

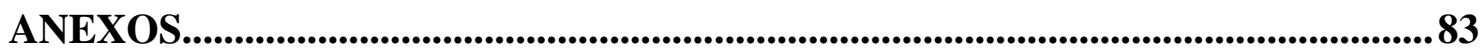

01 Termo de consentimento livre e esclarecido.....................................................8 83

02 Parecer do Comitê de Ética em Pesquisa da Secretaria de Saúde do

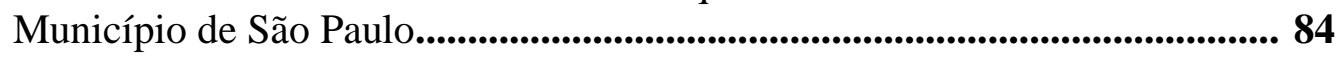

03 Questionários: ........................................................................................................8 86

3a Sobre o nível de conhecimento................................................................8 86

3b Caractarização do grupo de caminhada................................................. 87

3c Análise de prática profissional.............................................................8 88 


\section{RESUMO}

Introdução: No Brasil, o Ministério da Saúde desenvolve estratégias para intervir nos condicionantes das doenças crônicas não transmissíveis por meio da incorporação das Práticas Complementares e Integrativas em Saúde no SUS. Dentre estas práticas, se destacam os grupos de caminhada (GC) por seguirem os preceitos da Promoção da Saúde, contemplando, sobretudo, a autonomia dos profissionais e população. Estas práticas visam complementar as ações clínicas das Equipes de Saúde da Família (ESF) e os enfermeiros têm grande potencial para incorporar esta ação à sua prática profissional. Objetivo: Caracterizar a inserção e a prática dos enfermeiros nos grupos de caminhada (GC) das Unidades com ESF de São Paulo. Metodologia: Foram entrevistados 27 enfermeiros que participavam dos GC, utilizando-se instrumentos de caracterização do GC, da prática profissional do enfermeiro no GC e para avaliação do nível de conhecimento sobre Atividade Física para Promoção da Saúde (AF/PS) com o instrumento padronizado do Programa Agita São Paulo. O tratamento estatístico dos dados foi realizado utilizando-se os programas Excel ${ }^{\circledR}$ e SPSS. Resultados: Dentre as Unidades com ESF, 95 tinham GC, sendo que 38 eram organizados por enfermeiros. Na média, os GC tinham duração de 48 minutos e aconteciam 3 vezes por semana. A maioria dos enfermeiros (55\%) afirmou avaliar os usuários para inclusão no GC e em $40 \%$ dos grupos a caminhada era precedida por avaliação clínica. Quanto ao nível de conhecimento (NC) sobre AF/PS nenhum entrevistado acertou todas as questões em relação à intensidade, frequência semanal, duração e modo de execução diária para AF/PS, $40 \%$ acertaram apenas uma questão e $22 \%$ não acertou nenhuma. Conclusão: Apesar da inserção privilegiada dos enfermeiros para fortalecer ações de promoção da saúde na ESF o NC dos enfermeiros sobre AF/PS mostrou-se inadequado, indicando a necessidade de processos de educação continuada voltadas para a incorporação desses conceitos. Em relação aos GC nas Unidades de Saúde, sugere-se a elaboração de guias que norteiem as ações dos profissionais envolvidos tanto no aspecto instrumental quanto gerencial.

DESCRITORES E PALAVRAS CHAVE: Promoção da Saúde, Atividade Física, Prática Profissional, Enfermeiros, Práticas Complementares e Integrativas em Saúde, Grupos de Caminhada, Saúde da Família. 


\begin{abstract}
Introduction: In Brazil, the Ministry of Health has been developing strategies to intervene in the conditions of chronic, non-transmissible diseases through the incorporation of Complementary and Integrative Practices within the Brazilian National Healthcare System (SUS).

Among these practices, the one that most "stands out" is the Walking Groups (WG) by following the precepts of Health Promotions, contemplating, above all, the autonomy of professionals and the population. These practices are intended to complement the clinical actions of the Family Health Team (FHT) and the nurses have a great potential to incorporate these actions into their professional practice. Objective: To characterize the insertion and the practice of nurses in the WG of the FHT units in Sao Paulo. Methods: Twenty-seven (27) registered nurses who participated in the WG were interviewed. The instruments were used to characterize the WG, the professional practice of nurses in the WG and the standardized instrument for assessing the knowledge level regarding Physical Activities for Health Promotion (PA/HP) of the program called "Agita São Paulo". The statistical processing of data was performed using the programs Excel ${ }^{\circledR}$ and SPSS. Results: Within the FHT units, 95 had WG of which 38 were organized by nurses. On the average, the WG duration was 48 minutes and it took place 3 times per week. The majority of nurses (55\%) affirmed that they evaluated the users for inclusion into the WG and in $40 \%$ of the groups; the actual walking was preceded by a clinical evaluation. Regarding the knowledge level about PA/HP, none of the interviewees correctly answered all of the questions concerning the intensity, weekly frequency, duration and daily mode of implementation for PA/HP, $40 \%$ correctly answered only 1 question and 22\% incorrectly answered all of them. Conclusion: Despite the inclusion of privileged actions by the nurses to strengthen health promotion in the FHT, the inadequate scores concerning PA/HP, obtained by the nurses, clearly indicates a necessity for continuing education processes directed toward the incorporation of these concepts. In relation to the WG in the FHT Units, this study shows that there is a need to elaborate instruments to guide the actions of the professionals involved in both the managerial and instrumental aspect.
\end{abstract}

DESCRIPTORS AND KEY WORDS:

Health Promotion, Physical Activities, Professional Practices, Nurses, Complementaryand Integrative Practices in Health, Walking Groups, Family Health. 


\section{LISTA DE ILUSTRAÇÕES}

Gráfico 01 - Metas e Evolução do Número de Equipes de Saúde da Família Implantadas no Brasil. Brasil, 2010.............................................................. 05

Gráfico 02 - Evolução do Número de Municípios com Equipes de Saúde da Família Implantadas no Brasil. Brasil, 2010............................................ 05

Gráfico 03 - Evolução da População Coberta por Equipes de Saúde da Família Implantadas no Brasil. Brasil, 2010.............................................................. 06

Gráfico 04 - Projeção de óbitos em todas as idades por causa majoritária e grupo de renda. OMS 2005............................................................................. 10

Gráfico 05 - Projeção da perda de renda nacional devido a doenças cardíacas, AVC e diabetes. OMS 2005-2010.

Gráfico 06 - Taxa de mortalidade por doenças do coração entre homens com idade superior a 30 anos, de 1950 a 2002, na Austrália, Canadá, Estados Unidos e Reino Unido.

Figura 01 - Densidade demográfica nacional e Situação de Implantação das Equipes Saúde da Família. Brasil, 2007.

Figura 02 - Transição epidemiológica da mortalidade proporcional no Brasil. Brasil, 2007

Figura 03 - Eixos de intervenção Programa Mais Saúde. Brasil, 2007.

Figura 04 - Apresentação das ações voluntárias caracterizadas como atividade física. 


\section{LISTA DE QUADROS}

Quadro 01 - Proposta de um Modelo Abrangente de Planejamento para os Governos - OMS, 2005.

Quadro 02 - Conceitos fundamentais para prescrição / realização da atividade física terapêutica, 2007

Quadro 03 - Padrão de prescrição / realização da atividade física terapêutica, 2007.

Quadro 04 - Critérios para classificação do nível de atividade física de adultos e idosos de ambos os sexos, 2007

Quadro 05 - Programas internacionais de promoção da saúde através da atividade física.

Quadro 06 - Programas brasileiros de promoção da saúde através da atividade física

Quadro 07 - Padrão adequado para respostas referentes ao nível de conhecimento sobre AF/PS. 


\section{LISTA DE TABELAS}

Tabela 01 - Distribuição dos estabelecimentos da RBS e das UM e USF do município de São Paulo. São Paulo, 2009

Tabela 02 - Distribuição das atividades de PCIS, em relação ao tipo de atividade organizada, no município de São Paulo. São Paulo, 2008.

Tabela 03 - Distribuição das Unidades de Saúde estabelecimentos da RBS e das UBS, UM e USF do município de São Paulo. São Paulo, 2009.

Tabela 04 - Relação entre as USF e UM da cidade e as USF e UM com GC e com envolvimento de enfermeiros, nas cinco regiões do município de São Paulo. São Paulo, 2009.

Tabela 05 - Relação entre as USF e UM da cidade e as USF e UM com GC e com envolvimento de enfermeiros e que participaram da pesquisa nas cinco regiões do município de São Paulo. São Paulo, 2009.

Tabela 06 - Distribuição dos profissionais segundo características de envolvimento nos grupos de caminhadas. São Paulo, 2009.

Tabela 07 - Número e porcentagem de enfermeiros, segundo características de atividades executadas no grupo de caminhada. São Paulo, 2009.

Tabela 08 - Classificação do Nível de Conhecimento dos Enfermeiros sobre Atividade Física para Promoção da Saúde, de acordo com a quantidade de acertos para as variáveis do Questionário sobre o Nível de Conhecimento de Atividade Física para Promoção da Saúde. São Paulo, 2009. 
Tabela 09 - Número e porcentagem de acertos, segundo cada variável que do questionário do Nível de Conhecimento sobre Atividade Física para Promoção da Saúde. São Paulo, 2009

Tabela 10 - Distribuição das respostas referentes à quantidade mínima de dias por semana para a atividade física promover saúde. São Paulo, 2009.

Tabela 11 - Distribuição das respostas referentes à quantidade mínima de tempo por dia para a atividade física promover saúde. São Paulo, 2009.

Tabela 12 - Distribuição das respostas referentes ao nível de conhecimento sobre o modo que a atividade física promover saúde. São Paulo, 2009.

Tabela 13 - Distribuição das respostas referentes ao nível de conhecimento sobre a intensidade que a atividade física promover saúde. 


\section{LISTA DE ABREVIAÇÕES}

\begin{tabular}{|c|c|c|}
\hline \multirow{3}{*}{$\begin{array}{l}\text { ACS } \\
\text { ACSM }\end{array}$} & - & Agente Comunitário de Saúde \\
\hline & - & American College of Sports Medicine \\
\hline & & Colégio Americano de Medicina dos Esportes \\
\hline AFT & - & Atividade Física Terapêutica \\
\hline $\mathrm{AF} / \mathrm{PS}$ & - & Atividade Física para Promoção da Saúde \\
\hline AHA & - & American Heart Association \\
\hline & & Associação Americana de Cardiologia \\
\hline ATMT & - & Área Técnica de Medicinas Tradicionais \\
\hline $\mathrm{CAB}$ & - & Coordenação de Atenção Básica \\
\hline CDC & - & Centers for Disease Control and Prevention \\
\hline & & Centro Americano de Controle e Prevenção de Doenças \\
\hline CELAFISCS & - & $\begin{array}{l}\text { Centro de Estudos do Laboratório de Aptidão Física de } \\
\text { São Caetano do Sul }\end{array}$ \\
\hline DCNT & - & Doenças Crônicas não Transmissíveis \\
\hline EG & - & Estratégia Global \\
\hline ESF & - & Estratégia de Saúde da Família \\
\hline EUA & - & Estados Unidos da América \\
\hline $\mathrm{GC}$ & - & Grupos de Caminhada \\
\hline IBGE & - & Instituto Brasileiro de Geografia e Estatística \\
\hline ME & - & Ministério dos Esportes \\
\hline MS & - & Ministério da Saúde \\
\hline MT & - & Medicinas Tradicionais \\
\hline NAF & - & Nível de Atividade Física \\
\hline $\mathrm{NC}$ & - & Nível de Conhecimento \\
\hline NOB & - & Norma Operacional Básica \\
\hline OMS & - & Organização Mundial da Saúde \\
\hline PAB & - & Programa Agita Brasil \\
\hline PASP & - & Programa Agita São Paulo \\
\hline PAM & - & Programa Agita Mundo \\
\hline $\mathrm{PC} / \mathrm{AF}$ & - & Práticas Corporais / Atividade Física \\
\hline PICS & - & Práticas Integrativas e Complementares em Saúde \\
\hline PMS & - & Programa Mais Saúde \\
\hline PNAF & - & Plano Nacional de Atividade Física \\
\hline PNPS & - & Política Nacional de Promoção da Saúde \\
\hline PNPICS & - & Política Nacional de Práticas Integrativas em Saúde \\
\hline PQVMTPIS & - & Programa Qualidade de Vida com Medicinas \\
\hline
\end{tabular}




\begin{tabular}{|c|c|c|}
\hline \multirow{3}{*}{$\begin{array}{l}\text { PSF } \\
\text { QNC-AF/PS }\end{array}$} & - & Programa de Saúde da Família \\
\hline & - & Questionário sobre o Nível de Conhecimento de Atividade \\
\hline & & Física para Promoção da Saúde \\
\hline \multirow[t]{2}{*}{ RAFA/PANA } & - & Rede de Atividade Física das Américas \\
\hline & & The Physical Activity Network of the Americas \\
\hline RBS & - & Rede Básica de Saúde \\
\hline RNPS/AF & - & Rede Nacional de Promoção da Saúde e Atividade Física \\
\hline SES & - & Secretaria Estadual de Saúde \\
\hline SESC & - & Serviço Social do Comércio \\
\hline SMS & - & Secretaria Municipal de Saúde \\
\hline SF & - & Saúde da Família \\
\hline SOBEEsp & - & Sociedade Brasileira de Enfermagem nos Esportes - \\
\hline SP & - & São Paulo \\
\hline SUS & - & Sistema Único de Saúde \\
\hline UBS & - & Unidade Básica de Saúde \\
\hline USF & - & Unidade de Saúde da Família \\
\hline UM & - & Unidade Mista (UBS + USF) \\
\hline VIGITEL & - & Vigilância de Fatores de Risco e Proteção para Doenças \\
\hline
\end{tabular}




\section{INTRODUÇÃO}

\subsection{Promoção da Saúde}

O enfoque da atividade física (AF) como um instrumento de intervenção para a Promoção à Saúde (PS) vem tomando força nos últimos anos em consonância com a evolução do entendimento sobre o processo saúde - doença e a visão mais ampliada e menos reducionista sobre a saúde.

As primeiras abordagens sobre PS deram-se no século XIX, durante o pensamento médico social e foi reincorporado no início do século XX em resposta ao modelo médico-hospitalar medicamentoso ${ }^{1,2}$. Em 1974, produzido no Canadá, o "Informe Lalonde" ${ }^{2}$ foi o primeiro documento oficial a receber a denominação de PS e o primeiro a introduzir os conceitos de "determinantes de saúde" 3 .

Este documento influenciou as políticas sanitárias de diversos países subdividindo o "campo da saúde" em quatro grandes áreas: biológicas, ambientais, estilos de vida e organização dos serviços de saúde, além de estabelecer as bases para desenvolvimento de um novo paradigma ratificado através da "I Conferência Internacional sobre Promoção à Saúde”, realizado em Ottawa em 1986, expressos na carta de Ottawa que reafirma a importância da PS e aponta a influência dos aspectos sociais sobre a saúde dos indivíduos e da população ${ }^{1,2,4,5,6}$.

A partir dos resultados oriundos desta conferência, a saúde passou a ser reconhecida como resultante dos processos de determinação social e em resposta a esta afirmação, estabeleceu-se como estratégias principais de ação: a reorientação dos serviços e sistemas de saúde com o fortalecimento do nível primário de atenção, a elaboração de políticas públicas saudáveis, o favorecimento da participação popular, a criação de ambientes favoráveis à saúde e a construção de habilidades dos sujeitos ${ }^{5,6}$.

Portanto, entendendo-se o processo saúde-doença como resultado não apenas de relações biológicas individuais, mas resultante de relações mais amplas e complexas, deve-se considerar a estruturação da vida social dos indivíduos na 
sociedade moderna materializada através dos modos de organização dos meios de produção e de consumo. Com isso, o saber dos profissionais de saúde, focado na dimensão biológica individual, não apresenta capacidade de interferir em todos os condicionantes deste processo, configurando uma limitação a ser superada ${ }^{1,2,3}$.

Desta forma, a saúde quando analisada sob esta ótica necessita que, a organização da atenção e do cuidado em saúde envolva, ao mesmo tempo, ações que operem sobre os efeitos do adoecer do indivíduo e ações que visem o espaço coletivo social, além dos muros das unidades e do sistema de saúde. Este conceito amplo trabalha com a idéia de responsabilização múltipla de toda a sociedade nos processos e nos condicionantes, objetivos e subjetivos, da saúde e do adoecimento da população $^{1,2,7,8}$.

Considerando esse entendimento, o termo PS, que inicialmente foi utilizado como uma contraproposta aos resultados modestos obtidos pelo custoso modelo médico hospitalar evoluiu para um conceito ampliado associando-se a questões que vão além das esferas de ação do setor saúde. Esta conceituação ampliada transpassa por um conjunto de valores (ligados à vida, saúde e cidadania, dentre outros), passando por uma combinação de ações e estratégias do estado (políticas públicas saudáveis), da comunidade (reforço de ações comunitárias) e dos indivíduos (desenvolvimento de habilidades pessoais), além da combinação de ações e estratégias ligadas diretamente ao setor saúde (reorientação do sistema de saúde) e de parcerias intersetoriais ${ }^{3}$.

Assim, coloca-se ao setor saúde o desafio de construir intersetorialidade ${ }^{3}$ não pensada como uma estratégia única e/ou definitiva, a ser aplicada sobre os diferentes territórios e populações. Ao contrário, deve-se pensar a intersetorialidade de modo a responder às necessidades de saúde de uma coletividade, mobilizando os setores necessários para isso e, principalmente, envolvendo a população no percurso do diagnóstico da situação à avaliação das ações implantadas ${ }^{7}$. Partindo de uma concepção ampla do processo saúde-doença e de seus determinantes, propõe a articulação de saberes técnicos e populares, e a mobilização de recursos institucionais e comunitários, públicos e privados, para seu enfrentamento e resolução ${ }^{8}$. 
Portanto, foi a partir desse entendimento de PS que a presente pesquisa ancorou-se enquanto referencial teórico.

\subsection{Políticas Públicas e Promoção da Saúde no Brasil}

Estes conceitos ampliados de saúde encontram-se na base do processo de criação do Sistema Único de Saúde (SUS), formulado em 1988 e promulgado em 1990. Nesta política encontram-se a necessidade de criar políticas públicas para promover a saúde, o imperativo da participação social na construção do sistema e das políticas de saúde e considera-se a impossibilidade do setor sanitário responder sozinho à transformação dos determinantes e condicionantes para garantir opções saudáveis para a população ${ }^{3}$.

Ainda na perspectiva deste novo paradigma de saúde, em 1994 foi criado no Brasil o "Programa Saúde da Família" (PSF), atualmente denominado "Estratégia de Saúde da Família" (ESF), que se consolidou como a estratégia estruturante e prioritária de organização e reorientação do modelo de assistência básica do SUS, através de uma concepção que visa superar a antiga proposição de caráter exclusivamente centrado na doença caracterizado pelo atendimento a demanda espontânea, para um modelo desenvolvido por meio de práticas gerenciais e sanitárias, democráticas, ativas e participativas. A ESF é operacionalizada mediante a implantação de equipes multiprofissionais em unidades básicas de saúde com ações de promoção da saúde, prevenção, recuperação, reabilitação de doenças e agravos mais freqüentes, e na manutenção da saúde de um número definido de famílias, localizadas em uma área geográfica delimitada desta comunidade ${ }^{9,10,11}$.

A ESF é composta por no mínimo 01 médico e 01 enfermeiro sendo ambos generalistas, 01 auxiliar ou técnico de enfermagem e 6 (seis) agentes comunitários de saúde que dirigem suas ações para uma dada população cadastrada, composta por 600 a mil famílias, não excedendo o total de 4,5 mil pessoas, moradoras de uma área geográfica delimitada, configurando-se como a porta de entrada para um sistema de saúde hierarquizado e regionalizado, com ações de saúde orientadas para o cuidado 


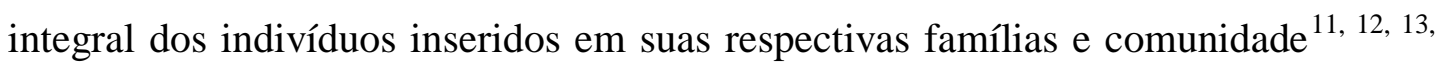
14. Já as Unidades Básicas de Saúde (UBS) tradicionais contam em suas equipes com médicos (clínicos, pediatras e ginecologista-obstetras), enfermeiros, dentistas, auxiliares de enfermagem e pessoal de apoio técnico. Atuam com uma programação de saúde estruturada por ciclo vital ou por agravos relevantes, destacando-se a presença muito menor de enfermeiros no âmbito assistencial. Em algumas destas UBS tradicionais há também a presença de médicos de diversas especialidades (dentre os quais oftalmologistas, dermatologistas, cardiologistas, pneumologistas), distribuídos irregularmente nas unidades instaladas no município. Nestas unidades, a demanda atendida se apresenta como espontânea e/ou encaminhada por outros serviços e neste caso não há adstrição de clientela, e a delimitação da área de abrangência se refere exclusivamente às ações de vigilância à saúde ${ }^{11}$.

Atualmente, a ESF apresenta 30.440 equipes de saúde da família (SF) distribuídas em 5.250 municípios (94,4\%), com cobertura de cerca de 96.3 milhões de pessoas $(53,3 \%)$, sendo parte do conjunto de prioridades políticas apresentadas pelo Ministério da Saúde (MS) e aprovadas pelo "Conselho Nacional de Saúde" para a expansão e a qualificação da atenção básica. Antes desta Estratégia, não havia no país, nos três níveis de governo - federal, estadual e municipal - uma proposta concreta e clara de assistência básica para o SUS ${ }^{15,16}$.

O crescimento do número de municípios atendidos e do número de ESF deuse principalmente a partir da implantação da "Norma Operacional Básica" do Sistema Único de Saúde - 1996 (NOB-SUS 96), que estabeleceu, dentre outras ações, uma política de incentivos e de remuneração diferenciada aos municípios que aderissem ao PSF. Dessa forma, houve um crescimento exponencial do número de ESF distribuídas em todo o país, na última década, conforme demonstram os gráficos 01, 02 e 03: 


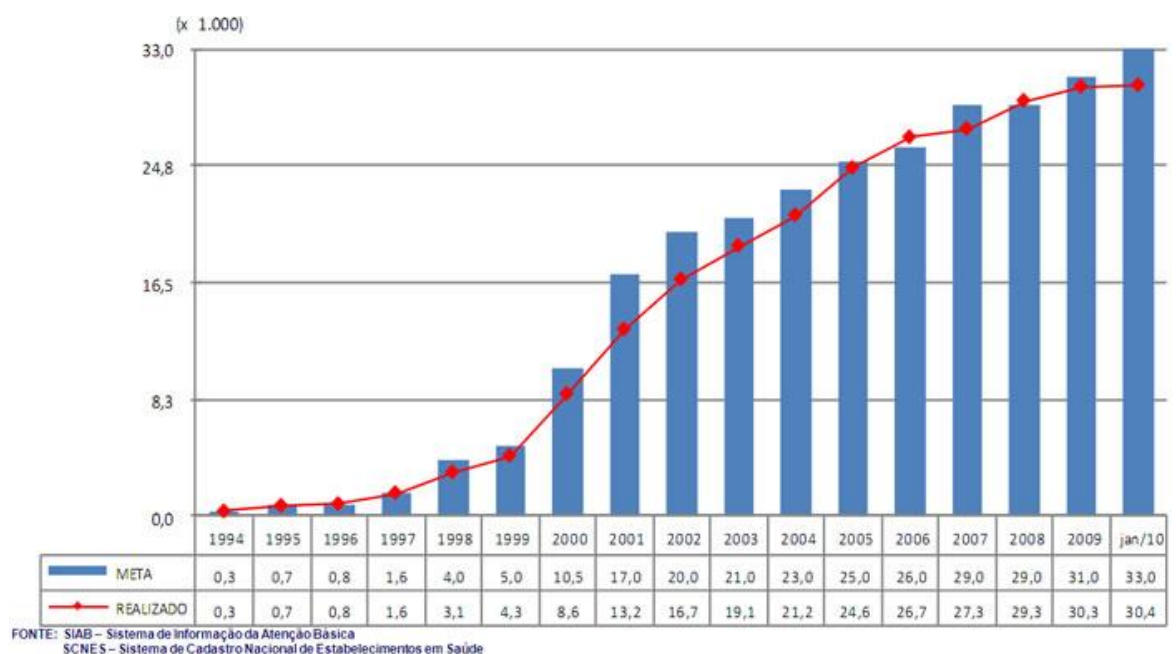

Fonte: Ministério da Saúde: Janeiro/2010.

Disponível em: http://dtr2004.saude.gov.br/dab/abnumeros.php\#numeros

Gráfico 01 - Metas e Evolução do Número de Equipes de Saúde da Família Implantadas no Brasil. Brasil, 2010.

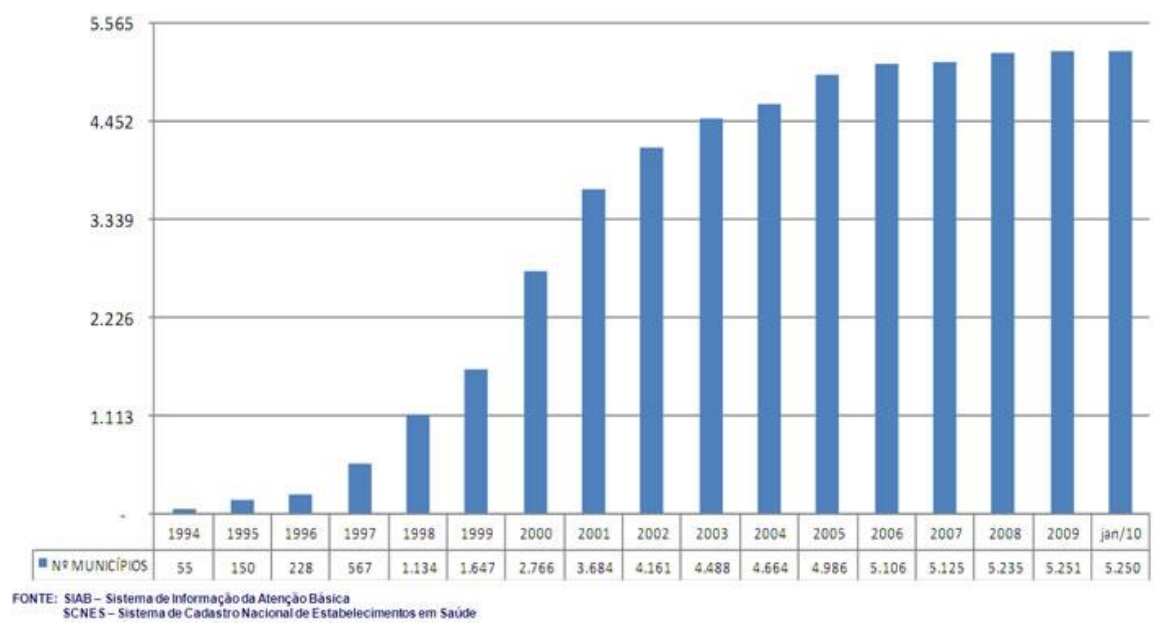

Fonte: Ministério da Saúde: Janeiro/2010. Disponível em: http://dtr2004.saude.gov.br/dab/abnumeros.php\#numeros

Gráfico 02 - Evolução do Número de Municípios com Equipes de Saúde da Família Implantadas no Brasil. Brasil, 2010. 


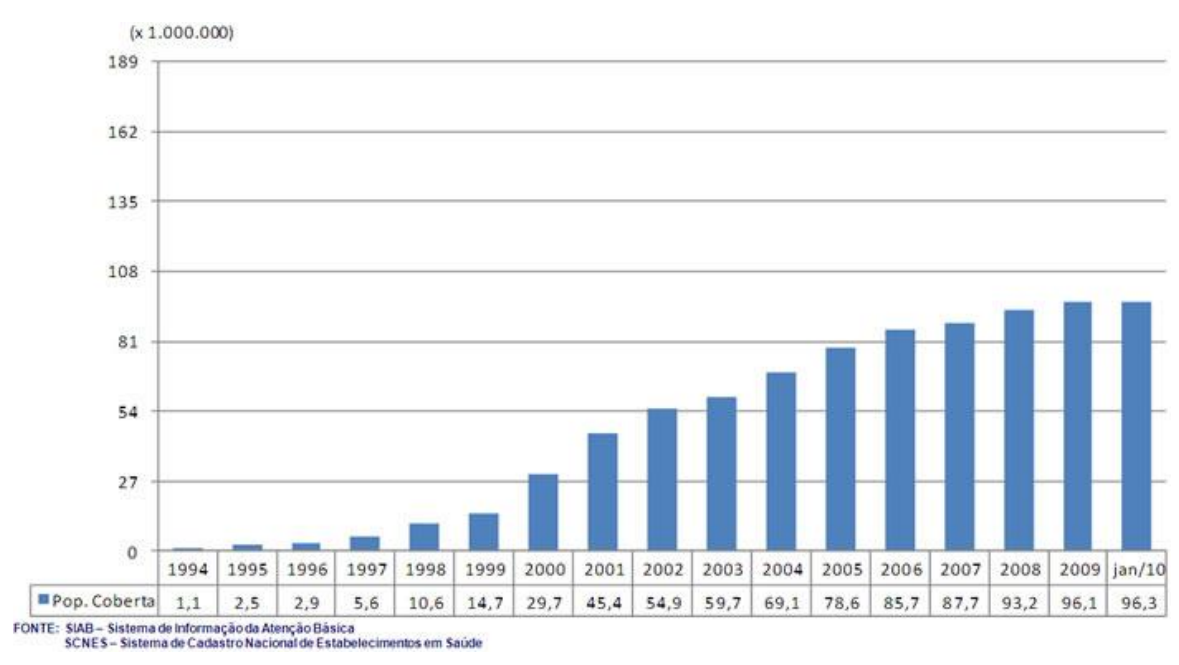

Fonte: Ministério da Saúde: Janeiro/2010.

Disponível em: http://dtr2004.saude.gov.br/dab/abnumeros.php\#numeros

Gráfico 03 - Evolução da População Coberta por Equipes de Saúde da Família Implantadas no Brasil. Brasil, 2010.

A responsabilidade pelo acompanhamento das famílias coloca para a ESF a necessidade de ultrapassar os limites classicamente definidos para a atenção básica no Brasil, especialmente no contexto do $\operatorname{SUS}^{9}$ e busca deslocar, a atenção e os esforços dos profissionais de saúde, da doença para os sujeitos, em sua potência de criação da própria vida, objetivando a produção de coeficientes crescentes de autonomia durante o processo do cuidado à saúde. Neste contexto, a ESF precisa ser capaz de atuar com criatividade e senso crítico, mediante uma prática humanizada, competente e resolutiva, que envolve ações de promoção, prevenção, recuperação e de reabilitação em saúde. Desta forma, pode-se dizer que, tal proposta apresenta consonância com uma perspectiva ampliada de saúde, como definida no âmbito do Movimento da Reforma Sanitária Brasileira, do SUS e das Cartas da PS, em particular a Carta de Ottawa, haja vista, estes termos estarem associados a um conjunto de valores tais como qualidade de vida, saúde, solidariedade, eqüidade, democracia, cidadania, desenvolvimento, participação e parceria ${ }^{3,7,8,18 ; 17}$.

Seguindo esta linha de entendimento da ESF como uma possibilidade de operacionalizar a PS no nível da atenção básica, recupera-se a "Política Nacional de Promoção da Saúde"”3 (PNPS), elaborada pelo MS no ano de 2006. Nesta política a 
PS é entendida como uma estratégia de articulação transversal, intersetorial, comprometida com a integralidade e equidade da atenção à saúde através da coresponsabilização dos distintos setores da sociedade na mobilização e na formulação de intervenções pela garantia da saúde.

Para tanto, a PNPS apresenta como objetivo geral "promover a qualidade de vida e reduzir vulnerabilidade e riscos à saúde relacionados aos seus determinantes e condicionantes - modos de viver, condições de trabalho, habitação, ambiente, educação, lazer, cultura, acesso a bens e serviços essenciais” e como alguns dos objetivos específicos "incorporar e implementar ações de promoção da saúde, com ênfase na atenção básica; e valorizar e otimizar o uso dos espaços públicos de convivência e de produção de saúde para o desenvolvimento das ações de Promoção da Saúde” (p. 13 e 14) $)^{3}$.

No seu processo de implantação, desde seu início, a ESF teve como foco prioritário os pequenos municípios com baixo Índice de Desenvolvimento Humano (IDH-M) e com baixa densidade demográfica e em áreas de risco nutricional ${ }^{13,16,19}$. Isto reflete nos dias atuais, ao se comparar os mapas (Figura 01) de distribuição das ESF no país e da densidade populacional brasileira fica claro o predomínio da distribuição das unidades e equipes de SF nos municípios com menos de 200.000 habitantes e com baixa densidade populacional. 


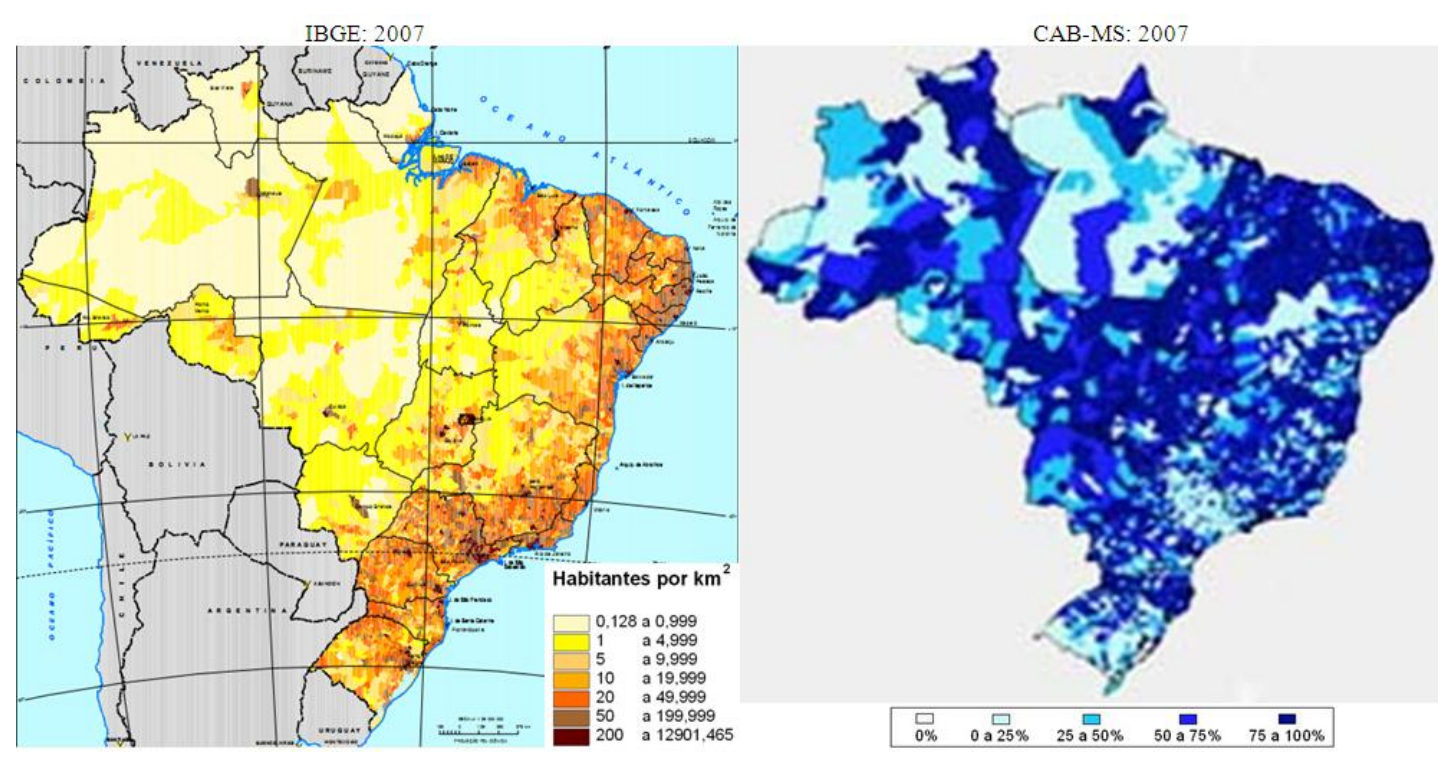

Mapas disponíveis em: http://www.ibge.gov.br/brasil_em_sintese/download/demografia.pdf e http://dtr2004.saude.gov.br/dab/abnumeros.php\#numeros

Figura 1 - Densidade demográfica nacional e Situação de Implantação das Equipes Saúde da Família. Brasil, 2007

Devido ao Plano de Atenção à Saúde - PAS, política de saúde adotada pelo município de São Paulo durante a maior parte da década de 90, o processo de desenvolvimento do SUS em São Paulo, através da municipalização da atenção básica e consequentemente a implantação das ESF, foi retardado. Neste período, coube ao Qualis (Qualidade Integral à Saúde), instituído através de um convênio entre o MS a Secretaria Estadual de Saúde (SES/SP) e o hospital Santa Marcelina em 1996, a tarefa de difundir as equipes de SF pelas regiões mais carentes da cidade de São Paulo ${ }^{20}$.

Após a municipalização da assistência básica da cidade de São Paulo, que iniciou somente em janeiro de 2001, a Coordenação de Atenção Básica da Secretaria Municipal de Saúde de São Paulo (CAB-SMS/SP) assumiu o compromisso de organizar a rede básica de saúde, tendo no PSF, sua estratégia, e na divisão de responsabilidades, seu eixo principal. Neste mesmo ano, a CAB-SMS instituiu as Redes de Apoio ao PSF (RA-PSF), cuja função principal era de normatizar, 
acompanhar e avaliar os processos de reorganização da atenção básica da cidade de São Paulo com foco na implantação e desenvolvimento do $\operatorname{PSF}^{16,21}$.

Em 2002, foi aprovado o Documento Norteador da SMS-SP que definia as responsabilidades das "Redes de Apoio à Implantação do PSF" na cidade, dentre elas as ações e responsabilidades de todos os participantes do PSF, desde os agentes até os coordenadores distrital e municipal, além da previsão da implantação de 1749 equipes de SF na cidade até o ano de 2004. Em janeiro de 2010, a SMS-SP divulgou que a cidade contava com 1169 equipes de $\mathrm{SF}^{22}$.

Trata-se, portanto, de um cenário complexo de implantação da ESF a partir do qual podem ser identificados elementos importantes para potencializar as ações de Promoção da Saúde, na perspectiva de ampliação do foco de atenção.

\subsection{Atividade Física: potencial de Promoção da Saúde na atenção}

\section{básica}

A "Estratégia Global da Organização Mundial da Saúde sobre Alimentação Saudável, Atividade Física e Saúde" (EG-OMS), aprovada na 57 Assembléia Mundial de saúde de 2004, foi considerada por Barreto, Passos, Cardoso et $\mathrm{al}^{23}$ e por Moretti, Almeida, Whestphal et $\mathrm{al}^{24}$ como um instrumento de promoção geral da saúde para populações e indivíduos. Essa estratégia tem como objetivo principal a redução dos principais fatores de risco das doenças crônicas não transmissíveis (DCNT) - alimentação pouco saudável e o sedentarismo - por meio de ações de: saúde pública e coletiva essenciais, medidas de promoção da saúde e prevenção de morbidades, ações de promoção e desenvolvimento de consciência e conhecimento acerca da influência positiva oriunda da prática regular de alimentação saudável e AF; além de fomentar a implantação e o fortalecimento de políticas e planos de ação direcionados a melhorar a alimentação e aumentar o nível de $\mathrm{AF}^{25}$.

As DCNT têm se configurado como um dos maiores problemas de saúde pública da atualidade ${ }^{26}$. A OMS projeta que a maior causa das mortes no mundo 
serão ocasionadas por DCNT (Gráfico 04) e que o impacto gerado por sua morbimortalidade ocasiona grandes - e subestimados - efeitos econômicos adversos para as famílias, comunidades e sociedades em geral ${ }^{27,28,29}$. No Brasil, $\mathrm{Nedel}^{30}$ em um estudo de anos de vida perdidos, evidencia que os brasileiros perdem, em média, 7,7 anos em função de DCNT.

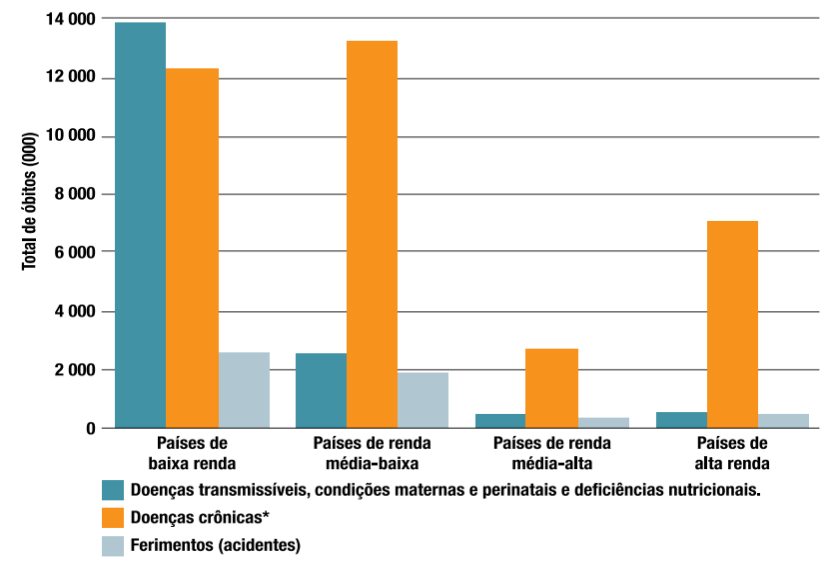

Fonte: OMS - Prevenção de DCNT: Investimento vital. OPAS (2005)

Gráfico 04 - Projeção de óbitos em todas as idades por causa majoritária e grupo de renda. OMS 2005

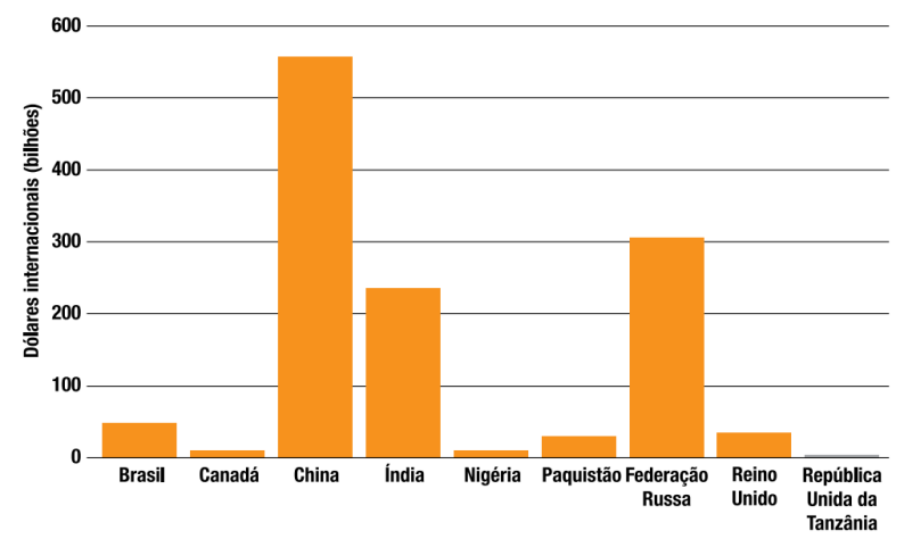

Fonte: OMS - Prevenção de DCNT: Investimento vital. OPAS (2005)

Gráfico 05 - Projeção da perda de renda nacional devido a doenças cardíacas, AVC e diabetes. OMS 2005-2010 
$\mathrm{A} \mathrm{OMS}^{29}$ afirma ainda que cerca de $80 \%$ das mortes provocadas por DCNT ocorrem em países em desenvolvimento. Séries históricas de estatísticas de mortalidade do MS disponíveis para as capitais dos estados brasileiros indicam que a proporção de mortes por DCNT (Figura 02) aumentou em mais de três vezes entre a década de 30 e 2005 tendo sido estas, responsáveis por 69\% das despesas do SUS com assistência hospitalar no Brasil em 2002, e por 73\% dos gastos com saúde na cidade de São Paulo em 2007 23,26,31,32.

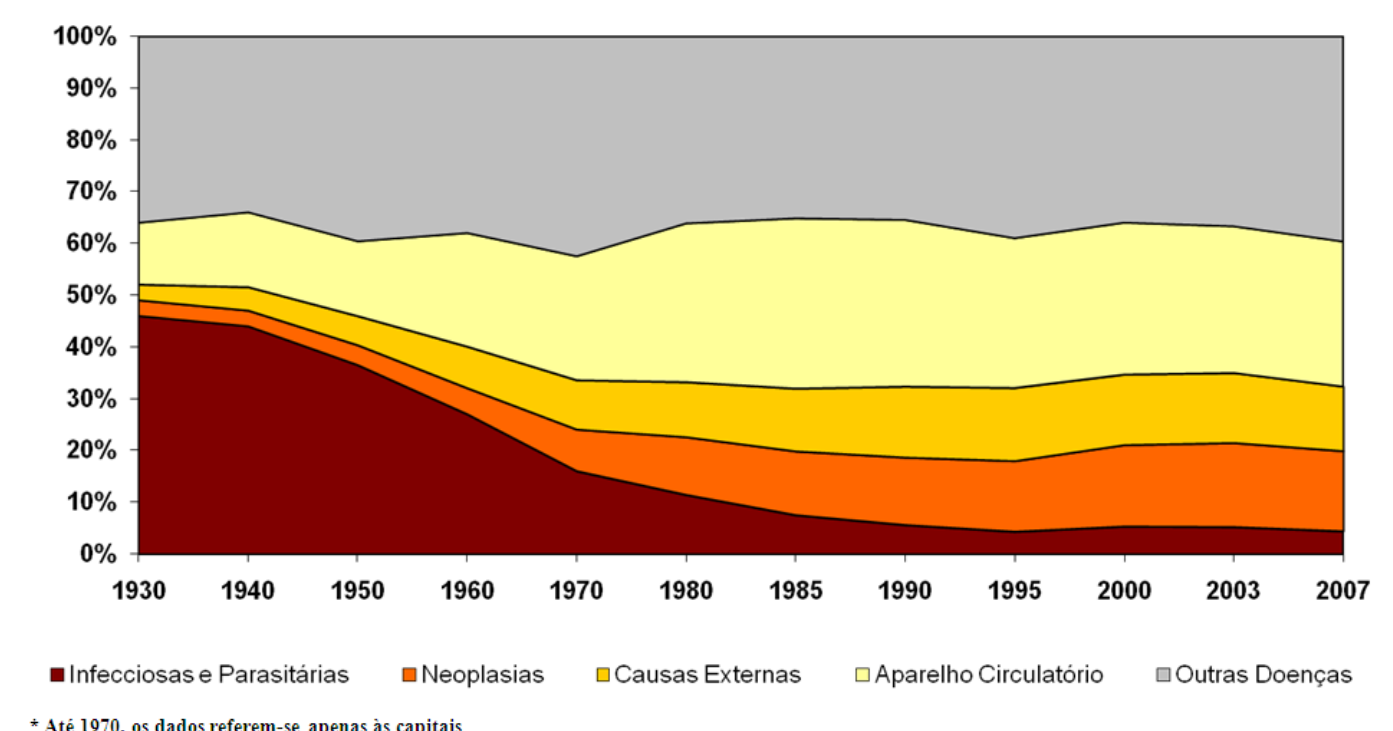

Fonte Secretaria de Vigilância em Saúde - MS.2007. Disponível em http://www.portal.saude.gov.br/portal/arquivos/doc/DCNT_CUIDADOExpoepi.ppt

Figura 02: Transição epidemiológica da mortalidade proporcional no Brasil.

Brasil, 2007

Considerando que $80 \%$ das DCNT, em especial as cardiovasculares podem ser prevenidas por ações governamentais e comportamentais ${ }^{25,29,33}$, a EGOMS estabeleceu aos Estados membros fortalecerem as estruturas existentes (ou estabelecidas outras novas) para aplicação desta estratégia via setor saúde, definir diretrizes sobre alimentação saudável e prática de AF e desenvolver processos mensuráveis de indicadores e resultados para acompanhar e avaliar com exatidão as medidas implementadas ${ }^{9,25}$. 
O compartilhamento dos fatores de risco, somado à urgência em deter o crescimento das DCNT no país, justifica a adoção de estratégias integradas e sustentáveis de prevenção e controle dessas doenças assentadas nos seus principais fatores de risco modificáveis - tabagismo, sedentarismo e alimentação inadequada $^{23}$.

\subsubsection{Atividade Física: Histórico mundial.}

Desde os tempos mais remotos, textos clássicos afirmavam os benefícios para a saúde advindos da prática de $\mathrm{AF}^{34,35}$. Hipócrates, considerado pai da medicina moderna já trazia o conceito de que a saúde era a expressão de uma condição de equilíbrio do corpo humano, obtida através de um modo de vida ideal, que incluía nutrição, excreção, exercício e repouso adequados ${ }^{36}$.

O movimento higienista ocidental europeu do século XIX já trazia à medicina conceitos de uma vida sadia ${ }^{36}$. Na metade do século passado, estudos epidemiológicos já apontavam a associação entre a prática de AF regular e questões relativas à saúde, dentre estes, Ferreira \& Najar ${ }^{37}$ apresentam a relação entre a prática de $\mathrm{AF}$ e a menor incidência de coronariopatias entre os cobradores de ônibus de Londres quando comparado com os motoristas.

$\mathrm{Na}$ década de 1970 diversas iniciativas foram desenvolvidas, principalmente em âmbito internacional, para promoção da saúde por meio da atividade física (PS/AF). A OMS aponta para o fato que entre 1970 e 2000 (gráfico 06), ações voltadas para a PS/AF associadas com alterações da dieta e redução do tabagismo ocasionaram redução de $70 \%$ da taxa de mortalidade das doenças cardiovasculares na Austrália, Canadá, Estados Unidos e Reino Unido, estimando que cerca de 20 milhões de mortes ocasionadas por DCNT foram evitadas ${ }^{29}$. 


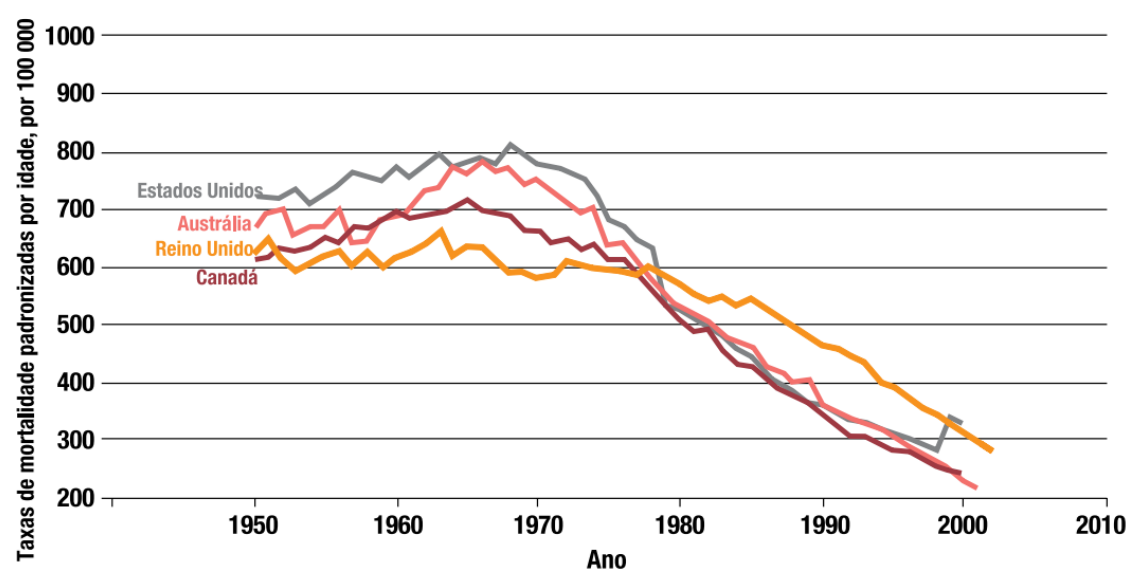

Fonte: OMS - Prevenção de DCNT: Investimento vital. OPAS (2005)

Gráfico 06 - Taxa de mortalidade por doenças do coração entre homens com idade superior a 30 anos, de 1950 a 2002, na Austrália, Canadá, Estados Unidos e Reino Unido

Os programas de PS/AF mais antigos de que se tem registro são o finlandês (North Karelia, 1972) e o inglês (Active for Life, 1979). Este último serviu de referência para os principais estudos científicos, clínicos e epidemiológicos, norteadores da PS/AF a partir da década de $80^{34,35,38}$.

Em 1994 o "Centro Americano de Controle e Prevenção de Doenças" (CDC) em conjunto com o "Colégio Americano de Medicina dos Esportes" (ACSM) apresentaram ao mundo um padrão científico, aprovado pela $\mathrm{OMS}^{39}$, para orientação e execução da AF moderada em adultos e idosos com definições baseadas em evidências científicas das áreas de epidemiologia fisiologia e clínica, através de pesquisas básicas, artigos de revisão da literatura ${ }^{40,41,42}$. Tais estudos propunham uma sistematização da $\mathrm{AF}$ em relação à intensidade (moderada), frequência semanal (5 dias por semana) e tempo diário da mesma (30 minutos contínuos ou acumulados) ${ }^{43}$.

Este protocolo foi um marco para a orientação e prática da AF para PS (AF/PS) ao romper com o próprio posicionamento do ACSM sobre a orientação de exercícios vigorosos voltados para o desenvolvimento da aptidão física (cardíaca, respiratória e muscular) e passou a enfatizar a relação entre AF e saúde por meio da 
incorporação de atividades moderadas no cotidiano (trabalho, lazer, atividades domésticas) das pessoas ${ }^{38,44,45}$.

A partir de 1997, a OMS expandiu seus esforços na PS/AF começando com um encontro de planejamento em Genebra ${ }^{46}$. No mesmo ano, a PS/AF foi tida como uma das ações prioritárias e como um dos desafios mais importantes das entidades governamentais e privadas para a saúde na $4^{\mathrm{a}}$ Conferência Internacional em Promoção de Saúde promovida em Jacarta.

Ainda em 1997, a OMS promoveu um encontro na Finlândia - The Active Living National Policy Group - com o objetivo de criar um grupo tarefa visando combater o sedentarismo e identificar pontos chaves para a PS através da AF. Foram recomendadas ações em diversos aspectos, tais como ${ }^{44}$ :

a- Identificar as principais estratégias, fatores de facilitação e de desenvolvimento de Políticas Nacionais de Programas de Vida Ativa;

b- Revisar e fornecer apoio existente para outros países visando promover Políticas de Vida Ativa;

c- Discutir a possibilidade e formas para estabelecer uma "rede" de políticas voltadas para a vida ativa visando nutrir políticas nacionais e ações em vida ativa e de propor os elementos de um plano de ação para uma política mundial entre o período 1997 - 2000.

Em 1998, a OMS promoveu um encontro em Ottawa, no qual foi proposta uma "Rede de Políticas Nacionais de Vida Ativa". Esta rede pode ser considerada como o embrião da "Rede de Atividade Física das Américas / The Physical Activity Network of the Americas" (RAFA/PANA) oficializada em 2000, no “XXIII Simpósio Internacional de Ciências dos Esportes”, realizado anualmente na cidade de São Paulo, com o objetivo de integrar membros de instituições públicas e privadas, nacionais e internacionais, a fim de compartilhar estratégias e informações para promover a saúde e qualidade de vida através da $\mathrm{AF}^{46}$. 
O início de uma rede regional para facilitar a promoção da AF nas Américas partiu de programas regionais e de recomendações internacionais e, esta rede foi estruturada nos encontros anteriores nas quais foram discutidas as bases estruturais da rede que, em 2000 culminou com a publicação do "Manifesto de São Paulo: Promovendo a Atividade Física nas Américas"46. Neste documento, os profissionais da saúde e educação, políticos e formadores de opinião foram chamados para ação em prol da melhoria e qualidade de vida, por meio do combate das DCNT relacionadas ao sedentarismo através da inclusão da AF no cotidiano das pessoas ${ }^{47}$.

Em 2002, estas redes se uniram, sob a coordenação da OMS e lançaram o "Programa Agita Mundo" (PAM), proclamando o dia 07 de Abril como o "Dia Mundial da Atividade Física". O objetivo principal do PAM é a PS por meio da AF em todos os países do mundo e atualmente encontra-se presente em mais de 40 países nos 5 continentes do mundo, com programas de promoção da AF em âmbito nacional, estadual ou municipal ${ }^{48}$.

Em 2005, a OMS estabeleceu como meta, a redução, em 2\% por ano até 2015, das mortes por DCNT em todo o mundo e para isso apresentou uma proposta de modelo de planejamento e intervenção para os governos nacionais desenvolverem estratégias de intervenções de saúde pública para promoção da AF baseadas em evidências, conforme descrição detalhada no quadro a seguir ${ }^{49}$ : 
Quadro 01 - Proposta de um Modelo Abrangente de Planejamento para os Governos - OMS, 2005

\begin{tabular}{|c|c|c|c|}
\hline \multirow{2}{*}{$\begin{array}{c}\text { Passos de intervenção } \\
\text { da política de ação }\end{array}$} & \multicolumn{2}{|c|}{$\begin{array}{c}\text { Intervenções proporcionais à } \\
\text { população }\end{array}$} & \multirow{2}{*}{$\begin{array}{c}\text { Intervenções } \\
\text { Individuais }\end{array}$} \\
\hline & Nível Nacional & Nível subnacional & \\
\hline BASE & \multicolumn{3}{|c|}{$\begin{array}{l}\text { Estimar as necessidades da população; informações sobre } \\
\text { os fatores de risco; disseminar as informações para a } \\
\text { população e incentivar ações promoção }\end{array}$} \\
\hline EXPANSÃO & \multicolumn{3}{|c|}{$\begin{array}{l}\text { Formular e adotar as políticas e ações de saúde pública } \\
\text { abrangentes e integradas, baseada em ações intersetoriais, } \\
\text { considerando os ciclos da vida, e as necessidades locais. }\end{array}$} \\
\hline DESEJÁVEL & \multicolumn{3}{|c|}{$\begin{array}{l}\text { Financiamento das ações, proposição de medidas } \\
\text { Legislativas e regulatórias, ações sobre o ambiente urbano } \\
\text { e meios de transporte que facilitem hábitos saudáveis, } \\
\text { Iniciativas de advocacy, Mobilização da Comunidade, } \\
\text { Organização dos serviços de saúde: protocolos baseados } \\
\text { em evidência, auto-cuidado dos portadores de DCNT, } \\
\text { Garantir as ações de toda linha de cuidado, equipe } \\
\text { multidisciplinar. }\end{array}$} \\
\hline
\end{tabular}

Fonte: Adaptado de Prevenção de DCNT: Investimento vital. OPAS (2005). Disponível em http://www.portal.saude.gov.br/portal/arquivos/doc/DCNT_CUIDADOExpoepi.ppt

Atualmente, nas Américas, 19 países apresentam-se como membros da RAFA/PANA por meio de suas entidades governamentais (nacionais, estaduais ou municipais) ou através de entidades não governamentais (privadas ou filantrópicas) e apresentam relatórios anuais dos programas de AF executados. Esta experiência motivou a criação de redes similares na Europa (HEPA), África (APAN) e nos países da Ásia do Pacífico (AP-PAN) ${ }^{46}$. 


\subsubsection{Atividade Física: histórico nacional}

No Brasil, o primeiro programa oficial de grande abrangência populacional de PS/AF intitulava-se "Educação e Saúde através do Exercício Físico e do Esporte" de iniciativa do MS em conjunto com o Ministério dos Esportes (ME) de 1986. Depois, somente na década de 90 surgiram dois novos programas voltados para PS/AF, ambos no Estado de São Paulo: o "Dia do Desafio", promovido pelo Serviço Social do Comércio (SESC) desde $1995^{50}$ e o "Programa Agita São Paulo" 38 (PASP), promovido pela Secretaria Estadual de Saúde (SES-SP) em parceria com o "Centro de Estudos do Laboratório de Aptidão Física de São Caetano do Sul” (CELAFISCS) desde $1996^{38}$.

Em 2001, tendo como base toda estrutura funcional do PASP o MS instituiu, em parceria com o CELAFISCS, o "Programa Agita Brasil" (PAB) visando aumentar o nível de AF da população brasileira ${ }^{51,52}$.

Em 2002, o "Documento para Discussão da Política Nacional de Promoção da Saúde" trouxe a tona a necessidade de se tomar decisões para o enfrentamento da realidade sanitária brasileira através de um documento que se insere no processo dialógico de teoria/prática, refletir/agir para a construção de uma PNPS que amplie nossa capacidade de gestão, atenção e parcerias, pautadas por um compromisso ético em defesa da vida ${ }^{53}$. Este documento ressalta que a Constituição de 1988 apresenta elementos para o desenvolvimento de ações e estratégias de PS e que sob a óptica desta, os princípios de universalidade, integralidade e eqüidade assim como as diretrizes de descentralização e organização hierarquizada podem ser potencializados $^{3,53}$.

A partir de 2005, o MS definiu a Agenda de Compromisso pela Saúde através do lançamento de três pactos ${ }^{54}$ : "Defesa do SUS"; "Pacto pela Vida" e o "Pacto de Gestão". Dentre as prioridades do "Pacto pela Vida", destaca-se a ênfase para o fortalecimento e qualificação da ESF através da PS e Educação em Saúde com foco na promoção de AF e na promoção de hábitos saudáveis de alimentação e de vida, controle do tabagismo, controle do uso abusivo de bebida alcoólica e cuidados especiais voltados ao processo de envelhecimento. 
Retomando as discussões da $8^{\mathrm{a}}$ Conferência Nacional de Saúde ${ }^{55}$ para ratificar a necessidade de que o processo saúde adoecimento seja compreendido e abordado a partir de sua determinação $\operatorname{social}^{56}$ e que a PS compreende a ação individual, a ação da comunidade e a ação e o compromisso dos governos na busca de uma vida mais saudável para todos e para cada $u^{57}$, é correto afirmar que a PNPS $^{3}$ de 2006 foi desenvolvida na esteira da EG-OMS ${ }^{25}$ e da Agenda de Compromisso pela Saúde, em especial no "Pacto pela Vida", com o intuito de organizar, facilitar o planejamento, realização, análise e avaliação do trabalho em saúde.

Estruturada nos preceitos da saúde coletiva, tomando como foco os modos de viver de sujeitos e comunidades, a PNPS estabelece estratégias e define as ações a serem desenvolvidas na rede básica e na comunidade.

Objetivando "promover a qualidade de vida e reduzir vulnerabilidade e riscos à saúde relacionados aos seus determinantes e condicionantes - modos de viver, condições de trabalho, habitação, ambiente, educação, lazer, cultura, acesso a bens e serviços essenciais (pg. 19)" a PNPS prevê o desenvolvimento de ações ligadas às áreas da alimentação saudável, prática corporal/atividade física (PC/AF), prevenção e controle do tabagismo, redução da morbimortalidade em decorrência do uso abusivo de álcool e outras drogas, redução da morbi-mortalidade por acidentes de trânsito, prevenção da violência e estímulo à cultura da paz e promoção do desenvolvimento sustentável ${ }^{3}$.

De acordo com Malta, Castro, Gosh et $\mathrm{l}^{58}$, com a oficialização da PNPS, o MS ratificou o desejo de institucionalização da promoção da saúde no SUS ${ }^{3,53}$, através do predomínio das ações do Ministério, como previa o Pacto pela Vida ${ }^{54}$ em prol da temática PC/AF.

Em 2006, dados obtidos por meio da "Vigilância de Fatores de Risco e Proteção para Doenças Crônicas por Inquérito Telefônico" (VIGITEL) ${ }^{33}$ demonstraram que $85 \%$ da população brasileira é sedentária $(29,2 \%)$ ou pratica AF de forma não regular ou ainda, realiza AF abaixo dos padrões mínimos adotados pela $\mathrm{OMS}^{39}$ para promoção da saúde. Em virtude destes dados e, em reconhecimento à 
relevância clínica e epidemiológica do sedentarismo na incidência e prevalência da freqüência, distribuição e evolução das DCNT, as ações do MS em prol da temática da AF, inicialmente previstas para o biênio 2006-2007, foram mantidas como prioritários até o ano de 2011 em virtude das complexidades inerentes a este tema ${ }^{54,58,59,60}$.

O VIGITEL foi implantado pelo MS objetivando monitorar por meio de entrevistas telefônicas realizadas em amostras probabilísticas em adultos de todas as capitais dos 26 estados brasileiros e no Distrito Federal, a freqüência e distribuição dos principais determinantes das DCNT no país (Tabagismo, Excesso de Peso e Obesidade, Dieta, Consumo de Bebidas Alcoólicas, AF, Estado de Saúde Ruim, Morbidade Referida e Prevenção de Câncer) ${ }^{29}$.

Entre os anos de 2006 e 2007 a estratégia do MS priorizou a descentralização das ações da PNPS por meio da organização da "Rede Nacional de Promoção da Saúde e Atividade Física" (RNPS/AF) através de repasse financeiro para entidades federadas que tiveram propostas aprovadas para PC/AF. Nestes dois anos, foram investidos quase R\$ 17 milhões em 209 projetos estaduais, municipais ou locais em todo o país ${ }^{61}$.

A partir de 2008, a estratégia do MS voltou-se para a manutenção e ampliação da RNPS/AF através da garantia do repasse financeiro para os Fundos Estaduais e Municipais por meio da portaria 2981/08 ${ }^{60}$ como forma de incentivar a implementação e o fortalecimento das ações específicas da PNPS, com ênfase na integração das ações de Vigilância, Promoção e Prevenção de DCNT com a ESF ${ }^{61}$.

Em abril de 2009, apresentando a redução do sedentarismo nacional de 29,2\% em 2006 para 26,3\% em $2008^{29}$, o MS, repetindo a parceria com o ME depois de 22 anos, lançou o "Plano Nacional de Atividade Física" (PNAF), que encontra-se inserido no "Programa Mais Saúde" (PMS) e tem com objetivo de elevar o índice de pessoas fisicamente ativas no país. Com orçamento previsto da ordem de R 60 milhões para ser investido até 2011, a meta do PMS é de elevar a participação dos municípios que integram a RNPS/AF, de 450 para 1.000 municípios $^{62,63}$. 
O PMS apresenta, dentre suas diretrizes estratégicas, a consolidação da PS e da intersetorialidade nas ações de saúde assim como, priorizar, em todos os eixos de intervenção, os objetivos e as metas do "Pacto pela Saúde", na dimensão do "Pacto pela Vida”. As medidas apresentadas no PMS são estruturadas por eixos que convergem para a construção de um sistema de saúde universal a qual se associa a um padrão de desenvolvimento nacional voltado para a qualidade de vida de seus cidadãos em suas múltiplas dimensões e que permitem articular a dimensão econômica e a dimensão social da saúde (figura 03$)^{63}$.

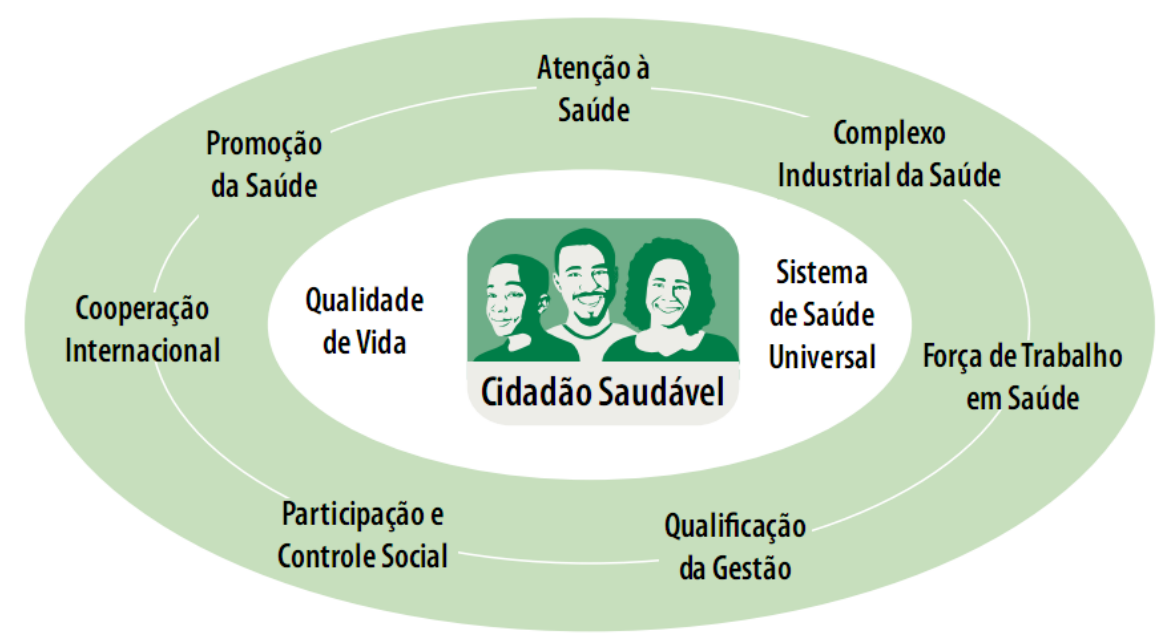

Fonte: Ministério da Saúde. Mais saúde - Direito de Todos 2008-2011. Brasil, 2007

Figura 03 - Eixos de intervenção Programa Mais Saúde. Brasil, 2007

\subsubsection{Atividade Física: Histórico municipal}

As experiências da PS/AF no Estado de São Paulo iniciaram com "Programa Educação e Saúde através do Exercício Físico e do Esporte" dos Ministérios da Saúde, Esportes e Educação (1986), com o "Dia do Desafio" do SESC (1995) ${ }^{50}$ e com o PASP da SES-SP $(1996)^{38}$.

De acordo com $\mathrm{MS}^{53}$ e com a Área Técnica de Medicinas Tradicionais (ATMT) da "Coordenação de Atenção Básica da Secretaria Municipal de Saúde de São Paulo" - CAB-SMS/SP ${ }^{64}$, desde 2001 há conhecimento de incentivo e ações de 
Práticas Integrativas e Complementares em Saúde (PICS) integradas nas unidades da RBS municipal.

Associada com as ações voltadas para incentivo da AF propostas pela PNPS pode-se afirmar que, a "Política Nacional de Práticas Integrativas e Complementares no SUS" (PNPIC-SUS) de 2006, serviu de parâmetro para que a prefeitura de São Paulo viesse a instituir, em junho de 2008, o "Programa Qualidade de Vida com Medicinas Tradicionais e Práticas Integrativas em Saúde" - PQVMTPIS oficializando assim, além das ações previstas nesta política, as ações de PC/AF na RBS previstas na PNPS ${ }^{59,64,65,66}$.

Segundo a ATMT-CABSMS ${ }^{66}$ a publicação da PNPIC-SUS, vem na esteira da "Estratégia da OMS sobre Medicina Tradicional 2002-2005" resultado de políticas e ações que a OMS desenvolve desde 1978 relacionadas ao incentivo e desenvolvimento das práticas de Medicinas Tradicionais (MT).

O termo medicinas tradicionais (MT) se reveste de grande heterogenia e polissemia, contemplando um vasto grupo de sistemas médicos e de cuidados à saúde além de complexos recursos, práticas e produtos terapêuticos objetivando qualquer forma de cura que não sejam necessariamente considerados parte da medicina tradicional ${ }^{65,68,69,70}$. O “Centro Nacional de Medicina Alternativa e Complementar dos EUA"71, em 2007, definiu os termos das ações das MT da seguinte forma:

- Práticas Complementares: quando essas são utilizadas em conjunto com práticas médicas, contudo havendo apenas comprovação empírica de sua eficácia;

- Práticas Alternativas: quando estas são empregadas no lugar, em substituição de uma prática médica;

- Práticas Integrativas: quando essas são utilizadas conjuntamente com as práticas médicas e não tendo resultados apresentado avaliações e comprovações científicas. 
A PNPIC-SUS incorporou ao SUS experiências e iniciativas nas RBS municipais e estaduais, legitimadas pela aceitação de parte da sociedade, das práticas de Medicina Tradicional Chinesa/Acupuntura, da Homeopatia, da Fitoterapia, da Medicina Antroposófica e do Termalismo-Crenoterapia ${ }^{65}$.

As PICS desenvolvidas nas unidades da rede municipal de saúde de São Paulo estão distribuídas, segundo a ATMT-CABSMS, nas seguintes categorias ${ }^{66}$ :

- Práticas Corporais das Medicinas Tradicionais: incluem-se as práticas da Medicina Tradicional Chinesa, da cultura tradicional brasileira (como capoeira), hindu e outras culturas, inclusive as danças circulares, que incorporam as tradições de vários povos;

- Práticas Meditativas: desenvolvidas as técnicas de meditação, orações e relaxamento.

- Práticas de Atividades Físicas: encontram-se além das Práticas Corporais das Medicinas Tradicionais, as práticas de caminhada, danças não-tradicionais, alongamentos, ginásticas e outros exercícios.

Moretti, Almeida, Whestphal et al $^{24}$ afirmam que é no pólo individual e grupal, numa perspectiva relacional microssocial, que as PICS podem contribuir para a PS agindo em termos de uma conceituação positiva de saúde, através de ações de fortalecimento, estímulo ou resgate da saúde e de qualidade de vida, transcendendo o tratamento focado no adoecimento.

O conceito das Práticas Corporais (PC) difere, significativamente, dos conceitos de AF e exercício físico, por considerar o ser humano em movimento através de sua gestualidade e de seus modos de se expressar corporalmente, atribuindo valores, sentidos e significados às diversas formas do indivíduo se manifestar por meio do corpo. Esta contempla duas racionalidades: a ocidental estruturada nas modalidades esportivas, ginásticas, danças e caminhada e a oriental, caracteriza-se pelas práticas de Tai-Chi-Chuan, Lian Gong, Yoga ou até mesmo pelas apresentações dos movimentos das artes marciais - Kung fu, karatê, Muai Thai, etc. Nesse sentido, as PC podem ser consideradas sob a óptica das ciências humanas e 
sociais, das artes, da filosofia e até mesmo dos saberes e conceitos populares, sem desconsiderar as conceituações das ciências biológicas e naturais ${ }^{4,72}$.

Para implantação da PC/AF como proposta estratégica para PS prevista PNPS faz-se necessário a estruturação de espaços e de programas para possibilitar esta ação ${ }^{3}$ assim como a definição clara dos conceitos relativos à definição, prescrição e execução da PC/AF.

No tocante à estruturação de espaço destinado à ação da PC/AF, em junho de 2008 foi regulamentado em São Paulo, por meio de decreto legal, a instalação e o uso de espaços nas unidades da rede de saúde para a realização de todas as práticas de PICS, dentre elas, PC/AF.

Segundo a ATMT-CABSMS ${ }^{73}$, em agosto de 2008, a cidade registrava 689 atividades de PICS, dentre as quais cerca de 580 eram PC/AF, integradas nas ações das seguintes unidades da rede municipal de saúde: Ambulatório de Especialidades, UBS, Centros de Apoio Psico-Social, Ambulatórios de Saúde Mental, Centros de Convivência e Cooperativa (Cecco), Centro de Referência de Saúde do Trabalhador (CRST), Centro de Referência da Aids (Craids), Centro de Testagem e Aconselhamento (CTA), Serviço de Atendimento Especializado (SAE), Centros de Referência Infantil e Unidades de Medicina Tradicional (UMT).

\subsubsection{Atividade Física: Protocolo de prescrição individual para adultos e idosos de ambos os sexos.}

Com a evolução dos estudos sobre AF e saúde, encontram-se diversas formas de definir a AF, sendo a mais usual na literatura o conceito de AF definida como qualquer movimento corporal, produzido voluntariamente pela musculatura esquelética, que resulte em gasto de energia ${ }^{74,38}$. Barbanti $^{75}$, em seu dicionário de termos de educação física define AF como "movimento corporal, produzido pela musculatura esquelética, desde os mais simples movimentos corporais até as mais complexas, coordenadas e metodizadas atividades executadas no contexto do 
Esporte, da Aptidão Física, de Atividades Lúdicas ou em Atividades Laborais e de Deslocamentos".

Cabe ampliar estas definições trazendo o conceito de que a AF é o processo produzido pela contração voluntária da musculatura esquelética, resultante do gasto de energia, independente do objetivo, podendo ou não resultar em movimentação de seguimentos corporais ou deste como um todo.

Desta forma, considerando todas as possibilidades de contração voluntária da musculatura esquelética, quase tudo o que fazemos de forma consciente pode ser considerado AF: ações extremamente simples como piscar ou mexer os olhos, mastigar, abrir e fechar a boca, até mesmo sorrir, escovar os dentes, escrever, até mesmo digitar este texto também pode ser considerado AF. Também são caracterizadas como AF ações mais complexas do ponto de vista da fisiologia e biomecânica tais como caminhar, descer ou subir escadas, tocar instrumentos musicais, dançar, praticar exercícios aeróbicos (corrida, natação, ciclismo, etc.) praticar exercícios resistidos (musculação, pilates, etc.) ou praticar esportes (amador ou profissional). Até mesmo ações de contração da musculatura esquelética que não resultem em alteração do comprimento das fibras musculares ou produza alteração da angulação de alguma articulação (contrações isométricas) também são caracterizadas como AF, como por exemplo, ficar parado de pé, praticar yoga ou alguns exercícios das ginásticas orientais, contrair o abdome, enrijecer de forma consciente os músculos do corpo.

A seguir, demonstro como todas as contrações voluntárias da musculatura são englobadas pela esfera da AF: 


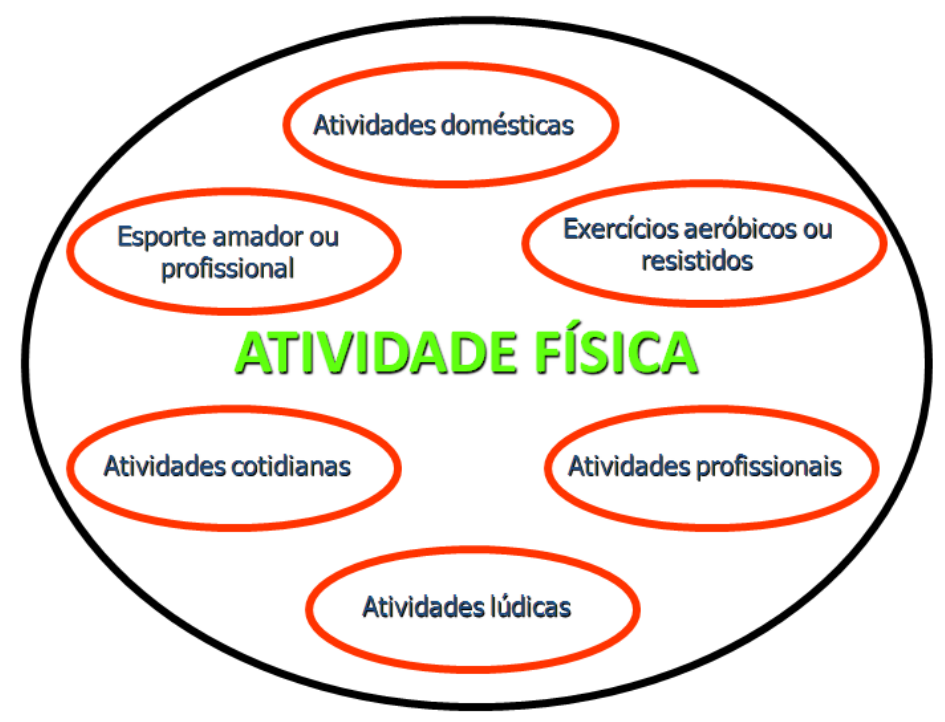

Figura 04 - Apresentação das ações voluntárias caracterizadas como atividade física.

De acordo com esta ampla definição, faz-se necessário definir a AF de forma a ser incorporada pelos profissionais de saúde em sua prática e pelos praticantes em suas atividades cotidianas profissionais ou domésticas.

Desta forma, quando a AF é prescrita ou executada seguindo critérios de intensidade, frequência, duração e modo de execução e, quando esta é prescrita ou praticada com fins de PS, tratamento e/ou prevenção de doenças, de ordem biológica ou psicológica ou ainda, quando esta prática é prescrita ou praticada visando o fortalecimento de uma comunidade ou de um grupo social específico em seus aspectos de interpretação e intervenção da sua realidade, torna-se mais adequado entendê-la e denominá-la como atividade física terapêutica (AFT).

Para incorporação da AFT por parte dos profissionais de saúde e dos praticantes é importante que sejam compreendidos os conceitos fundamentais para prescrição e execução objetivada e padronizada. O quadro 02 apresenta todos os valores e conceitos de acordo com a recomendação da AFT incorporada pela $\mathrm{OMS}^{39}$ e pelo $\mathrm{PASP}^{38}$. 
Quadro 02 - Conceitos fundamentais para prescrição / realização da atividade física terapêutica, 2007

\section{Conceitos Fundamentais}

\section{Prescrição de Atividade Física Terapêutica}

\begin{tabular}{|c|c|}
\hline VARIÁVEL & DEFINIÇÃO \\
\hline Frequência & $\begin{array}{l}\text { Quantidade total de dias por semana em que os indivíduos executam AF } \\
\text { moderada ou intensa }\end{array}$ \\
\hline Duração & Quantidade total de minutos de atividade física executadas por dia \\
\hline Modo & 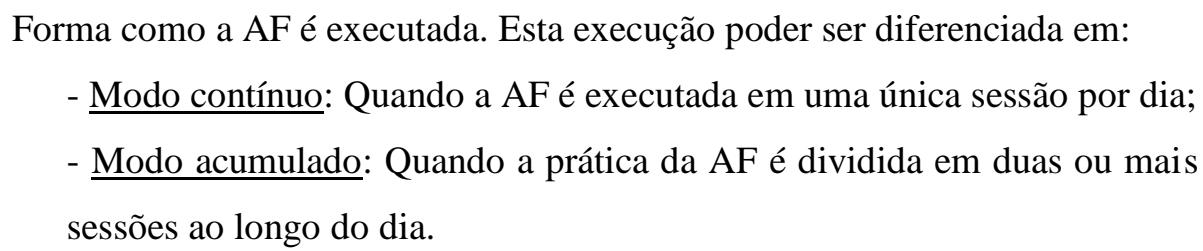 \\
\hline Intensidade & 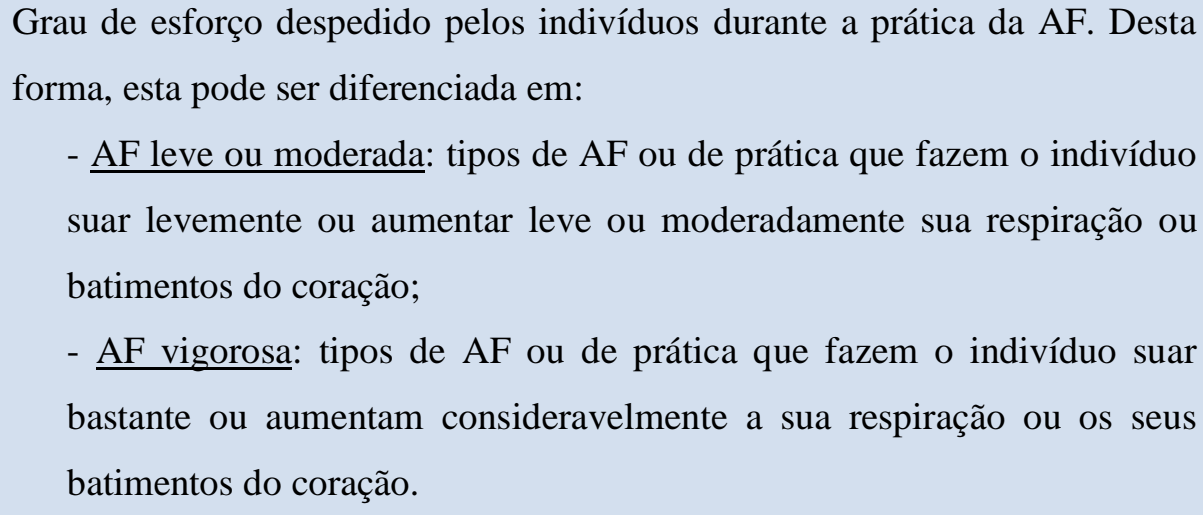 \\
\hline
\end{tabular}

Fonte: Adaptado pelo Programa Agita São Paulo, 1998

Para prescrição e execução da AFT moderada ou vigorosa em adultos e idosos, tem-se como padrão a recomendação proposta em 1994 pelo CDC em conjunto com o ACSM reforçados em 2007 pela "Associação Americana de Cardiologia" (AHA) ${ }^{43,76}$ e que são adotados por governos e pela comunidade científica nacional e internacional - OMS, OPAS, RAFA/PANA, MS, ME, SES/SP, 
SMS/SP, Sociedades Brasileiras de Medicina nos Esportes, de Cardiologia, de Hipertensão, de Diabetes e de Enfermagem nos Esportes (SBME, SBC, SBH, SBD e SOBEEsp) de acordo ao que segue:

Quadro 03 - Padrão de prescrição / realização da atividade física terapêutica, 2007

\begin{tabular}{|c|c|c|}
\hline PRESCR & \multicolumn{2}{|c|}{ PADRÕES E VALORES MÍNIMOS } \\
\hline VARIÁVEL & AFT MODERADA & AFT VIGOROSA \\
\hline Frequência & 5 (cinco) dias por semana & 3 (três) dias por semana \\
\hline Duração & 30 minutos por dia & 20 minutos por dia \\
\hline Modo & $\begin{array}{l}\text { Contínuo: } 30 \text { minutos ininterruptos, } \\
\text { ou } \\
\text { Acumulado: } 30 \text { minutos divididos } \\
\text { em } 2 \text { (duas) ou } 3 \text { (três) sessões com } \\
\text { tempo mínimo } 10 \text { (dez) minutos por } \\
\text { sessão }\end{array}$ & $\begin{array}{l}\text { Contínuo: } 20 \text { (vinte) minutos } \\
\text { executados de forma ininterrupta } \\
\text { ou com breves períodos de } \\
\text { descanso (30 a } 90 \text { segundos) } \\
\text { entre cada série de exercícios / } \\
\text { atividade quando esta assim se } \\
\text { apresentar }\end{array}$ \\
\hline Intensidade & Moderada & Vigorosa \\
\hline
\end{tabular}

Fonte: Adaptado de Haskell et al. Circulation [on line] 2007 Programa Agita São Paulo. SES/São Paulo, 1998

Estas definições de AFT devem ser apropriadas pelos profissionais de saúde e incorporadas às suas práticas de forma a ampliar suas possibilidades de interpretação e de intervenção em todos os aspectos relativos ao processo saúde-doença nos âmbitos individual, familiar e coletivo tanto na esfera da atenção básica como também em todas as especialidades da prática hospitalar e de reabilitação. 
Considerando apenas os aspectos clínicos e fisiológicos da AFT, para classificar o Nível de atividade física (NAF) dos indivíduos deve-se seguir os padrões definidos pela $\mathrm{OMS}^{39}$ e adotadas pelo VIGITEL ${ }^{33}$ apresentados no Quadro 04.

Quadro 04 - Critérios para classificação do nível de atividade física de adultos e idosos de ambos os sexos, 2007

\section{CLASSIFICAÇÃo DO NÍVEL DE ATIVIDADE FÍSICA}

\begin{tabular}{|c|c|c|c|c|}
\hline CLASSIFICAÇÃO & FREQUÊNCIA & DURAÇÃO & TIPO & TOTAL \\
\hline SEDENTÁRIO & Não faz & Não faz & Não faz & -- \\
\hline ATIVO & $<3$ dias/sem & $<20 \mathrm{~min} / \mathrm{dia}$ & Vigorosa & $<60 \mathrm{~min} / \mathrm{sem}<3 \mathrm{dias} / \mathrm{sem}$ \\
\hline INSUFICIENTE & $<5$ dias/sem & $<30 \mathrm{~min} / \mathrm{dia}$ & Moderada & $<150 \mathrm{~min} / \mathrm{sem}<5$ dias $/ \mathrm{sem}$ \\
\hline $\begin{array}{c}\text { FISICAMENTE } \\
\text { ATIVIVO }\end{array}$ & $\begin{array}{l}\geq 3 \mathrm{dias} / \mathrm{sem} \\
\geq 5 \mathrm{dias} / \mathrm{sem} \\
\geq 5 \mathrm{dias} / \mathrm{sem}\end{array}$ & $\begin{array}{l}\geq 20 \mathrm{~min} / \mathrm{dia} \\
\geq 30 \mathrm{~min} / \mathrm{dia} \\
\geq 30 \mathrm{~min} / \mathrm{dia}\end{array}$ & $\begin{array}{l}\text { Vigorosa } \\
\text { Moderada } \\
\text { Caminhada }\end{array}$ & $\begin{array}{l}\geq 60 \mathrm{~min} / \mathrm{sem} \geq 3 \mathrm{dias} / \mathrm{sem} \\
\geq 150 \mathrm{~min} / \mathrm{sem} \geq 5 \mathrm{dias} / \mathrm{sem} \\
\geq 150 \mathrm{~min} / \mathrm{sem} \geq 5 \mathrm{dias} / \mathrm{sem}\end{array}$ \\
\hline
\end{tabular}

Fonte: Adaptado de Haskell et al. Circulation [on line] 2007 Programa Agita São Paulo. SES/São Paulo, 1998

\subsubsection{Atividade Física: Programas de Promoção da Saúde populacional}

Em 1990, o então presidente da "Federação Internacional de Educação Física" já alertava sobre a necessidade de serem iniciados programas de saúde pública para o esclarecimento da população sobre a importância da AF e a inclusão de programas de exercícios em todas as fases da vida, garantindo a promoção da saúde e a melhora da qualidade de vida atuando assim na prevenção e redução das DCNT relacionadas ao sedentarismo ${ }^{77}$. 
Dentre os programas internacionais de AF, o quadro 05 apresenta uma lista com os principais de alguns países, estruturados a partir de 1970.

Quadro 05 - Programas internacionais de promoção da saúde através da atividade física.

\begin{tabular}{|lcc|}
\hline \multicolumn{1}{c}{ PROGRAMA } & PAÍS / ENTIDADE & ANO \\
\hline \hline North Karelia & Finlândia & 1972 \\
Active for life & Inglaterra & 1979 \\
Challenge Day (dia do desafio) & Canadá & 1985 \\
Active Living & Canadá & 1992 \\
Active Australian & Austrália & 1997 \\
Muévete Bogotá & Colômbia & 1998 \\
Envelhecimento Ativo & OMS & 1999 \\
Mexa-se Mais & Portugal & 1999 \\
Health people 2.000 & EUA & 2000 \\
Agita Mundo / Move for Health & CELAFISCS / OMS & 2002 \\
Health people 2.010 & EUA & 2010 \\
\hline \hline
\end{tabular}

No Brasil, nota-se um aumento do número de programas de PC/AF principalmente a partir desta década. Diversos fatores podem ser destacados para este fato como resultados significativos das diversas experiências em âmbito nacional e internacional, incentivo da $\mathrm{OMS}^{25,27,28,29}$ por meio da divulgação de informes, guias, experiências e resultados internacionais, incentivo financeiro do $M^{60,61,62,63}$ para desenvolvimento, manutenção e ampliação das ações PS/AF e o amadurecimento e reestruturação dos programas de PS/AF criados na década de 90. O Quadro 06, a seguir, demonstra alguns dos programas brasileiros de PS. 
Quadro 06 - Programas brasileiros de promoção da saúde através da atividade física.

\begin{tabular}{|c|c|c|c|}
\hline PROGRAMA & ENTIDADE & $\begin{array}{c}\text { ABRANGÊNCI } \\
\text { A }\end{array}$ & ANO \\
\hline $\begin{array}{l}\text { Educação e Saúde } \\
\text { através do Exercício } \\
\text { Físico e do Esporte }\end{array}$ & $\mathrm{MS} / \mathrm{ME}$ & Nacional & 1986 \\
\hline Dia do Desafio & SESC & Inter municipal & 1995 \\
\hline Agita São Paulo & CELAFISCS / SES-SP & Estadual & 1996 \\
\hline Agita Brasil & CELAFISCS / MS & Nacional & 2001 \\
\hline $\begin{array}{l}\text { Caminhando para a } \\
\text { Saúde }\end{array}$ & SMS / Santo André & Municipal & 2003 \\
\hline Agita Sampa & CELAFISCS / SMS-SP & Municipal & 2007 \\
\hline Agita Família & SES Tocantins & Estadual & 2009 \\
\hline
\end{tabular}

O Programa Educação e Saúde através do Exercício Físico e do Esporte pautado no binômio "Exercício Físico e Saúde", iniciou em 1986 através da parceria entre a Coordenação de Doenças Crônico-Degenerativas do MS Secretaria de Educação Física e de Desportos do Ministério da Educação e do Desporto, apresentava como objetivo principais capacitar profissionais das áreas de Educação, através de metodologia de ensino a distância, em Exercício Físico e Saúde e, implementar, junto às Universidades Federais e Estaduais e junto às Secretarias Estaduais e Municipais de Saúde, equipes locais para o fomento de programas de AF e saúde junto à população ${ }^{49}$.

Entre 1987 a 1988, o Programa foi implantado em 14 estados, através de convênios com as Universidades Federais e Estaduais de Educação Física e Secretaria de Educação Física e Desporto do ME. Em 1998, foi instituído o Comitê Técnico Científico de assessoramento das ações do Programa através da Portaria 3.711 do MS. Contando com a participação da Unicamp na Coordenação Geral do Programa, foram produzidos materiais de educação à distância (1986 e 1996) e, em 2001 tem-se a notícia do último encontro do Programa - III Encontro Nacional do 
Programa Educação e Saúde através do Exercício Físico e do Esporte, na qual foram reiterados os objetivos do programa, o qual já contava com a presença dos 27 estados brasileiros ${ }^{37,49}$.

Tendo como inspiração o "Challenge Day" - "Dia do Desafio", iniciado no Canadá em 1985 por meio da ParticipAction, entidade desportiva canadense, foi difundido pelo mundo através das ações da Trim \& Fitness International Sport for All Association (TAFISA), de origem alemã, e chegou ao Brasil em 1995, por meio do SESC São Paulo que, desde 1998 coordena as ações deste programa no Continente Americano. Este evento, realizado sempre na última quarta-feira do mês de Maio, consiste em mobilizar o maior número de participantes em torno da idéia de praticar pelo menos 15 minutos consecutivos de qualquer AF ou esportiva ${ }^{50}$.

Em termos de sua operacionalização, a inscrição e a realização acontecem oficialmente por meio das prefeituras municipais que após manifestarem seu interesse são agrupadas em sete categorias, seguindo o critério do número oficial de habitantes disponibilizado pelo Instituto Brasileiro de Geografia e Estatística (IBGE) para as cidades brasileiras e pelo número oficial de habitantes fornecido pelos próprios órgãos municipais das cidades estrangeiras. Em seguida realiza-se um sorteio que estabelece o desafio entre duas ou três comunidades da mesma categoria, que irão disputar qual delas consegue mobilizar o maior percentual de habitantes, em relação à sua população oficial ${ }^{50}$.

Iniciado no Estado de São Paulo em 1996, fruto da parceria entre a Secretaria de Estado da Saúde do Estado de São Paulo com o CELAFISCS, o Programa Agita São Paulo tem como objetivos principais incrementar o nível de conhecimento da população do Estado de São Paulo sobre a AF/PS e aumentar o nível de AF da população do Estado de São Paulo ${ }^{37,38,44}$. O Programa que tem como base o protocolo de prescrição de AFT aceito pela OMS e que foi desenvolvido pelo CDC em conjunto com ACSM em $1995^{43}$ e validado em 2007 pela $\mathrm{AHA}^{76}$.

Desde 1998, junto com o desenvolvimento da RAFA/PANA, o PASP ${ }^{38}$ foi utilizado como padrão para criação de programas similares nos países da América latina (Programa Muévete Bogotá - Colômbia; A Moverse - Argentina) ${ }^{44}$. 
A partir de 1999, o PASP, iniciou o seu processo de municipalização sendo implantado, inicialmente, em diversos municípios do Estado, dentre eles, os Programas Agita Limeira, Agita Ribeirão, e o Agita Piracicaba ${ }^{52}$.

A partir destas ações no Estado de São Paulo, outros municípios do Brasil e do exterior implementaram ações similares, como por exemplo os programas: Agita Canela - RS, Agita Cornélio - Cornélio Procópio - PR, Mexe Campina - PA, Agita Bahia - BA, Agita Nova Lima - MG, Agita Maúés - AM e Agita Campo Grande - MS, além dos Programas Active Trinidad Tobago e Risaralda Activa Colômbia ${ }^{44}$.

Com o processo de ampliação da rede de municipalização do PASP, em 2001 foi estruturado pelo MS o "Programa Agita Brasil"51 recebendo incentivo do ministério através do treinamento e contratação de multiplicadores espalhados em todas as regiões do país. Em 2002, o PAB contava com cerca de 2.200 multiplicadores espalhados no país e atualmente, a "Rede Agita Brasil", composta por estados, municípios, e entidades particulares conta com a participação de mais de 350 parceiros espalhados por cidades de todas as regiões do território nacional ${ }^{52}$.

Ainda em 2002, o PASP ${ }^{38}$ foi considerado como um Programa Modelo de PS/AF ${ }^{45}$ pela OMS na $54^{\mathrm{a}}$ Assembléia Mundial da Saúde e motivou esta entidade a lançar o "Programa Agita Mundo" e a instituir, a partir de 06 de Abril de 2003, este dia como Dia Mundial da $\mathrm{AF}^{48}$. Em 2005, o $\mathrm{PASP}^{38}$ recebeu, por suas ações no combate ao sedentarismo e na PS/AF, o "10 Prêmio CDC Internacional de Atividade Física e Saúde Pública" ${ }^{\text {,8,64 }}$

Em 2005 iniciaram as ações de aproximação do PASP com a CAB-SMS/SP e, esta parceria foi oficializada, em maio de 2007, por meio de decreto oficial, na qual culminou com o lançamento do "Programa Agita Sampa"78 que apresenta os mesmos moldes de logística, organização, estrutura e prática que o PASP. 


\subsubsection{Atividade Física: Incorporação à prática dos enfermeiros}

O processo de trabalho no setor saúde pode ser entendido como um conjunto de saberes, instrumentos e meios, tendo como sujeitos profissionais que se organizam para produzirem serviços de modo a prestarem a assistência individual e coletiva para obtenção de produtos e resultados decorrentes de sua prática ${ }^{79}$.

A prática de enfermagem, mais especificamente dos enfermeiros, determinada historicamente e resultante da expressão dos modos de organização social, integra-se às práticas dos outros trabalhadores de saúde como um coletivo que responde pela produção de serviços de saúde ${ }^{80}$. Desta forma, a prática do enfermeiro é parte de um processo coletivo de trabalho que tem como finalidade produzir ações de saúde, caracterizando-se por um saber específico, com ações contínuas e articuladas com os demais membros da equipe, na construção dos objetos comuns de trabalho no setor saúde ${ }^{81}$.

Considerados isoladamente, a Promoção da Saúde e a AF apresentam diversas possibilidades de interpretação, vertentes e caminhos. Quando ambos os termos são associados - PS/AF - estas possibilidades mais que se multiplicam, tornando assim, difícil a operacionalização destes conceitos à prática profissional dos enfermeiros, muito em virtude dos termos serem pouco ou nada abordados nos cursos de graduação de enfermagem, pela escassa literatura relacionando a PS/AF à enfermagem e, ainda, somam-se a isso o não posicionamento e ações oficiais das entidades reguladoras de enfermagem (Conselho Federal de Enfermagem - Cofen, Conselhos Regionais de Enfermagem - Corens e Associação Brasileira de Enfermagem - Aben) a respeito da incorporação destes conceitos as práticas dos enfermeiros. Conceitos que são polissêmicos, extremamente incipientes e ainda atravessam seu paradigma de construção e estruturação por meio de guias oficiais norteando as ações nas dimensões estrutural (MS), particular (SES e SMS) e singular (Prática profissional).

Desta forma, por tudo o que já foi exposto, retoma-se o $\mathrm{PASP}^{38}$ como o melhor programa de PS/AF a ser incorporado pelos enfermeiros às suas práticas profissionais nas dimensões estrutural (Cofen, Aben e SOBEEsp), particular (Coren 
e Aben regional) e singular (prática profissional). Dentre as vantagens que o protocolo de prescrição / execução de AFT do PASP $^{38}$ apresenta, há de se ressaltar:

1. Fácil entendimento e operacionalização tanto em ações individuais quanto coletivas não necessitando cursos de capacitação extensivos e caros;

2. Ser aplicável em qualquer tipo de PC/AF (caminhada, ginásticas orientais, danças, atividades domésticas, atividades de trabalho, atividades de lazer, etc);

3. Os mesmos valores mínimos de prescrição da AFT (5 dias por semana, 30 minutos por dia executados de forma contínua ou acumulada, em intensidade moderada) deste protocolo também poderem ser utilizados para diagnóstico da prática de AF (fisicamente ativo, insuficientemente ativo e sedentarismo);

4. Ausência de restrições legais ou clínicas;

5. Ausência da necessidade de adaptações para incorporação deste protocolo às práticas profissionais.

Retomando as condições históricas da vida humana desde a pré-história até os dias atuais, a locomoção dos homens considerada como sair de um ponto espacial qualquer a outro ponto, faz-se prioritariamente pelo ato de caminhar. Desde a mais tenra idade, na transição entre as fases do lactente para o infante, somos ansiosos ao estimular os primeiros passos da criança e até comemoramos o acontecimento deste processo. Tal fato, estímulo e incentivo para caminhar, também se repetem nos nossos pacientes que estão em fase de reabilitação. Para sair da cama pela manhã e iniciar nossas atividades cotidianas, uma das primeiras ações é de se levantar para caminhar. Caminhamos para tudo, para ir ao trabalho, a escola, para passear, visitar amigos, etc. Caminhar é tão inerente à condição humana quanto a nossa própria condição de vida. Desta forma, em consideração a esta afirmação, pode-se analisar o ato de caminhar sob diversas ópticas.

Contudo, independente da óptica que se observa o fenômeno caminhar, ato de se locomover de um ponto a outro, em toda análise este será considerado como uma ação humana primordial de vida historicamente constituída como tal desde o período 
pré- histórico, podendo este ato ser moldado pelos aspectos de inserção e interação social assim como pelos objetivos desta ação, terapêutico por exemplo.

Para a introdução de novas tecnologias na prática profissional de enfermagem, destinadas a ampliar as possibilidades de ação terapêutica voltadas às demandas e necessidades da população, há que se considerarem todos os fatores inerentes a esta ação. Dentre as considerações voltadas à incorporação de novas tecnologias à prática profissional de enfermagem, destaco as seguintes:

- os custos e o tempo gastos no processo de capacitação profissional para incorporação desta tecnologia à prática profissional dos enfermeiros;

- as possibilidades de incorporar esta ação também à prática dos profissionais de nível superior ${ }^{82}$ tanto quanto dos auxiliares e técnicos de enfermagem assim como os custos relativos ao processo de capacitação destes;

- o impacto terapêutico e social das ações desta tecnologia ${ }^{82}$;

- as possibilidades de desenvolvimento e valorização da profissão com a incorporação desta nova prática;

- a autonomia e respaldo legal para utilização desta tecnologia;

- a amplitude terapêutica desta nova tecnologia por meio das questões de trans e inter disciplinaridade inerentes a viabilização desta prática em todas as especialidades e áreas de atuação da enfermagem;

- a adesão dos profissionais a esta nova tecnologia;

- os efeitos colaterais e as possíveis iatrogenias que esta nova tecnologia pode provocar;

- a adesão e as possibilidades de incorporação desta tecnologia por parte dos pacientes.

Com isso, podemos verificar que as possibilidades de ações resultantes da organização de Grupos de Caminhada (GC) não necessitam ficar restritas apenas no 
indivíduo em seu aspecto biológico. Estas ações, quando incorporadas ao eixo de PS previstos no SUS e na ESF, podem contemplar o fortalecimento do individuo em suas relações familiares e sociais, podem vislumbrar e reivindicar a melhoria do espaço público para a execução destas próprias atividades assim como de muitas outras, podem trabalhar e promover a ocupação de outros espaços coletivos em parcerias com outros setores da sociedade alheios ao setor saúde além de estruturar o desenvolvimento de atividades intersetoriais que promovam a melhoria da qualidade de vida da população adstrita na Unidade de Saúde da Família (USF). Ou seja, incorpora-se neste processo, conceitos de PS na implantação das PC/AF.

Visando o fortalecimento da profissão de enfermagem por meio da incorporação de novas tecnologias a sua ação e tendo como pano de fundo a PNPS, este estudo apresenta como questão norteadora principal, o desejo de saber como o enfermeiro está inserido nos GC das ESF da rede básica de saúde da cidade de São Paulo com foco na Prática Profissional dos Enfermeiros.

Contudo, quando se analisa a atual forma de operacionalização do processo de aplicação da AFT nas unidades da rede básica de saúde, poucas são as informações sobre como estes conceitos e ações materializam-se na prática profissional dos enfermeiros. Desta forma, considerando a escassa produção científica relacionando a AFT às práticas específicas dos enfermeiros é que se pretende, com este estudo, investigar como está inserida a AFT, mais precisamente os GC, nas práticas profissionais dos enfermeiros das USF catalogados pela CABPMSP bem como o nível de conhecimento sobre o protocolo de prescrição de AFT para PS. 


\section{OBJETIVOS}

\subsection{Objetivo Geral}

Caracterizar a atuação do enfermeiro nos grupos de caminhada das Unidades de Estratégia de Saúde da Família do município de São Paulo.

\subsection{Objetivos Específicos}

1. Caracterizar os grupos de caminhada das Unidades de Saúde da Família, catalogados pela Coordenação de Atenção Básica da prefeitura municipal de São Paulo (CAB-PMSP);

2. Caracterizar a atuação do enfermeiro no grupo de caminhada;

3. Avaliar do nível de conhecimento dos enfermeiros que atuam nos grupos de caminhada para prescrição de AF. 


\section{METODOLOGIA}

\subsection{Tipo de pesquisa}

Trata-se de um estudo exploratório, descritivo, transversal, de abordagem quantitativa.

Foram realizadas entrevistas com os enfermeiros das ESF das unidades do município de São Paulo que apresentavam GC ativos, por meio de instrumentos estruturados aplicados pelo autor deste estudo no período de junho a novembro de 2009.

\subsection{Cenário do estudo}

Este estudo foi realizado nos grupos de caminhada das ESF do município de São Paulo catalogados pela ATMT-CABSMS em $2008^{73}$.

Dentre as ESF, foram consideradas as existentes em todas as USF das cinco regiões do município de São Paulo assim como, também foram incluídas as ESF existentes nas Unidades denominadas Mistas (UM) em que coexistem os dois modelos de atenção, tradicional e o de saúde da família, sendo que apenas os enfermeiros que pertenciam às equipes de saúde da família participaram do estudo.

Em Junho de 2009, de acordo com os dados disponibilizados pela CABSMS/SP ${ }^{83}$ a cidade de São Paulo contava com 799 estabelecimentos de saúde, entre Ambulatório de Especialidades (AE), Centro de Atenção Psico Social (CAPS), Ambulatórios de Saúde mental, Serviço de Assistência Especializada em Doenças Sexualmente Transmissíveis e Aids (SAE-DST/AIDS), Centro de Referência em Saúde infantil (CRSI) ou do Trabalhador (CRST), Centro de Saúde Escola (CSE), UBS tradicionais, Unidades Mistas (UM) e Unidade Saúde da família (USF) compunham a Rede Básica de Saúde (RBS) do município. 
Dentre todos os estabelecimentos de Saúde de São Paulo, aproximadamente $30 \%$ destes (Tabela 01) constituiu-se pelo grupo formado pelas unidades com ESF USF e UM.

Tabela 01 - Distribuição dos estabelecimentos da RBS e das UM e USF do município de São Paulo. São Paulo, 2009.

\begin{tabular}{|c|c|c|c|c|c|c|}
\hline \multicolumn{7}{|c|}{ ESTABELECIMENTOS DA REDE BÁSICA DE SAÚDE DE SÃO PAULO } \\
\hline \multirow{3}{*}{ TOTAL } & \multicolumn{6}{|c|}{ UNIDADES DE SAÚDE DE SÃO PAULO COM ESF } \\
\hline & \multirow{2}{*}{$(\mathrm{N})$} & \multirow{2}{*}{$(\%)$} & \multicolumn{2}{|c|}{ USF } & \multicolumn{2}{|c|}{ UM } \\
\hline & & & $(\mathrm{N})$ & $(\%)$ & $(\mathrm{N})$ & $(\%)$ \\
\hline 799 & 235 & 29,4 & 149 & 63,4 & 86 & 36,6 \\
\hline
\end{tabular}

Em 2008, de acordo com a ATMT-CABSMS ${ }^{73}$ estavam cadastradas 689 PICS que se distribuíam em 418 estabelecimentos da RBS de São Paulo, o que corresponde a 52,3\% do total de estabelecimentos. Estas atividades foram agrupadas em Caminhada, Práticas Orientais (PO) e Outras PCIS conforme demonstra a tabela 02.

Tabela 02 - Distribuição das atividades de PCIS, em relação ao tipo de atividade organizada, no município de São Paulo. São Paulo, 2008.

\begin{tabular}{ccccccc}
\hline \multicolumn{6}{c}{ Atividades de Práticas Integrativas em Saúde } \\
\hline \multirow{2}{*}{ Total } & Caminhada & \multicolumn{2}{c}{ Práticas Orientais } & \multicolumn{2}{c}{ Outras PCIS } \\
& $(\mathrm{N})$ & $(\%)$ & $(\mathrm{N})$ & $(\%)$ & $(\mathrm{N})$ & $(\%)$ \\
\hline 689 & 139 & 20,2 & 397 & 57,6 & 153 & 22,2 \\
\hline \multicolumn{7}{l}{ Fonte: Coordenação de Atenção Básica da SMS-SP: Área Técnica das MTPIS Agosto/2008 }
\end{tabular}

Considerando PCIS executadas apenas nas unidades com ESF, estas estruturavam-se em 242 USF ou UM das quais 95 (39,3\%) apresentavam GC $^{73}$, constituindo-se assim o universo deste estudo. (tabela 03) 
Tabela 03 - Distribuição das Unidades de Saúde estabelecimentos da RBS e das UBS, UM e USF do município de São Paulo. São Paulo, 2009.

\begin{tabular}{|c|c|c|c|c|c|c|}
\hline \multirow{4}{*}{ TOTAL } & \multicolumn{6}{|c|}{ UNIDADES DE SAÚDE DE SÃO PAULO COM ESF E PICS } \\
\hline & \multicolumn{6}{|c|}{ UNIDADES DE SAÚDE DE SÃO PAULO COM ESF E COM GC } \\
\hline & \multirow{2}{*}{$(\mathrm{N})$} & \multirow{2}{*}{$(\%)$} & \multicolumn{2}{|c|}{ USF } & \multicolumn{2}{|c|}{ UM } \\
\hline & & & $(\mathrm{N})$ & $(\%)$ & $(\mathrm{N})$ & $(\%)$ \\
\hline 242 & 95 & 30,1 & 69 & 72,6 & 26 & 27,4 \\
\hline
\end{tabular}

\subsection{População e amostra do estudo}

O estudo foi constituído por toda a população de enfermeiros das ESF do município de São Paulo que participavam direta ou indiretamente dos GC das USF ou UM.

Para definição da participação direta do enfermeiro nos GC, este deveria se enquadrar em um dos seguintes critérios:

1) Contato com os participantes do GC, através de avaliações clínicas de inclusão, retorno ou continuidade;

2) Atividades de orientação aos participantes do grupo; e

3) Realizar a caminhada juntamente com o grupo ao menos uma vez por mês.

$\mathrm{O}$ envolvimento indireto do enfermeiro junto ao $\mathrm{GC}$ foi definido quando este não apresenta, em momento algum, contato direto com os participantes do grupo de caminhada, atuando apenas em questões administrativas junto aos funcionários responsáveis, tais como supervisão, elaboração da escala dos funcionários.

Definido o universo da pesquisa, foi efetuado contato telefônico junto aos gerentes das Unidades com ESF e com GC para se determinar quais destes grupos contavam com a participação dos enfermeiros. Com esta etapa, definiu-se que a população deste estudo seria composta por 38 enfermeiros. Dentre estes, 4 não foram 
encontrados após três tentativas e 7 se recusaram a participar do estudo, resultando em um total de 27 enfermeiros entrevistados, sendo que 16 eram das USF e 11 das UM.

Os critérios para inclusão dos sujeitos nesta pesquisa foram:

- O GC da unidade (USF ou UM) estar ativo no momento da entrevista;

- O enfermeiro apresentar envolvimento com o GC de forma direta ou indireta no mínimo há um mês;

- Concordar em participar da entrevista assinando o termo de consentimento livre e esclarecido.

E os critérios de exclusão foram:

- O enfermeiro ser envolvido com o GC de forma direta ou indireta por período inferior a um mês;

- O enfermeiro não participar de forma contínua junto ao grupo de caminhada no momento da coleta de dados;

- O enfermeiro encontrar-se de férias ou licença no momento da entrevista ou não ser encontrado na unidade em mais de 03 tentativas;

\subsection{Material e Método}

\subsubsection{Etapas da Pesquisa}

Inicialmente, foram selecionadas as Unidades de Saúde que apresentavam programas de caminhada catalogados, até agosto de 2008, pelo PQVMTPIS, da CAB-SMS ${ }^{73}$.

Após o levantamento dessas Unidades buscou-se identificar quais eram USF e UM para a inclusão no estudo. Para tal, utilizou-se dos dados fornecidos pela CAB- 
SMS/SP referentes ao conjunto e à classificação dos estabelecimentos da rede básica de saúde (RBS) por coordenadoria de saúde, em $2009^{84}$.

Identificadas as USF e UM, foi realizado contato telefônico com a gerência destas Unidades com o objetivo de confirmar a existência do GC e levantar a participação de enfermeiros nos grupos.

A coleta de dados foi realizada através da aplicação de questionários através de entrevistas efetuadas direta e exclusivamente pelo pesquisador nas UM ou USF, das cinco regiões do Município de São Paulo, que continham grupos de caminhada catalogados pela ATMT-CABSMS ${ }^{73}$.

A seguir serão descritas, resumidamente, as etapas do estudo para a seleção e coleta da amostra.

Etapa 1 - Levantamento do número total de Unidades de Saúde localizados na Cidade de São Paulo catalogadas pela CAB-SMS. Para efetuar o levantamento das unidades básicas de saúde das cinco regiões da cidade de São Paulo, foram selecionadas as unidades identificadas como UBS no documento elaborado pela Coordenação de Epidemiologia e Informação da Secretaria Municipal de Saúde de São Paulo - CEInfo-SMS ${ }^{83}$. Este documento traz a relação de todos os Estabelecimentos da RBS da SMS divididas por subprefeitura. Desta forma, foi efetuado o agrupamento e contagem manual das UBS por Coordenadoria Regional de Saúde e por subprefeituras. No caso das UBS listadas neste documento, este não traz a sua condição frente à presença de ESF.

Etapa 2 - Identificação das Unidades de Saúde agrupadas de acordo com a sua condição de presença de ESF. Para esta identificação, foi utilizado dados disponibilizados diretamente pela diretoria da CABSMS que apresentavam a classificação das unidades que continham ESF em USF ou UM por sub prefeitura e por Coordenadoria Regional de Saúde.

Etapa 3 - Levantamento das Unidades de Saúde com GC como atividade de PICS na Cidade de São Paulo catalogadas pela ATMT-CABSMS. Para efetuar o levantamento das unidades básicas de saúde das cinco regiões da cidade de São 
Paulo, foram selecionadas as unidades identificadas como UBS ou CSE que apresentavam a atividade "Caminhada" no documento elaborado pela ATMTCABSMS $^{73}$. Este documento, de Agosto de 2008, estruturado no formato folder, num total de 5 (cinco), sendo um para cada Coordenadoria Regional de Saúde da cidade de São Paulo, continha a relação de todas as unidades que apresentam projetos relacionados à PICS, sendo que a caminhada estava inserida neste conjunto.

Etapa 4 - Identificação dentre as unidades que apresentavam GC, aquelas que se estruturavam por meio da ESF, sendo em UM ou em USF. Para esta identificação, foi efetuado o cruzamento entre os dados obtidos na Etapa 02 com os dados obtidos na Etapa 04, definindo-se assim, o Universo desta Pesquisa.

Etapa 5 - Contato telefônico com a gerência das USF e UM a fim de identificar quais contavam com o envolvimento de enfermeiros junto aos GC, definindo-se a População deste Estudo. Para os envolvimentos confirmados, foi definido os dias mais apropriados para a realização da entrevista.

Em maio de 2009, foram realizadas cinco entrevistas piloto com enfermeiros envolvidos em grupos de caminhada catalogados pelo PQVMTPIS-CABSMS ${ }^{73}$ de UBS tradicionais da zona norte e oeste da cidade com o objetivo de avaliar o entendimento destes frente aos objetivos das questões dos instrumentos elaborados no interior desta pesquisa - Caracterização do Grupo de Caminhada e Análise de Prática Profissional. Os testes indicaram que não houve problemas de entendimento frente aos questionamentos relacionados ao $\mathrm{GC}$ ou aos aspectos de prática profissional e, também não houve, por parte dos entrevistados, sugestões de alteração ou inclusão de novas questões no instrumento.

\subsection{2 - Descrição dos instrumentos de pesquisa}

Uma breve caracterização da população do estudo foi realizada através das variáveis idade, tempo de formado, tempo de trabalho no PSF, tempo de trabalho na UBS e especialidade. 


\section{Questionário 1: Nível de Conhecimento}

Para verificação do nível de conhecimento (NC) dos enfermeiros sobre AF/PS foi utilizado o "Questionário sobre o Nível de Conhecimento de Atividade Física para Promoção da Saúde” (QNC-AF/PS), utilizado pelo Programa Agita São Paulo, desde $1996^{38}$. Este questionário é composto por quatro questões, sendo cada questão estruturada para analisar, de forma independente, as variáveis do NC-AF/PS.

Este instrumento é composto por questões que determinam os valores mínimos de AFT moderada para adultos recomendados pela $\mathrm{OMS}^{39}$ e PASP $^{38}$ referentes à freqüência e duração, assim como, os conceitos referentes à intensidade e ao modo de como a AFT deve ser prescrita / executada. No caso do entrevistado responder que a AFT deve ser realizada de modo indiferente (modo contínuo ou acumulado), este deverá mencionar o menor tempo proposto para a prática da sessão fracionada.

Serão considerados para análise de cada variável os valores e as definições que constam da nova recomendação para prescrição e execução da AFT moderada em adulto, proposta em 1994 pelo CDC em conjunto com o $\mathrm{ACSM}^{38}$, que é aceita pela $\mathrm{OMS}^{39}$ e pelo $\mathrm{MS}^{60}$, reafirmados em 2007 pela Associação Americana de Cardiologia (AHA) $)^{76}$.

Desta forma, definidas as variáveis e a referência para definição dos seus conceitos, o Quadro 07 apresenta o padrão considerado adequado para as respostas referentes ao NC- AF/PS dos enfermeiros, constituindo-se os seguintes critérios de análise. 
Quadro 07 - Padrão adequado para respostas referentes ao nível de conhecimento sobre AF/PS.

\begin{tabular}{|c|c|}
\hline VARIÁVEL & AFT MODERADA \\
\hline Frequência & 5 (cinco) dias por semana \\
\hline Duração & 30 minutos por dia \\
\hline Modo & $\begin{array}{l}\text { Não importa o modo. } \\
\text { A AFT pode ser executada de modo: } \\
\text { - Contínuo: Execução de } 30 \text { minutos diários ininterruptos, ou } \\
\text { - Acumulado: Execução de } 30 \text { minutos diários podendo estes ser } \\
\text { divididos em } 2 \text { (duas) ou } 3 \text { (três) sessões com tempo mínimo por } \\
\text { sessão } 10 \text { (dez) minutos }\end{array}$ \\
\hline Intensidade & Moderada \\
\hline
\end{tabular}

Fonte: Adaptado de Haskell et al. Circulation [on line] 2007 Programa Agita São Paulo. SES/São Paulo, 1998

Como as variáveis do QNC-AF/PS permitem a análise independente, desta forma, o NC-AF/PS dos enfermeiros será classificado da seguinte forma:

- CONHECIMENTO PLENO: ocorrerá nos casos em que os valores e conceitos de TODAS as questões do questionário do NC-AF/PS forem respondidas de acordo com os valores e conceitos propostos na nova recomendação para prescrição e execução da AFT moderada em adulto;

- CONHECIMENTO PARCIAL: ocorrerá nos casos em que os valores e conceitos de pelo menos UMA das questões do questionário do NC-AF/PS for respondida de acordo com os valores e conceitos propostos na nova recomendação para prescrição e execução da AFT moderada em adulto; 
- CONHECIMENTO INADEQUADO: ocorrerá nos casos em que os valores e conceitos de NENHUMA das questões do questionário do NCAF/PS forem respondidas de acordo com os valores e conceitos propostos na nova recomendação para prescrição e execução da AFT moderada em adulto;

Para caracterização do GC e identificação da prática profissional de enfermagem foram elaborados instrumentos específicos. A construção do instrumento contou com a participação dos membros do Grupo de Pesquisa do Departamento de Enfermagem em Saúde Coletiva da Escola de Enfermagem da USP, intitulado "Modelos Tecno-Assistenciais e a Promoção da Saúde”* (Anexo 3).

\section{Questionário 2: Caracterização do Grupo de Caminhada}

Esse instrumento é composto por questões relacionadas ao tempo de existência do GC, frequiência e duração da atividade, utilização de protocolos para identificação de sedentarismo nas consultas de enfermagem e fluxo de encaminhamento para participação no GC.

\section{Questionário 3: Análise de Prática Profissional}

Para conhecer as características relacionadas à prática profissional do enfermeiro junto ao grupo de caminhada, o questionário avalia o tempo que participa do grupo, a motivação para o início e a continuidade da sua participação, atividades executadas no grupo e demais profissionais envolvidos no grupo.

\subsubsection{Tratamento e análise dos dados}

A tabulação dos dados foi feita utilizando-se o programa Microsoft Office Excel 2007® e o tratamento foi feito utilizando-se os programas Microsoft Office Excel 2007® e SPSS 12.0 (Statistical Package for the Social Sciences).

* Informações sobre o Grupo de Pesquisa "Modelos Tecno-Assistenciais e a Promoção da Saúde" podem ser encontradas no site: http://www.ee.usp.br/pesquisa/grupromo/ 
Foram efetuadas análises descritivas das variáveis contínuas deste estudo, por meio de agrupamento das respostas semelhantes, realizando a contagem da freqüência e o cálculo percentual. Para algumas destas variáveis, também foram efetuados cálculos dos valores de média aritmética, desvio padrão e mediana dos dados de algumas questões.

Para a análise das correlações entre as variáveis referentes ao nível de conhecimento e as demais do questionário, primeiro foram efetuados testes para verificar se as variáveis tinham distribuição normal - teste de Kolmogorov-Smirnov - e posteriormente foram aplicados os testes de correlação - teste T, Qui quadrado e Fisher. Foi adotado o nível de significância $\mathrm{p}<0,05$.

\subsection{Aspectos éticos}

O estudo obteve aprovação do Comitê de Ética em Pesquisa da Secretaria Municipal de Saúde de São Paulo (CEP/SMS), através do parecer de número 267/09 (ANEXO 02) para coleta de dados em todas as Unidades de Saúde das cinco Coordenadorias Regionais da cidade de São Paulo. Para esta autorização, foi necessária a assinatura do Coordenador da Atenção Básica da SMS/SP.

A privacidade do entrevistado foi garantida no momento da coleta de dados através da garantia da não identificação do sujeito da pesquisa no momento de divulgação dos dados evitando assim qualquer prejuízo em relação às suas atividades cotidianas, pessoais e profissionais.

Os participantes foram informados sobre os objetivos da pesquisa e das questões relativas à análise e confidencialidade dos dados, nos termos da Resolução 196/96. Após estes esclarecimentos, todos os entrevistados que participaram da pesquisa assinaram o termo de consentimento livre e esclarecido (ANEXO 01). 


\section{RESULTADOS}

\subsection{Caracterização dos grupos de caminhada das equipes de saúde} da família de cidade de São Paulo.

Dentre as Unidades com ESF da cidade de São Paulo, 38 apresentavam GC com a participação de enfermeiros, ou seja, 16,2\% das Unidades Básicas com ESF do município de São Paulo (tabela 04). Considerando apenas as unidades da Regional Norte, esta proporção não atingiu 5\%.

Tabela 04 - Relação entre as USF e UM da cidade e as USF e UM com GC e com envolvimento de enfermeiros, nas cinco regiões do município de São Paulo. São Paulo, 2009.

\begin{tabular}{cccc}
\hline \multirow{2}{*}{$\begin{array}{c}\text { Coordenadorias de } \\
\text { Saúde }\end{array}$} & Total & \multicolumn{3}{c}{ GC com Enfermeiros } \\
\cline { 2 - 4 } & & $(\mathrm{N})$ & $(\%)$ \\
\hline Leste & 56 & 12 & 21,4 \\
Sul & 68 & 13 & 19,1 \\
Sudeste & 46 & 08 & 17,4 \\
Norte & 43 & 02 & 4,7 \\
Centro Oeste & 22 & 03 & 13,6 \\
Município de São Paulo & 235 & 38 & 16,2 \\
\hline
\end{tabular}

Das 38 unidades de saúde com ESF que contavam com GC com envolvimento de enfermeiros, 27 participaram do estudo (71,1\%). O maior número de grupos encontra-se nas regiões leste e sul, com menor proporção de entrevistados enquanto que o menor encontra-se nas regiões norte e centro oeste com $100 \%$ dos enfermeiros entrevistados (tabela 05). 
Tabela 05 - Distribuição dos Grupos de Caminhada com enfermeiros entrevistados nas Unidades com ESF da cidade de São Paulo e por Coordenadoria de Saúde. São Paulo, 2009.

\begin{tabular}{cccc}
\hline \multirow{2}{*}{$\begin{array}{c}\text { Coordenadorias de } \\
\text { Saúde }\end{array}$} & \multicolumn{3}{c}{ GC com Enfermeiros Entrevistados } \\
\cline { 2 - 4 } & Total & $(\mathrm{N})$ & $(\%)$ \\
\hline Leste & 12 & 08 & 66,7 \\
Sul & 13 & 08 & 61,5 \\
Sudeste & 08 & 06 & 75,0 \\
Norte & 02 & 02 & 100,0 \\
Centro Oeste & 03 & 03 & 100,0 \\
Município de São Paulo & 38 & 27 & 71,1 \\
\hline
\end{tabular}

Considerando o tempo de existência dos GC nas unidades que compuseram a amostra deste estudo, este variou de 04 meses a 10 anos, com média de 04 anos (Desvio Padrão $(\mathrm{dp})=3,1)$ e com mediana de 3,0 anos. Quanto a realização da caminhada, esta variou de 2 a 5 dias por semana, com média de 3 dias por semana $(\mathrm{dp}=1)$ e mediana de 3,0 dias. Com relação a duração, o GC variou de 15 a 75 minutos, com média de 48 minutos $(\mathrm{dp}=15)$ e mediana de 60 minutos.

Quanto ao encaminhamento dos pacientes para o GC (Tabela 06) em nenhuma das unidades ocorreu de uma única forma ou se apresentou com indicação exclusiva de uma categoria profissional. Os pacientes foram encaminhados para o GC em sua maioria pelos enfermeiros $(92,6 \%)$, seguido pelos médicos $(88,9 \%)$ e pelos ACS $(77,8 \%)$.

Quase a totalidade destes GC contavam com a participação de ACS $(92,6 \%)$, sendo também significativo o percentual de participação de educadores físicos $(51,9 \%)$ e dos profissionais de nível médio da enfermagem $(51,9 \%)$. 
Tabela 06 - Distribuição dos profissionais segundo características de envolvimento nos grupos de caminhadas. São Paulo, 2009.

VARIÁVEIS N

$(\%)$

Encaminhamento do paciente aos GC

\begin{tabular}{cll}
\hline Enfermeiro & 25 & 92,3 \\
Médico & 24 & 88,9 \\
ACS & 21 & 77,8 \\
Auxiliar e/ou Técnico de enfermagem & 18 & 66,7 \\
Solicitação do próprio paciente & 16 & 59,3 \\
\hline Profissionais envolvidos com GC & & \\
ACS & 25 & 92,3 \\
Auxiliar e/ou Técnico de enfermagem & 14 & 51,9 \\
Educador Físico & 14 & 51,9 \\
Outros profissionais graduados de saúde & 09 & 33,3 \\
Médicos & 08 & 29,6 \\
\hline
\end{tabular}

\subsection{Caracterização dos enfermeiros e de suas práticas nos grupos}

\section{de caminhada}

Dos 27 enfermeiros que participaram deste estudo, a maioria absoluta era composta por mulheres $(85,2 \%)$, com idade média de 34 anos $(\mathrm{dp}=7,1)$ e com mediana de 33 anos, sendo 23 anos a idade mínima e 50, a máxima.

Com relação à experiência profissional, o tempo de formado variou de um ano e oito meses a 25 anos, com uma média de 9,6 anos de formado ( $d p=7,3)$ e com mediana de 8 anos. O tempo de experiência trabalhando em Equipes de Saúde da Família variou de 05 meses a 9 anos, com uma média de 4,4 anos de trabalho em $\operatorname{ESF}(d p=3,0)$ e com mediana de 4 anos. Em relação ao tempo em que este profissional trabalha na unidade em que se encontrava no momento da entrevista, este variou de 03 meses a 9 anos, com média de 3,3 anos $(\mathrm{dp}=2,5)$ e com mediana de 
2,5 anos. Quanto ao tempo em que este enfermeiro participa do GC este variou de 2 meses a 4 anos, com média de 1,9 anos $(\mathrm{dp}=1,4)$ e com mediana 2,9 anos.

Com relação ao envolvimento com o GC, quase a totalidade da amostra $(92,6 \%)$ envolve-se nas atividades e responsabilidades do GC de forma contínua, somente 2 enfermeiros, de USF da região leste e norte relataram que a organização e gerência do GC da unidade era uma atividade compartilhada com os outros enfermeiros em esquema de rodízio da unidade. Estes 02 enfermeiros, quando indagados sobre o interesse em continuar envolvidos com o GC, um manifestou o desejo de suspender a participação e o outro enfermeiro revelou o desejo de participar da atividade de forma contínua. Do restante da amostra, 09 enfermeiros $(33,3 \%)$ desejavam compartilhar a participação no GC com outros enfermeiros da unidade em sistema de rodízio.

Sobre as atividades executadas pelos enfermeiros nos GC, a Tabela 07 mostra que 55,6\% dos enfermeiros caminhavam com o grupo pelo menos uma vez por mês. Destes, a maior parte era composta por enfermeiros que caminhavam com o GC 01 vez por mês $(53,3 \%)$ sendo que houve ainda enfermeiros que caminhavam 2 vezes por mês $(6,7 \%)$ e enfermeiros que caminhavam com o grupo 1 vez por semana $(40,0 \%)$.

Em 55,6\% dos GC os enfermeiros afirmaram efetuar avaliação clínica para inclusão dos usuários junto ao GC da unidade e, em 40,7\% dos GC a caminhada era precedida por avaliação clínica, predominantemente pela aferição da pressão arterial, antes do início da caminhada. Em relação à consulta de enfermagem relacionada ao acompanhamento dos participantes do GC, esta ocorria em 10 unidades $(37,3 \%)$.

A maior parte dos enfermeiros $(74,1 \%)$ relatou elaborar escala de distribuição dos responsáveis por caminhar junto com os participantes do grupo e destes, 07 $(25,9 \%)$ relataram atuar de modo discreto oferecendo apenas respaldo administrativo ao funcionário mais envolvido com o GC. 
Tabela 07 - Número e porcentagem de enfermeiros, segundo características de atividades executadas no grupo de caminhada. São Paulo, 2009.

\begin{tabular}{ccc}
\hline VARIÁ VEIS & N & $(\%)$ \\
\hline Caminhar com o Grupo & & \\
Nunca & 12 & 44,4 \\
01 vez por mês & 08 & 29,7 \\
02 ou mais vezes por mês & 07 & 25,9 \\
\hline Avaliação clínica dos participantes do GC & & \\
Inclusão no Grupo & 15 & 55,6 \\
Acompanhamento / Retorno & 11 & 40,7 \\
\hline Outras formas de participação no GC & 10 & 37,0 \\
\hline Atividades Administrativas: Escalas, dias, horários & 20 & \\
Participação discreta: respaldo clínico e administrativo & 07 & 25,9 \\
Não participa de forma ativa no GC & 02 & 7,4 \\
\hline
\end{tabular}

\subsection{Nível de conhecimento dos enfermeiros sobre Atividade Física} para Promoção da Saúde

$\mathrm{O}$ NC-AF/PS dos enfermeiros, composto pelo conhecimento destes às variáveis interdependentes que determinam os valores mínimos referentes à freqüência e a duração de AF/PS bem como a intensidade desta atividade e modo como esta deve ser executada, foi avaliado por meio do QNC-AF/PS, composto por quatro questões, uma para cada variável, conforme foi descrito na metodologia. (Anexo 03)

Nenhum dos entrevistados apresentou Conhecimento Pleno sobre os conceitos relacionados à AF/PS, de acordo com o padrão de classificação proposto neste estudo, adotado pela OMS (2005) e pelo MS (2008). 
Foram classificados como tendo Conhecimento Inadequado $06(22,2 \%)$ enfermeiros entrevistados, ou seja, não responderam adequadamente a nenhuma das questões do QNC-AF/PS. Desta forma, a maior parte da amostra foi classificada como Conhecimento Parcial (77,8\%) do QNC-AF/PS (tabela 08).

Tabela 08 - Classificação do Nível de Conhecimento dos Enfermeiros sobre Atividade Física para Promoção da Saúde, de acordo com a quantidade de acertos do Questionário sobre o Nível de Conhecimento de Atividade Física para Promoção da Saúde. São Paulo, 2009.

\begin{tabular}{cccc}
\hline CLASSIFICAÇÃO & QUANTIDADE DE ACERTOS & $\mathbf{N}$ & $(\boldsymbol{\%})$ \\
\hline $\begin{array}{c}\text { CONHECIMENTO } \\
\text { INADEQUADO }\end{array}$ & Nenhuma das 05 questões & 06 & 22,2 \\
\hline & Somente 01 questão & 11 & 40,7 \\
CONHECIMENTO & 02 questões & 06 & 22,2 \\
PARCIAL & 03 questões & 03 & 11,1 \\
& 04 questões & 01 & 3,7 \\
\hline CONHECIMENTO & Todas as 05 questões & 00 & -- \\
PLENO & & & \\
\hline
\end{tabular}

$\mathrm{Na}$ análise independente da quantidade de acertos para cada questão do QNC$\mathrm{AF} / \mathrm{PF}$ (tabela 09), em nenhuma destas houve índice percentual de acertos igual ou superior a 50\%. A variável que apresentou índice de acerto mais próximo deste valor foi a que determina o tempo mínimo necessário para a prática da AF diária promover saúde $(48,1 \%)$, seguida da variável que determina a intensidade que a $\mathrm{AF}$ deve ser executada $(44,4 \%)$. Na variável que determina o modo como a AF pode ser executada, $06(22,2 \%)$ responderam de forma correta, ou seja, que não importa o modo como a AF seja executada (contínua ou acumulada). Contudo, apenas 01 $(16,6 \%)$ destes 06 enfermeiros apontou o valor de tempo correto para a prática da AFT fracionada. (3a). 
Tabela 09 - Número e porcentagem de acertos, segundo cada tipo de questão sobre o Nível de Conhecimento sobre Atividade Física para Promoção da Saúde. São Paulo, 2009.

\begin{tabular}{ccc}
\hline & \multicolumn{3}{c}{ Repostas Corretas } \\
\cline { 2 - 3 } Tipo de questão & $\mathrm{N}$ & $(\%)$ \\
\hline Tempo & 13 & 48,1 \\
Intensidade & 12 & 44,4 \\
Modo & 06 & 22,2 \\
Dias & 04 & 14,8 \\
\hline
\end{tabular}

Analisando as respostas de todos os enfermeiros para cada questão, é possível perceber que não houve uma grande variação no padrão das escolhas para as alternativas do QNC-AF/PS.

Na questão que avalia o NC dos enfermeiros sobre a quantidade mínima de dias por semana que a atividade deve ser executada (tabela 10), a maioria absoluta das respostas $(66,7 \%)$ apontaram para um mínimo de 03 dias por semana e, de todas as respostas, apenas $01(3,7 \%)$ afirmou não saber a quantidade mínima de dias que a pessoa deve executar a AF por semana. 
Tabela 10 - Distribuição das respostas referentes à quantidade mínima de dias por semana para a atividade física promover saúde. São Paulo, 2009.

\begin{tabular}{ccc}
\hline DIAS POR SEMANA & $\mathbf{N}$ & $(\boldsymbol{\%})$ \\
\hline 1 & -- & \\
2 & -- & \\
3 & 18 & 66,7 \\
4 & 01 & 3,7 \\
5 & 04 & 14,8 \\
6 & -- & -- \\
7 & 03 & 3,7 \\
Não Sei & 01 & \\
\hline Total & & $\mathbf{2 7}$ \\
\hline
\end{tabular}

$\mathrm{Na}$ questão que avalia o NC dos enfermeiros sobre a quantidade mínima de tempo por dia que a atividade deve ser executada (tabela 11), a maior parte dos entrevistados $(48,1 \%)$ apontaram a alternativa correta -30 minutos.

Tabela 11 - Distribuição das respostas referentes à quantidade mínima de tempo por dia para a atividade física promover saúde. São Paulo, 2009.

\begin{tabular}{ccc}
\hline TEMPO POR DIA & $\mathbf{N}$ & $(\boldsymbol{\%})$ \\
\hline 20 & 01 & 3,7 \\
30 & 13 & 48,1 \\
35 & 01 & 3,7 \\
40 & 04 & 14,8 \\
45 & 02 & 7,4 \\
60 & 06 & 22,3 \\
\hline
\end{tabular}


$\mathrm{Na}$ questão que avalia o NC dos enfermeiros sobre o modo que a atividade deve ser executada (tabela 12), a maioria absoluta (63\%) indicou que esta deve ser executada de modo contínuo.

Tabela 12 - Distribuição das respostas referentes ao nível de conhecimento sobre o modo que a atividade física promover saúde. São Paulo, 2009.

\begin{tabular}{ccc}
\hline MODO DE EXECUÇÃO & N & (\%) \\
\hline Contínuo - Única sessão & 17 & 63,0 \\
Acumulado - 2 ou 3 sessões & 04 & 14,8 \\
Não importa o modo & 06 & 22,2 \\
Não sei & -- & -- \\
\hline Total & & $\mathbf{2 7}$ \\
\hline
\end{tabular}

$\mathrm{Na}$ questão que avalia o $\mathrm{NC}$ dos enfermeiros sobre a intensidade que a atividade deve ser executada (tabela 13), somente 02 alternativas foram indicadas, 15 $(55,6 \%)$ foram os enfermeiros que referiram que a $\mathrm{AF}$ deve ser executada de modo vigoroso e $12(44,4 \%)$ indicaram que a $\mathrm{AF}$ deve ser executada de acordo com o padrão adotado neste estudo, ou seja, de intensidade moderada.

Tabela 13 - Distribuição das respostas referentes ao nível de conhecimento sobre a intensidade que a atividade física promover saúde. São Paulo, 2009.

\begin{tabular}{ccc}
\hline INTENSIDADE DE EXECUÇÃO & N & $(\boldsymbol{\%})$ \\
\hline Leve & -- & -- \\
Moderada & 12 & 44,4 \\
Vigorosa & 15 & 55,6 \\
Não Sei & -- & -- \\
\hline Total & & $\mathbf{2 7}$ \\
\hline
\end{tabular}


Para verificar a correlação entre os acertos das variáveis que mensuram o NCAF/PS com o tipo de unidade, com os tempos de formado, de experiência em ESF, de trabalho na própria unidade e de participação no grupo, foi aplicado, inicialmente, o teste Kolmogorov-Smirnov foi utilizado para verificar a normalidade dessas variáveis o qual demonstrou que houve distribuição normal para todas estas variáveis.

A partir destes resultados, foram aplicados os testes T, Qui-quadrado e Fisher para verificação das correlações e, nenhum dos testes aplicados demonstraram diferenças estatísticas para as correlações efetuadas. A única exceção ocorreu na correlação feita entre as variáveis Tempo de Experiência em ESF e Dias mínimos de prática de AF/PS $(\mathrm{p}=0,41)$, a qual demonstrou que as 4 respostas corretas nesta variável ocorreu no grupo com maior tempo de experiência. 


\section{DISCUSSÃO}

Este estudo investigou como os GC estão distribuídos e estruturados na ESF da cidade de São Paulo, assim como, em que condições ocorrem à inserção dos enfermeiros nestes grupos por meio da análise de sua prática profissional e do nível de conhecimento sobre atividade física para promoção da saúde.

Para estruturação dos GC nas ESF, devem ser consideradas as condições inerentes a esta atividade associada às práticas do profissional responsável, através de suas competências clínicas, administrativas, gerenciais, éticas e legais.

Tais aspectos são relevantes quando analisados no contexto da ESF, que tem maior contato com o cotidiano da população e também pela perspectiva da PS. Em virtude disto, neste estudo, fez-se um recorte que privilegia o modelo de atenção por possibilitar a avaliação das ações oferecidas pelas unidades além de propiciar informações relevantes para criação de instrumentos norteadores da prática profissional em estudos e trabalhos futuros.

Diversos estudos demonstram o aumento do interesse pelas PICS por parte dos profissionais e da população como um todo ${ }^{70,86,86,87}$. De Simoni ${ }^{88}$ observa que práticas como caminhada, lian gong, yoga, tai chi chuan, toque terapêutico, reiki entre outras vêm tendo boa aceitação e repercussão entre os profissionais e principalmente por parte dos usuários.

Desde 2001, há registros de que estabelecimentos da RBS no Brasil e de São Paulo oferecem PICS aos seus usuários como forma diferenciada de produzir saúde, compor relações sociais e consequentemente melhorar a qualidade de vida da população ${ }^{20,64,66}$. O incremento de diferentes abordagens nos serviços de saúde configura-se uma prioridade do MS, tornando acessíveis opções preventivas e terapêuticas aos usuários do $\mathrm{SUS}^{65}$. No Brasil, o número de municípios que oferecem algum tipo de PICS saltou de 230 em 2004 para 1.340 em 2008. Em 2007, foram realizadas 27.646 práticas, enquanto que em 2008, o SUS contabilizou 126.652 - crescimento de $358 \%{ }^{89}$. 
No município de São Paulo, aproximadamente 52,3\% dos estabelecimentos da RBS municipais, desenvolve alguma PICS. As PO correspondem à maioria dessas PICS $(57,6 \%)$, seguida pela caminhada $(20,2 \%)^{73,83,90}$.

Quando se considera os aspectos relacionados à escolha das PC/AF implantadas nos estabelecimentos da RS, um estudo realizado com gerentes das unidades de saúde do distrito do Butantã - SP demonstrou alguns motivos que podem influenciar na definição desta escolha ${ }^{72}$ :

1. Identificação do profissional com a atividade executada: motivo mais recorrente, segundo os relatos das gerentes das unidades: "O Tai Chi deve ter a ver com essa formação da "E”, as coisas que ela foi buscando e conhecendo e acabou trazendo...", "Eu acho que o Tai Chi Pai Lin, ele foi escolhido por causa da "Em.", que era instrutora que mais gostava...". (pg 05)

2. A praticidade da atividade: "A caminhada, acho que é um pouco tradicional na visão, um pouco mais médica, a coisa da AF regular e a caminhada é tida como uma AF mais fácil de ser feita”. (pg 05)

3. As possibilidades de adequação das ações desta prática aos grupos de maior morbidade: “... além do idoso, a gente fez uma programação das necessidades de saúde pública, enfim, estar pensando na morbidade da unidade para pensar quais são os grupos prioritários, então aí ela começa a fazer um trabalho corporal com hipertensos e diabéticos, que seria a nossa maior morbidade, e também o trabalho corporal com gestantes, que é uma das nossas prioridades na unidade pública”. (pg 05)

4. Direcionamentos da SMS: “... o certo seria fazer um diagnóstico da região, de ver de onde estas pessoas vêm, eu não tenho isso ainda, e fazemos práticas chinesas, porque foi uma disponibilidade que a secretaria ofereceu $o$ curso, se a coordenadoria tivesse oferecido capoeira, estaríamos fazendo capoeira, se tivessem dado samba, estaríamos fazendo samba, entendeu? Porque tem a ver um pouco com o que a secretaria de saúde elege como a prática do momento”. (pg 06) 
Em São Paulo, a organização de Encontros Científicos ${ }^{66,90,91}$, além dos Cursos de Capacitação oferecidos à funcionários e multiplicadores sociais ${ }^{72}$, indicam a influência da SMS em prol da incorporação e ampliação das PO como modalidade terapêutica principal de PICS na RBS do município.

Os organizadores do Programa "Caminhando para Saúde” das Secretarias de Saúde e de Lazer de Santo Andrée ${ }^{92}$, afirmam que “... o interesse pela caminhada é que ela pode se tornar autônoma com grande facilidade, ou seja, a pessoa ganha essa condição, ganha autonomia, adquire prazer em caminhar, mesmo fora do programa, ela pode continuar a fazer" $(\mathrm{pg}, 56)^{92}$.

É importante ressaltar que a escolha de qualquer PICS tanto por parte dos profissionais dos serviços quanto por parte das estruturas diretivas de saúde, devem ocorrer considerando que as condições de vida das pessoas se dão fora das esferas da atenção em saúde, e que pauta-se no dinamismo das suas relações sociais, familiares e profissionais ${ }^{3,8,10}$. Neste sentido, a caminhada é uma atividade que proporciona autonomia aos usuários por já estar inserida na vida das pessoas. A caminhada também proporciona autonomia profissional, caracterizada pelas possibilidades de incorporação desta atividade às práticas profissionais de todos os enfermeiros.

Associando-se a estas considerações, Villas Boas, Araújo \& Timóteo ${ }^{93}$ ressaltam que o trabalho do enfermeiro se dá numa inter-relação e interdependência com outros saberes e os outros profissionais na (da) saúde. Essa prática profissional, se expressa na competência humana para "o cuidar", em suas múltiplas dimensões teórico-científica, estruturada pelo conjunto de saberes adquiridos, constituídos e construídos de forma inter e trans disciplinares.

Sendo a prática profissional, também constituída através do conjunto de procedimentos $^{94}$, torna-se urgente a necessidade de redimensioná-la para atender aos novos arranjos e desenhos, nos diferentes processos de trabalhos atualmente disponíveis e incentivados no SUS. 
Desta forma, em virtude da complexidade e das possibilidades de como os GC inseridos na prática profissional do enfermeiro podem ser avaliados, foram utilizados três instrumentos, com diferentes abordagens, para que a aproximação ao objeto de estudo fosse realizada sob a perspectiva da PS.

Os instrumentos utilizados neste estudo procuraram captar os dados objetivos relativos à inserção e estruturação dos GC, gerenciados por enfermeiros, nas Unidades de Saúde com ESF. Estes instrumentos, associados com o QNC-AF/PS, buscaram iluminar as condições a respeito de como esta atividade se insere nas ações clínicas e administrativas destes profissionais.

Como demonstraram os resultados deste estudo, corroborados por outros estudos $^{72,92,95,96,97,98}$ a maior parte dos GC na ESF contam com a participação de enfermeiros e de ACS.

Desta forma, diante destes novos paradigmas, torna-se necessário e imprescindível repensar os processos de trabalho ${ }^{93}$ do enfermeiro, bem como associar metodologias, instrumentos e conhecimentos diferentes aos atualmente instituídos.

Considerando especificamente os GC, estudos têm demonstrado que a inclusão das PC/AF como PICS contribuem para a ampliação da coresponsabilidade dos indivíduos pela saúde e para o aumento do exercício da cidadania $^{65,87,88,92,97}$. Contudo, diante desta realidade, quase a totalidade dos trabalhos publicados encontrados na literatura nacional e internacional abordam as $\mathrm{PC} / \mathrm{AF}$, em especial a caminhada, considerando, "apenas" os benefícios desta atividade nos praticantes ${ }^{82,99,100,101}$ ou a considerando sobre a forma de teste para avaliação de pacientes com agravos cardiorespiratórios, por meio do teste de caminhada de 06 minutos* ${ }^{102,103,104,105,106 .}$

\footnotetext{
* Adaptado do teste de corrida de 12 minutos (Teste de Cooper) teste de caminhada de seis minutos (TC6M) desenvolvido inicialmente para avaliar a capacidade física de adultos com patologias cardíacas e pulmonares atualmente vem sendo muito utilizado como uma alternativa para avaliar o condicionamento cardiorrespiratório de indivíduos saudáveis de qualquer idade. Enright PL. The Six-Minute Walk Test. Respiratory Care. August 2003vol 48no 8. Disponível em: http://www.rcjournal.com/contents/08.03/08.03.0783.pdf).
} 
Poucos são os trabalhos que abordam a caminhada sob a óptica do profissional, considerando os aspectos de organização e manutenção destas atividades na unidade de saúde. Também, poucos são os trabalhos que mostram as percepções dos profissionais acerca da incorporação desta atividade em sua prática profissional.

Nuñez \& Ciosak $^{95}$ demonstra que, as dificuldades relatadas pelos enfermeiros da RBS de Santo Amaro - SP para exercer as PICS, foram principalmente relacionadas à falta de cursos de capacitação, tabus e preconceitos da equipe profissional e dos usuários de sua unidade assim como a limitação dos recursos físicos e humanos necessários para estruturação e manutenção destas atividades.

Com relação às condições de operacionalização dos GC nas unidades, cabe ressaltar que, por não haver, na literatura nacional ou internacional, recomendações ou diretrizes referentes a este processo, desta forma, os dados referentes à estruturação de GC encontrados em outros trabalhos serão relacionados com os dados deste estudo sem, contudo, afirmar que este ou aquele está certo ou errado, ou que este é melhor ou pior do que aquele.

Incluso no Plano Municipal de Saúde de Santo André, o Programa "Caminhando para a Saúde" conta com GC regulares em 22 estabelecimentos da RBS, organizados prioritariamente por educadores físicos e que ocorrem, em média, $2,5(\mathrm{dp}=0,5)$ dias por semana ${ }^{98}$. No município de São Paulo, com a implantação do Núcleo de Apoio à Saúde da Família (NASF), observa-se uma expressiva participação desse profissional nos GC $(51,9 \%)$, mas ainda com grande predomínio dos ACS, principalmente por se tratar de Unidades com ESF. Já a periodicidade do GC encontrada no presente estudo foi em média de 3 dias por semana. Considerando o padrão de prescrição de AFT em adultos aceito pela $\mathrm{OMS}^{39}$ o qual determina que esta seja executada por no mínimo 05 dias por semana, as médias e as medianas referentes aos dias de atividades de ambos os GC encontram-se diferentes da recomendação. Em São Paulo, 06 GC (22,2\%) encontravam-se estruturados com atividades de acordo com o previsto no protocolo de prescrição. 
Na 5 $5^{\text {a }}$ Região do Estado do Paraná, 08 das 09 atividades de PC/AF eram realizadas por meio da organização de GC e, destas 04 (50\%) apresentavam enfermeiros como responsáveis e que acompanhavam o grupo na caminhada, ao menos, 01 vez por mês. Em três grupos o tempo de caminhada era de trinta minutos e no outro de vinte minutos, com média de 27,5 minutos ${ }^{96}$. Dados semelhantes foram encontrados no presente estudo, na qual 40,0\% das ESF com GC contavam com a participação de enfermeiros que, em sua maioria caminhavam com o grupo de 1 a 4 vezes por mês $(55,6 \%)$. Com relação ao tempo da caminhada, estes se apresentaram de forma mais heterogênea, variando de 15 a 75 minutos de atividade entre as unidades, com média de 48 minutos.

Em ambos os casos, a maior parte dos grupos apresentam tempo de caminhada equivalente ao mínimo proposto na recomendação de prescrição de AFT aceita pela $\mathrm{OMS}^{39}$ que é de 30 minutos por dia. Contudo, mesmo considerando os casos dos grupos que não disponibilizaram esta ação com tempo igual ao valor mínimo diário, os relatos de ambos os estudos demonstram que esta atividade raramente ocorre de forma isolada, tendo, associado a esta, outras atividades de PC. A isso, soma-se o fato de que em ambos os estudos não foram considerados o tempo médio gasto pelo indivíduo da sua casa até a unidade.

O tempo médio de existência dos GC em São Paulo foi de quatro anos, o que vem de encontro com Programas de incentivo à atividade física, como o Agita Sampa e com a instituição do Programa Qualidade de Vida com Medicinas Tradicionais e Práticas Integrativas em Saúde - PQVMTPIS, quando o município oficializou além das ações previstas nesta política, as ações de PC/AF na RBS previstas na PNPS $^{59,64,65,66}$.

Com relação ao nível de conhecimento dos usuários, Knuth et al ${ }^{107}$ demonstrou, que entre os moradores de Pelotas - RS, o percentual de conhecimento sobre os efeitos da AF na prevenção e tratamento da HAS foi de $82 \%$ e para DM foi de 47,2\%. Matsudo \& Matsudo ${ }^{108}$, ao analisar o nível de atividade física (NAF) da população do Estado de São Paulo demonstrou que o percentual dos indivíduos fisicamente ativos era consideravelmente maior $(54,2 \%)$ dentre aqueles que 
conheciam o $\mathrm{PASP}^{38}$ quando comparados com aqueles não conheciam o Programa $(31,9 \%)$.

Warschauer \& D’Urso ${ }^{98}$ apresentam o descontentamento da equipe profissional de uma UBS tradicional do distrito do Ipiranga - SP frente à baixa adesão dos usuários da unidade nas atividades do GC. Nestes casos, é preciso rever a estratégia de implementação dessas práticas que devem contemplar todos os aspectos da PS. Reis, Fortuna, Oliveira et $\mathrm{al}^{97}$, demonstram em seu estudo, através de observação participante das atividades do GC executadas em uma USF do interior de São Paulo, que o GC ocorre diariamente e que este "tem vida própria" e "é de posse dos usuários da unidade" que cobram empenho e participação tanto por parte dos usuários quanto dos funcionários. Este autor ressalta ainda que, durante a caminhada, acontecem discussões sobre questões relativas à unidade, as condições da comunidade e aos aspectos relativos à política local, o que, certamente, contribui para a alta adesão desses usuários ao GC.

Considerando o conhecimento sobre AF/PS em profissionais de saúde, este pode ser demonstrado de forma direta, por meio de questionários e entrevistas e de forma indireta por meio da análise de suas ações. Monteiro \& Faro ${ }^{109}$ indicam que $52,2 \%$ dos alunos de enfermagem da USP acreditam que a AF deve ser recomendada apenas para quem apresente alterações de saúde e apenas $8 \%$ acreditam na prevenção de doenças ou PS através da prática regular de AF. Nas Unidades Básicas de Saúde dos estados do Sul e Nordeste o aconselhamento para AF foi inferior a 30\% nos adultos e cerca de $38 \%$ nos idosos sendo que, a maior destas orientações deu-se entre os profissionais de saúde mais ativos fisicamente ${ }^{110,111}$. O índice de sedentarismo entre graduandos de nutrição (68\%), enfermagem $(70 \%)$ e medicina $(79 \%)^{112}$ da Universidade de Brasília é extremamente elevado.

Retomando os valores da recomendação para prescrição / execução da AFT, todos os estudos encontrados na literatura nacional e internacional apontam para um NC-AF/PS parcial ou inadequado dos profissionais de saúde frente aos valores desta recomendação ${ }^{44,113,114}$. Ao considerarmos outros estudos sobre o NC-AF/PS realizados sem padrão de análise claramente definidos também encontramos os mesmos achados ${ }^{109}$. 
Quando se consideram os trabalhos analisados por meio do QNC-AF/PS e que tiveram como valores de referência aqueles recomendados para AFT moderada como fonte para análise das respostas, três estudos foram encontrados na literatura nacional, todos avaliando o NC-AF/PS de profissionais de saúde $44,113,114$ e um internacional $^{115}$, que verificou o NC-AF/PS da população de Santa Fé de Bogotá da Colômbia. Não foi encontrado nenhum estudo que avaliação especificamente o NCAF/PS de enfermeiros. Desta forma, o nível de acertos das questões relativas ao QNC-AF/PS destes trabalhos serão comparados com os resultados do presente estudo.

Com relação à questão sobre frequência mínima semanal da AFT, apenas $13,5 \%$ da amostra (n: 653) do estudo efetuado por Ribeiro, Andrade, Oliveira et al ${ }^{113}$ com alunos de educação física de 04 entidades de ensino superior de São Paulo responderam 05 dias. Andrade ${ }^{44}$, em seu estudo com 110 profissionais de saúde de São Caetano do Sul, e Seixas, Matsudo, Matsudo et al $^{114}$, após entrevistar 516 ortopedistas brasileiros demonstraram índices de acertos de 7,7\% e 18,9\%, respectivamente. $\mathrm{O}$ índice acertos dos enfermeiros deste estudo foi de 14,8\%. Em todos estes estudos, o nível de acertos nesta questão não ultrapassou 20\%. O maior índice de acerto foi da amostra com ortopedistas, seguido pelos enfermeiros. Entretanto, Gámez, Venegas, Barón ${ }^{115}$ em seu estudo com a população (1360 moradores) de Santa Fé de Bogotá, na Colômbia, demonstrou que 57\% dos entrevistados acertaram a quantidade mínima de dias por semana recomendada para a prática da AFT, sugerindo que processos de comunicação social podem tem um impacto positivo sobre o conhecimento da população em geral, recomendando-se essa ação como complementar as práticas dos serviços de saúde.

$\mathrm{Na}$ questão relacionada ao tempo mínimo diário da AFT, 96,3\% dos estudantes de educação física responderam que este deveria ser de 30 minutos $^{113}$. Os índices de acerto desta variável foram de $42,3 \%$ entre os profissionais de saúde de São Caetano do $\mathrm{Sul}^{44}$ e de $42,7 \%$ entre os médicos ortopedistas ${ }^{114}$. Para a amostra dos enfermeiros deste estudo, o índice de acertos, $48,1 \%$. No caso da população de Santa Fé de Bogotá ${ }^{115}$, apenas $30 \%$ dos entrevistados consideram que se deve realizar AFT durante 30 minutos. 
$\mathrm{Na}$ análise independente da variável intensidade da AFT, 55,6\% dos estudantes de educação física indicaram que o grau de esforço proposto na recomendação para AFT em adultos é moderado ${ }^{113}$. No caso dos profissionais de saúde de São Caetano do $\mathrm{Sul}^{44}$ e dos médicos ortopedistas ${ }^{114}$, os índices de acerto para esta variável foram de 45,8\% e 44,1\%, respectivamente. Entre os enfermeiros dos GC de São Paulo, 44,4\% acreditam que a intensidade moderada é a recomendada. Entre os moradores de Santa Fé de Bogotá ${ }^{115}, 71 \%$ afirmaram que a intensidade da AFT deve ser moderada.

O nível de conhecimento sobre o modo de prática da AFT, 22,8\% entre os estudantes de educação física afirmaram que não importava o modo de prática da AFT, podendo esta ser executada de modo contínuo ou acumulada ${ }^{113}$. Já entre os profissionais de São Caetano do Sul, 39,6\% destes apontaram para o modo determinado na recomendação de $\mathrm{AFT}^{44}$. Não houve avaliação destas variáveis entre os ortopedistas brasileiros. O índice de acertos entre os enfermeiros dos GC de São Paulo foi de $22,2 \%$. Entre os moradores de Santa Fé de Bogotá ${ }^{115}$, ninguém indicou que não importa o modo como a $\mathrm{AF}$ pode ser realizada, $63 \%$ da amostra indicou que este deveria ser praticada de modo contínuo e os outros $37 \%$ indicou que deveria ser de modo acumulado.

Os estudos acima demonstram que os piores índices de acertos estão nas questões relativas à frequência mínima semanal e ao modo de prática. Em todas as questões, exceto a que trata sobre a frequência mínima semanal, o índice de acertos dos estudantes de educação física foi superior. Isso se deve, principalmente, ao campo de conhecimento específico desse profissional. Porém, de um modo geral, o conhecimento de todos os profissionais de saúde avaliados é extremamente baixo em relação à recomendação de AFT que foi proposta em 1994 e vem sendo divulgada no Estado de São Paulo desde 1996 pelo $\mathrm{PASP}^{38}$, no Brasil desde 2001 pelo PAB $^{51}$ e no mundo desde 2002 pelo $\mathrm{PAM}^{48}$. O nível de conhecimento dos enfermeiros se manteve na média dos outros profissionais, apresentando o segundo melhor nível de acertos na maioria das questões. 
Nenhum enfermeiro acertou todas as questões, a maioria (40,7\%) só acertou uma questão e 22,2\% não acertou nenhuma. A única variável que se associou, de forma significativa estatisticamente, foi o tempo de experiência em ESF com os dias mínimos para a prática de AF/PS.

Outros estudos, com profissionais de saúde, apontados por Andrade ${ }^{44}$, assim como efetuados pela SOBEEsp* também encontraram resultados semelhantes. Estes resultados configuram-se ainda mais preocupantes, quando se comparam estes com as ações destes profissionais (índices de sedentarismo), e com o nível de conhecimento da população a cerca do mesmo tema.

Apesar do baixo NC-AF/PS dos enfermeiros encontrado neste estudo, a participação desses profissionais nos GC são bastante significativas, já que 92,6\% dos pacientes são encaminhados também por esses profissionais aos grupos, $40 \%$ caminhavam com o grupo ao menos uma vez por semana, sendo que $92,6 \%$ se envolvem de forma contínua e que 55,6\% realizam avaliação clínica para inclusão no grupo. Além de a maioria $(74,1 \%)$ referir ser responsável pela elaboração da escala dos profissionais que acompanham a caminhada.

Estes dados sobre a inserção dos enfermeiros nos grupos de caminhada e o nível de conhecimento sobre AF/PS, indicam a necessidade da construção de guias práticos e de processos de educação continuada para tentar minimizar estas dificuldades apresentadas.

Nuñez \& Ciosak", ao analisar o "Saber e o Fazer" de enfermeiros da RBS do distrito do Butantã - SP resume a definição destes sobre as Terapias Alternativas / Complementares: "tratamento ministrado ao paciente sem medicamentos tradicionais, que o profissional pode utilizar junto ou não à medicina propriamente dita, com terapias complementares; qualquer ação de intervenção natural ou comportamental nos hábitos, que verifiquem na alimentação, repouso, lazer, ou em todas as necessidades humanas básicas; e tem como objetivos a cura, a melhora da qualidade de vida ou minimizar o sofrimento dos pacientes." Porém, é necessário

*Os trabalhos intitulados - Análise do Nível de Conhecimento sobre Atividade Física para Promoção da Saúde dos Graduando de Enfermagem de uma instituição particular de Ensino. Novembro, 2007; e Nível de Conhecimento sobre Atividade Física para Promoção da Saúde: Análise da apreensão da informação de palestra. Novembro, 2007 - foram apresentados na modalidade Pôster na V Semana Científica de Enfermagem da Uni Sant`Anna, realizada no período entre 12 a 15 de Maio de 2008, na cidade de São Paulo, Brasil. 
que o enfermeiro saiba, não apenas, conceituar as Terapias Alternativas/Complementares como saiba também operacionalizá-las corretamente em sua prática.

A escolha e a estruturação de qualquer PICS na ESF, para uma unidade ou para toda a rede, não deve ocorrer de forma acrítica ou ancorada e direcionada pelos valores sociais do momento histórico em que estas se aplicam (atividade da moda) ou ainda, direcionada pelas crenças e percepções individuais dos sujeitos responsáveis pela materialização destas práticas. Da mesma forma, que não podem ocorrer apenas sob a óptica biológica individualizante e estruturada por meio de condicionantes de ordem clínica, fisiológica e biomecânica. Além do conhecimento específico sobre como devem ser prescritas e orientadas essas atividades, avaliadas no presente estudo, é necessário também considerar as PICS como um construto multidimensional, de natureza objetiva e subjetiva com propósito emancipador das ações e práticas profissionais, assim como, um processo de fortalecimento da autonomia dos sujeitos sociais envolvidos.

Desta forma, a estruturação de qualquer PICS deve ser contextualizada por meio das inter-relações entre a saúde e a organização social sob a vertente da determinação social dos indivíduos, moldados por suas condições de vida e trabalho e relativizado pelo contexto histórico e cultural no qual estes se inserem, sejam estes funcionários ou usuários da unidade $\mathrm{e}^{8,12,68,69,114,116}$.

Neste contexto, o enfermeiro precisa ser capaz de identificar as necessidades sociais de saúde da população sob a sua responsabilidade, além de intervir no processo saúde/doença dos indivíduos, família e coletividade ${ }^{116}$. 


\section{CONCLUSÃO}

Este estudo, desde seu início, teve o propósito de apresentar as condições da inserção dos enfermeiros, de equipes de saúde da família, nos grupos de caminhada da cidade. Por considerar que uma profissão também se faz por meio da interpretação de suas ações, achamos necessário "parar" para "fotografar" a ação dos enfermeiros, atuantes nesta transição paradigmática, na qual as PICS estão cada vez mais inseridas no contexto de atenção da saúde.

Isto justificou a escolha metodológica deste trabalho, vislumbrada desde o início, como um "funil", com objetivo de conduzir o pesquisador e o leitor nas características das condições de distribuição das unidades de saúde, das PICS, dos GC e, por fim, dos enfermeiros inseridos neste contexto, partindo da dimensão estrutural, passando pela dimensão particular e encerrando na dimensão singular deste processo.

A PS, entendida como estratégia de produção social de saúde, iluminou todos os passos desta pesquisa na busca pela aproximação da AFT às práticas profissionais do enfermeiro de ESF.

As atuais condições de distribuição DCNT no Brasil ${ }^{14,26,30,33,}$ assim como suas possibilidades de intervenção ${ }^{24,25,28,31}$ serviu de combustível e aguçou ainda mais este pesquisador no olhar sobre as perspectivas inerentes às PICS estruturadas por meio dos GC.

Desta forma, este estudo mostrou que nos aspectos relacionados à oferta de PICS estruturadas por meio do PQVMTPIS da SMS/SP, os dados apresentados nesta pesquisa nos permitem considerar que estas atividades apresentam boa inserção nas unidades de saúde da cidade, em especial nas USF e UM, principalmente considerando o fato de que até 2008, praticamente não haviam incentivos federais ou municipais para tais ações.

Considerando-se os estímulos do $\mathrm{MS}^{63}$ e da SMS/SP ${ }^{66,78}$, acreditamos que, em bem pouco tempo, tais abordagens tornarão disponíveis as PICS como opções 
terapêuticas a todos os usuários do SUS, em especial da cidade de São Paulo, contribuindo assim, para a ampliação da co-responsabilidade entre os profissionais e os sujeitos individuais e coletivos no processo saúde e doença $^{65,117}$.

Considerando a estruturação dos GC por meio de sua incorporação às atividades cotidianas das unidades de saúde, é preciso que se definam diretrizes para guiar a ação deste processo no âmbito da dimensão singular das práticas de trabalho.

A EG-OMS sobre "Alimentação Saudável, Atividade Física e Saúde”25, assim como a PNPS $^{3}$ e a PNPIC-SUS ${ }^{65}$, ambas do MS são bons exemplos de guias estruturais de ação na Dimensão Estrutural.

O Programa do município de São Paulo "Qualidade de Vida com Medicinas Tradicionais e Práticas Integrativas em Saúde" ${ }^{66}$ assim como os Programas Agita São Paulo ${ }^{38}$ - Estadual - e o Programa Agita Sampa ${ }^{78}$ Municipal, podem ser considerados como guias estruturais de ação na Dimensão Particular.

Contudo, na Dimensão Singular do processo de trabalho em saúde coletiva, ainda não há critérios definidos ou guias norteando as ações dos gerentes e dos profissionais, na maior parte dos casos enfermeiros e ACS, para a incorporação das PICS às atividades das unidades de saúde.

Isto é extremamente urgente e necessário, em virtude dos achados deste estudo, ampliados por dados ${ }^{72,90,92,96,98,114}$ que demonstram que a materialização das PICS nas unidades de saúde do país - escolha, implantação, manutenção e aprimoramento da atividade - caracteriza-se por processos acríticos, não científicos e em função das características e crenças pessoais do profissional que assume esta responsabilidade.

Entretanto, ainda na Dimensão Singular do processo de trabalho, a recomendação para prescrição / execução de atividade física terapêutica pode e deve, ser considerado como um guia existente para as ações dos enfermeiros voltadas para 
a detecção de sedentarismo assim como para a prescrição de qualquer da AFT. Principalmente se considerar o fato de que esta recomendação não precisa de adaptações para a sua incorporação nas fases do da SAE relativas ao histórico, prescrição e evolução de enfermagem.

Contudo, mesmo diante de todas as comprovações científicas demonstrando a eficácia no tratamento ou prevenção das DCNT por meio da associação da AFT 82,99,100,101 os baixos NC-AF/PS demonstrados pelos profissionais de saúde justificam a adoção de estratégias de educação continuada em saúde voltadas para reverter esta realidade.

Ferreira, Matsudo, Braggion et al ${ }^{118}$ demonstraram que através de um simples programa de orientação da prática de AFT de acordo com os padrões adotados pela OMS e pelo PASP, efetuado 5 minutos por dia uma vez por semana, por 12 semanas, aumentou a duração e a frequência da caminhada em idosas em 150\% e 97,6\%, respectivamente, considerando os valores pré-intervenção.

Desta forma, concluímos este trabalho apontando para três ações urgentes a serem desenvolvidas no âmbito da Dimensão Singular:

1. Necessidade da construção de instrumentos que guiem as ações dos profissionais na incorporação dos conceitos da AFT às suas práticas profissionais;

2. Desenvolvimento e Criação de novas estratégias de abordagem dos profissionais, voltadas para a incorporação e utilização dos conceitos da AFT em suas práticas profissionais;

3. Priorização na escolha da Caminhada como modalidade de Prática Complementar e Integrativa em Saúde. 


\section{REFERÊNCIAS BIBLIOGRÁFICAS:}

1. Czeresnia D. Conceito de saúde e a diferença entre prevenção e promoção. In: Czeresnia D, Freitas CM, organizadores. Promoção da Saúde: conceitos, reflexões e tendências. Rio de Janeiro: Ed. Fiocruz; 2003. p 39-53.

2. Buss, PM. Uma introdução ao conceito de Promoção da Saúde. In: Czeresnia D, Freitas CM, organizadores. Promoção da Saúde: conceitos, reflexões e tendências. Rio de Janeiro: Ed. Fiocruz; 2003. p 39-53.

3. Brasil. Ministério da Saúde. Secretaria de Vigilância em Saúde. Política nacional de promoção da saúde. Brasília; 2006.

4. Carvalho YM, Freitas FF. Atividade física, saúde e comunidade. Cadernos Saúde Coletiva 2006; 14 (3): 489-506.

5. Heidmann ITSB, Almeida MCA, Boebs AE, Wosny AM, Monticelli M. Promoção à Saúde: Trajetória histórica de suas concepções. Texto e Contexto Enfermagem 2006; 15(2): 352-8.

6. Brasil. Ministério da Saúde. As cartas de promoção à saúde. Brasília; 2002.

7. Campos GW, Barros RB, Castro MA. Avaliação da Política Nacional de Promoção da Saúde. Ciência \& Saúde Coletiva 2004; 9(3): 745-9.

8. Buss PM. Promoção da saúde e qualidade de vida. Ciência e Saúde Coletiva 2000; 5(1): 163-77.

9. Brasil. Ministério da Saúde. Secretaria de Atenção à Saúde. Departamento de Atenção Básica. Manual de estrutura física das unidades básicas de saúde: saúde da família. Brasília; 2006.

10. Silveira Filho AD. O SUS e a saúde da família. In: Brasil. Ministério da Saúde. Cadernos Metropolitanos: Saúde da Família: panorama, avaliação e desafios. Brasília: Ministério da saúde; 2004. v.2. p. 15-8.

11. Henrique F, Calvo MCM. Grau de implantação do Programa Saúde da Família e indicadores sociais. Ciência \& Saúde Coletiva 2009; 14 Supl 1: 1359-65.

12. Brasil. Conselho Nacional de Secretários de Saúde. A estratégia Saúde da Família em Atenção Primária e Promoção da Saúde. Brasília: CNASS; 2007. v.8. 
13. Brasil. Ministério da Saúde. Departamento de Atenção Básica. Coordenação de Acompanhamento e Avaliação. Avaliação na Atenção Básica em Saúde: caminhos da institucionalização. Brasília; 2005.

14. Ministério da Saúde. Departamento de Atenção Básica. Boletim Informativo de Atenção Básica e Saúde da Família [boletim na Internet]. 2004 [citado 2007 Set 10]. Disponível em: http://dtr2004.saude.gov.br/dab/numeros.

15. Brasil. Ministério da Saúde. Secretaria de Atenção à Saúde. Departamento de Atenção Básica. Avaliação normativa do Programa Saúde da Família no Brasil: monitoramento da implantação e funcionamento das equipes de saúde da família: 2001-2002. Brasília; 2004.

16. Viana ALD, Dal PMR. A reforma do sistema de saúde no Brasil e o Programa de Saúde da Família 2005; 15 Supl: 225-64.

17. Brasil. Ministério da Saúde. Secretaria de Atenção à Saúde. Departamento de Atenção Básica. Política Nacional de Atenção Básica. 4. ed. Brasília: Ministério da Saúde; 2007.

18. Brasil. Ministério da Saúde. As Cartas de Promoção à Saúde. Brasília: Ministério da Saúde; 2002.

19. Campos, FE; Aguiar, RAT; Oliveira VB: O desafio da expansão do Programa de Saúde da Família nas grandes capitais brasileira. Rev. Saúde Coletiva, Rio de Janeiro, 12(1): 47-58, 2002

20. Capistrano Filho D. O programa de saúde da família em São Paulo. Estudos Avançados 13 (35), 1999

21. São Paulo. Secretaria Municipal de Saúde, Coordenadoria do Programa de Saúde Da Família. Documento Norteador: Responsabilidades da Rede de Apoio à Implantação do PSF. São Paulo: Secretaria Municipal de Saúde, 2002.

22. São Paulo (Município). Portal de notícias da Prefeitura Municipal de São Paulo. Avanços na área da Saúde municipal antecipam as metas da Agenda 2012 [periódico na internet]. São Paulo; 2010. [citado 2010 mar 15]. Disponível em: http://www.prefeitura.sp.gov.br/portal/a_cidade/noticias/index.php?p=34484.

23. Barreto SM, Passos VM, Cardoso AR, Lima-Costa MF. Quantifying the risk of coronary artery disease in a community: the Bambuí project. Arq Bras Cardiol 2003; 81(6):556-61. 
24. Moretti AC, Almeida V, Whestphal MF, Bógus CM. Práticas Corporais/Atividade Física e Políticas Públicas de Promoção da Saúde. Saúde Soc 2009; 18(2): 346-54.

25. World Health Organization (WHO). Global strategy on diet, physical activity and health. Geneva: WHO; 2004. [Fifty-Seventh World Health Assembly, WHA57.17].

26. Brasil. Ministério da Saúde. Secretaria de Vigilância em Saúde. Departamento de Análise de Situação em Saúde. Saúde Brasil 2007: uma análise da situação de saúde no Brasil. Brasília: Ministério da Saúde; 2008.

27. World Health Organization (WHO). Diet, nutrition and the prevention chronic diseases. Geneva: WHO; 2003. [WHO Technical Report Series, 916].

28. World Health Organization (WHO). The world health report 2002. Reducing risks, promoting healthy life. Geneva: WHO; 2002.

29. Organização Pan-Americana de Saúde (OPAS). Prevenção de Doenças Crônicas não Transmissíveis: Um investimento Vital. Canadá: OMS; 2005.

30. Nedel FB, Rocha M, Pereira J. Anos de vida perdidos por mortalidade: um dos componentes da carga de doenças. Revista Saúde Pública 1999; 33 (5): 461-69.

31. Brasil. Ministério da Saúde. Diretrizes e recomendações no cuidado integral de doenças crônicas não-transmissíveis. Promoção da saúde, vigilância, prevenção e assistência. Brasília: Ministério da Saúde; 2008.

32. São Paulo (Município). Secretaria Municipal de Saúde. Coordenação de Vigilância em Saúde. Almanaque Doenças Crônicas Não-Transmissíveis. ${ }^{\mathrm{a}}$. ed. São Paulo: Secretaria Municipal de Saúde; 2005.

33. Ministério da Saúde. Secretaria de Vigilância em Saúde. Secretaria de Gestão Estratégica e Participativa. Vigitel Brasil 2006: vigilância de fatores de risco e proteção para doenças crônicas por inquérito telefônico: estimativas sobre frequiência e distribuição sócio-demográfica de fatores de risco e proteção para doenças crônicas nas capitais dos 26 estados brasileiros e no Distrito Federal em 2006. Brasília: Ministério da Saúde; 2007.

34. Palma A. Atividade física, processo saúde-doença e condições sócio-econômicas: uma revisão da literatura Rev Paul Educ Fís 2000; 14(1): 97-106.

35. Pitanga FJG. Epidemiologia, Atividade Física e Saúde: Artigo de Revisão. Rev Bras Ciên e Mov 2002; 10(3): 49-54. 
36. Oliveira MAC, Egry EY. A historicidade das teorias interpretativas do processo saúde-doença. Rev Esc Enf USP 2000: 34(1): 9-15.

37. Ferreira MS, Najar AL. Programas e campanhas de promoção da atividade física. Ciência e Saúde Coletiva 2005; 10 Supl.: 207-19.

38. São Paulo (Estado). Programa Agita São Paulo. São Paulo; 1998.

39. World Health Organization (WHO). Centers for Disease Control (CDC). Promoting physical activity: a best buy inpublichealth. Atlanta: Collaborating Center on Physical Activity and Health Promotion; 2000.

40. Amercian College Sciences Medicine (ACSM). The recommend quantity and quality of exercise for developing and maintaining cardiorespiratory and muscular fitness in healthy adults. Med Sci Sports Exerc 1990; 22: 265 -74.

41.Caspersen CJ. Physical activity epidemiology: Concepts, methods, and applications to exercise science In: Exercise and Sports Reviews. 1989. 423-473.

42. Centers for Disease Control CDC. Physical activity and the prevention of coronary heart disease. Morb Mortal Wkly Rep 1993; 42(35): 669-72.

43. Pate, RR et al. Physical activity and public health. A recommendation from the Centers for Disease Control and Prevention and the American College of Sports Medicine. Journal of American Medical Association 1995; 273 (5): 402-07.

44. Andrade D R. Atividade física e promoção da saúde: Conhecimento e prática dos profissionais de saúde do município de São Caetano do Sul. Universidade de São Paulo [dissertação]. São Paulo: Faculdade de Saúde Pública, Universidade de São Paulo; 2001.

45. Matsudo, SM, Matsudo VR et al. Nível de atividade física da população do Estado de São Paulo: análise de acordo com o gênero, idade, nível socioeconômico, distribuição geográfica e de conhecimento. Rev Bras Ciên e Mov 2002; 10(4): 41-50.

46. Rafa-Pana. Rede de Atividade Física das Américas [folder]. Disponível em: http://www.sportsalut.com.ar/rafa/art2\%20.pdf

47. Manifesto de São Paulo para a promoção da Atividade Física nas Américas. Sessão Especial Rev. Bras. de Ciência e Movimento v.8 n.1 p.63-66 
48. Centro de Estudos do Laboratório de Aptidão Física de São Caetano do Sul. CELAFISCS. Agita Mundo: Projeto de celebração do dia mundial da atividade física. São Caetano do Sul: CELAFISCS; 2009.

49. Brasil. Ministério da Saúde. Ministério do Esporte. Curso a distância em exercício físico e saúde: Programa de educação e saúde através do exercício físico e do esporte [folder]. Brasília; 2005. Disponível em: http://bvsms.saude.gov.br/bvs/folder/10006001568.PDF.

50. SESC. Dia do Desafio. Congresso Cultura Corporal [homepage na internet]. São Paulo; 2006. [citado 2009 out 02]. Disponível em: www.sescsp.org.br/sesc/images/upload/conferencias/362.rtf.

51. Brasil. Ministério da Saúde. Secretaria de Políticas Públicas. Projeto Promoção da Saúde. Programa nacional de atividade física "Agita Brasil": atividade física e sua contribuição para a qualidade de vida. Rev Saude Publica 2002; 36(2): 254-6.

52. Matsudo VKR, Matsudo SM, Araújo TL, Andrade D, Andrade E, Oliveira L, Braggion G. Agita São Paulo - Agita Brasil. In: Dacosta L, organizador. Atlas do Esporte no Brasil . Rio de Janeiro: CONFEF; 2006. p. 16.10-11.

53. Brasil. Ministério da Saúde. Secretaria de Vigilância em Saúde. Política nacional de promoção da saúde: Documento para discussão. Brasília: Ministério da Saúde; 2002 .

54. Brasil. Ministério da Saúde. Secretaria Executiva Diretrizes operacionais: Pactos pela Vida, em Defesa do SUS e de Gestão. Brasília: Ministério da Saúde; 2006.

55. Brasil. Ministério da Saúde. Relatório final da $8^{\text {a }}$ Conferência Nacional de Saúde. Brasília; 1986.

56. Brasil. Ministério da Saúde. O SUS de A a Z: garantindo saúde nos municípios. $3^{\text {a }}$. ed. Brasília: Ministério da Saúde; 2009.

57. Brasil. Ministério da Saúde. Cartilha: VAMOS PROMOVER NOSSA SAÚDE? Brasília: Ministério da Saúde; 2008.

58. Malta DC, Castro AM, Gosch CS, Cruz DKA, Bressan A, Nogueira JD et al. A Política Nacional de Promoção da Saúde e a agenda da atividade física no contexto do SUS. Epidemiol Serv Saúde 2009; 18(1): 79-86.

59. Brasil. Ministério da Saúde. Secretaria de Vigilância à Saúde. Diretrizes e recomendações para o cuidado integral de doenças crônicas não-transmissíveis: 
promoção da saúde, vigilância, prevenção e assistência. Brasília: Ministério da Saúde, 2008a

60. Brasil. Ministério da Saúde. Portaria $n^{0}$ 2981. Autoriza repasse financeiro do Fundo Nacional de Saúde aos Fundos Estaduais e Municipais de Saúde para incentivo à implementação e ao fortalecimento das ações específicas da Política Nacional de Promoção da Saúde, com ênfase na integração das ações de Vigilância, Promoção e Prevenção de Doenças e Agravos Não-Transmissíveis coma Estratégia de Saúde da Família no ano de 2008 [portaria na internet]. Brasília; 2008 [citado 2009 abr 07]. Disponível em: http://portal2.saude.gov.br/portal/arquivos/pdf/p2981.pdf.

61. Brasil. Ministério da Saúde. Secretaria de Vigilância em Saúde. Caderno de Destaques SVS - Gestão 2007/2008. Brasília; 2008.

62. Brasil. Ministério da Saúde. Conselho Nacional de Secretarias de Saúde. Proposta de financiamento das ações da Política Nacional de Promoção da Saúde. Brasília; 2009.

63. Brasil. Ministério da Saúde. Mais Saúde: Direito de todos 2008-2011. Brasília; 2007.

64. São Paulo (Município). Portal de notícias da Prefeitura Municipal de São Paulo. Prefeito participa de encontro sobre práticas alternativas de medicina. [periódico na internet]. São Paulo; 2007. [citado 2010 fev 05]. Disponível em: http://www.prefeitura.sp.gov.br/portal/a_cidade/noticias/index.php?p=18796

65. Brasil. Ministério da Saúde. Secretaria de Atenção à Saúde. Departamento de Atenção Básica. Política Nacional de Práticas Integrativas e Complementares no SUS - PNPIC-SUS. Brasília; 2006.

66. São Paulo (Município). Secretaria Municipal de Saúde, Coordenação da Atenção Básica. Áreas Técnicas - Medicinas Tradicionais [periódico na internet]. São Paulo; 2008. [citado 2010 jan 23]. Disponível em: http://www2.prefeitura.sp.gov.br/secretarias/saude/areas tematicas/0047

67. Organización Mundial de la Salud (OMS). Estrategia de la OMS sobre medicina tradicional 2002-2005. Genebra; 2002.

68. Luz MT. Cultura contemporânea e medicinas alternativas: novos paradigmas em saúde no fim do século XX. Rev. Saúde Coletiva 2005; 15 Supl.: 145-176. 
69. Tesser CD, Barros NF. Medicalização social e medicina alternativa e complementar: pluralização terapêutica do SUS. Rev Saúde Pública 2008; 42(5): 914-20.

70. Tesser CD. Práticas complementares, racionalidades médicas e promoção da saúde: contribuições poucos exploradas. Cad Saúde Pública 2009; 25(8):1732-42.

71. United States of America. U.S. Department of Health and Human Services. National Institutes of Health. National Center for Complementary and Alternative Medicine. What is Complementary and Alternative Medicine? Bethesda; 2007. Disponível em: http://nccam.nih.gov/health/whatiscam/\#1

72. Warschauer M, Carvalho YM, Martins CL, Freitas FF. As escolhas das práticas corporais e dos profissionais que as conduzem nas unidades básicas de saúde do distrito butantã-SP [relatório de pesquisa]. São Paulo: Universidade de São Paulo; [ s.d.]. Disponível em: http://www.cbce.org.br/cd/resumos/003.pdf.

73. São Paulo (Município). Secretaria Municipal da Saúde. Coordenação de Assistência Básica. Área Técnica da Medicina Tradicional e Práticas Integrativas em Saúde: Programa Qualidade de Vida com Medicinas Tradicionais e Práticas Integrativas em Saúde [Folder]. São Paulo; 2008. [citado 209 jan 17] Disponível em: http://www.cmacupuntura.org.br/downloads/relacao_programa_qualidade_vida.pdf

74. Caspersen C, Powell K, Christensen G. Physical activity, exercise, and physical fitness: definitions and distinction for health-related research. Public Health Rep 1985; 100 (2): 126-31.

75. Barbanti VJ. Dicionário de Educação Física e Esporte. São Paulo: Manole; 2002.

76. Haskell WL, Powell KE, Franklin BA, Health GW. Physical Activity and Public Health Updated Recommendation for Adults from the American College of Sports Medicine and the American Heart Circulation. Circulation 2007; 116(9): 1081-93.

77. Andrews JC. Educação para um estilo de vida ativo no século XXI. Revista Brasileira de Ciência e Movimento 1990; 4(4): 43-60.

78. São Paulo (Município). Portal de notícias da Prefeitura Municipal de São Paulo. Prefeito regulamenta programa Agita Sampa de atividades físicas [periódico na internet]. São Paulo; 2007. [citado 2010 fev 05]. Disponível em: http://www.prefeitura.sp.gov.br/portal/a_cidade/noticias/index.php?p=16949 
79. Mendes-Gonçalves RBM. Tecnologia e organização social das práticas de saúde: características tecnológicas de processo de trabalho na rede estadual de centros de saúde de São Paulo. São Paulo: Hucitec; 1994.

80. Nascimento MS, Nascimento MAA. Prática da enfermeira no Programa de Saúde da Família: a interface da vigilância da saúde versus as ações programáticas em saúde. Ciência e Saúde Coletiva 2005; 10(2): 333-45.

81. Almeida MCP, Rocha JSY. O saber da enfermagem e sua dimensão prática. São Paulo: Cortez; 1989.

82. Matsudo VKR, Araújo TL, Matsudo SMM. Andar: passaporte para a saúde. Diagn Tratamento 2006; 11(2): 119-23.

83. São Paulo (Município). Secretaria Municipal de Saúde. Coordenação de Epidemiologia e Informação. Relação das Unidades da Secretaria Municipal de Saúde por região do Município de São Paulo [banco de dados]. São Paulo; 2008.

84. São Paulo (Município). Secretaria Municipal de Saúde. Coordenação da Atenção Básica. Relação das Unidades de Saúde da Família e Unidades Mistas da Secretaria Municipal de Saúde por região do Município de São Paulo [banco de dados]. São Paulo; 2008.

85. Luz MT. Medicina e racionalidades médicas: estudo comparativo da medicina ocidental contemporânea, homeopática, chinesa e ayurvédica. In: Canesqui AM, organizadora. Ciências sociais e saúde para o ensino médico. São Paulo: Editora Hucitec; 2000. p. 181-200.

86. Barros NF. Da medicina biomédica à complementar: um estudo dos modelos da prática médica [Dissertação]. Campinas: Faculdade de Ciências Médicas, Universidade Estadual de Campinas; 2002.

87. Organización Mundial de la Salud. Estrategia de la OMS sobre medicina tradicional 2002-2005. Genebra: Organización Mundial de la Salud; 2002.

88. De Simoni CL. Ginástica terapêutica chinesa Lian Gong: estudo de caso da inserção no SUS [dissertação]. Salvador: Instituto de Saúde Coletiva da Universidade Federal da Bahia; 2005.

89. Brasil. Ministério da Saúde. Portal de notícias do Ministério da Saúde. Acesso à medicina não convencional cresce no SUS [periódico na internet]. Brasil; 2010 [citado 2010 mar 09]. Disponível em: 
http://portal.saude.gov.br/portal/aplicacoes/noticias/default.cfm?pg=dspDetalheNotic ia\&id_area $=124 \& C O \_N O T I C I A=11001$

90. São Paulo (Município). Portal de notícias da Prefeitura Municipal de São Paulo. Programa estimula acesso da população à medicina alternativa [periódico na internet]. São Paulo; 2008. [citado 2010 fev 13]. Disponível em: http://www.prefeitura.sp.gov.br/portal/a_cidade/noticias/index.php?p=24265

91. São Paulo (Município). Portal de notícias da Prefeitura Municipal de São Paulo. Prefeito participa de encontro sobre práticas alternativas de medicina [periódico na internet]. São Paulo; 2008. [citado 2010 fev 13]. Disponível em: http://www.prefeitura.sp.gov.br/portal/a_cidade/noticias/index.php?p=18796

92. Warschauer M. "Lazer e Saúde": as práticas corporais no sistema público de Santo André [Dissertação]. São Paulo: Escola de Educação Física e Esporte, Universidade de São Paulo; 2008

93. Villas Boas LMFM, Araújo MBS, Timóteo RPS. A prática gerencial do enfermeiro no PSF na perspectiva da sua ação pedagógica educativa: uma breve reflexão. Ciência \& Saúde Coletiva, 13(4):1355-1360, 2008

94. Merhy EE. O ato de governar as tensões constitutivas do agir em saúde como desafio permanente de algumas estratégias gerenciais. Cien Saude Colet 1999; 4(2):305-314.

95. Nuñez HMF, Ciosak SI. Terapias alternativas/complementares: o saber e o fazer das enfermeiras do distrito administrativo 71 - Santo Amaro - São Paulo Rev Esc Enferm USP 2003; 37 (3):11-8.

96. Coutinho SS. Atividade Física no Programa Saúde da Família, em municípios da

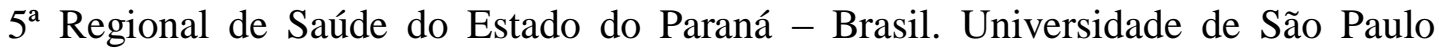
[dissertação]. Ribeirão Preto: Escola de Enfermagem da USP; 2005.

97. Reis MAS, Fortuna CM, Oliveira CT, Durante MC. A organização do processo de trabalho em uma unidade de saúde da família: desafios para a mudança das práticas. Interface - Comunic., Saúde, Educ., 2007. ISSN 1414-3283.

98.96. Warschauer M \& D'Urso L. Ambiência e formação de grupo em programas de caminhada. Saude e Soc. [online]. 2009, vol.18, suppl.2, pp. 104-107.

99. Frank LD, Andresen MA, Schmid TL. Obesity relationships with community design, physical activity, and time spent in cars. Am J Prev Med. 2004;27(2):87-96. 
100. Guimarães JMN, Caldas CP A influência da atividade física nos quadros depressivos de pessoas idosas: uma revisão sistemática. Rev Bras Epidemiol. 2006; 9(4): 481-92

101. Barroso WKS, Jardim PCBV, Vitorino PV, Bittencourt A, Miquetichuk F. Influência da atividade física programada na pressão arterial de idosos hipertensos Rev Assoc Med Bras 2008; 54(4): 328-33

102. Araujo, Clênia Oliveira et al. Diferentes padronizações do teste da caminhada de seis minutos como método para mensuração da capacidade de exercício de idosos com e sem cardiopatia clinicamente evidente. Arq. Bras. Cardiol. [online]. 2006, vol.86, n.3, pp. 198-205

103. Rubim VSM, Drumond CN, Romeo JLM, Montera MW. Valor prognóstico do teste de caminhada de seis minutos na insuficiência cardíaca. Arq. Bras. Cardiol. [online]. 2006, vol.86, n.2, pp. 120-125

104. Cipriano JR G, Yuri D, Bernadelli GF, Branco JNR. Avaliação da segurança do teste de caminhada dos 6 minutos em pacientes no pré-transplante cardíaco. Arq. Bras. Cardiol. [online]. 2009, vol.92, n.4, pp. 312-319

105. Camargo VM, Martins BCS, Jardim C, Fernandes CJC, Hovnanian A, Souza R. Validação de um protocolo para o teste de caminhada de seis minutos em esteira para avaliação de pacientes com hipertensão arterial pulmonar. J. bras. pneumol. [online]. 2009, vol.35, n.5, pp. 423-430. ISSN 1806-3713.

106. Cataneo DC,Kobayasi S, Carvalho LR, Paccanaro RC, Cataneo AJM. Accuracy of six minute walk test, stair test and spirometry using maximal oxygen uptake as gold standard. Acta Cir. Bras. [online]. 2010, vol.25, n.2, pp. 194-200

107. Knuth AG et al. Conhecimento de adultos sobre o papel da atividade física na prevenção e tratamento de diabetes e hipertensão: estudo de base populacional no Sul do Brasil. Cad. Saúde Pública. [online]. 2009, 25(3): 513-520

108. Matsudo, SM; Matsudo, VR et al. Nível de atividade física da população do Estado de São Paulo: análise de acordo com o gênero, idade, nível socioeconômico, distribuição geográfica e de conhecimento. Rev. Bras. Ciên. e Mov. [online]. 2002, v. 10 n. $4:$ p. $41-50$

109. Monteiro, C.R.; Faro, A.C.M. Atividade Física segundo a percepção dos estudantes de enfermagem; Rev. Lat. Americana de Enf. [online]. 2006, 14(6) 
110. Siqueira FCV, Nahas VM, Facchini LA, Piccini RX, Tomasi E, Thumé E, Silveira DS, Mallal PC et al. Atividade física em profissionais de saúde do Sul e Nordeste do Brasil. Cad. Saúde Pública. [online]. 2009, 25(9):1917-1928

111. Siqueira FCV, Nahas VM, Facchini LA, Piccini RX, Tomasi E, Thumé E, Silveira DS, Mallal PC et al. Aconselhamento para a prática de atividade física como estratégia de educação à saúde. Cad. Saúde Pública, Rio de Janeiro, 25(1):203-213, jan, 2009

112. Marcondelli P, Costa THM, Shimitz BAS. Nível de atividade física e hábitos alimentares de universitários do $3^{\circ}$ ao $5^{\circ}$ semestres da área da saúde. Rev. Nutr., Campinas, 21(1):39-47, jan./fev., 2008

113. Ribeiro MA, Andrade DR, Oliveira LC, Brito CFDA, Matsudo SMM, Araújo, TL, Andrade EA, Figueira JR AJ, Braggion G, Matsudo VKR et al. Nível de conhecimento sobre atividade física para a promoção da saúde de estudantes de educação física. Rev. Bras. Ciên. e Mov. Brasília. [online]. 2010, v.9, n.3 p. 31-37

114. Seixas AM, Matsudo SM, Matsudo VKR Andrade, E.I. Braggion, G.F. Padrão da prescrição de atividade física realizada por médicos ortopedistas brasileiros. Rev. Bras. de Ciência e Movimento, v.11 n.2 63-69, 2003.

115. Gámez R, Venegas AS, Barón HY, Pinto AMA, Rodríguez ATR, et al. Conhecimento, percepção e nível da atividade física dos cidadãos de Santa Fé de Bogotá, 1999. Rev. Bras. Ciên. e Mov. [online]. 2000, v.8 n. 4 p. 51-71

116. Chiesa AM, Fracolli EA, Sousa MF. Enfermagem, academia e saúde da família. Rev Bras Saúde Fam. 2002; 2(4):52-59.

117. Tesser CD, Barros NF: Medicalização social e medicina alternativa e complementar: pluralização terapêutica do SUS. Rev Saúde Pública 2008;42(5):91420

118. Ferreira M, Matsudo S, Braggion G. Efeitos de um programa de orientação de atividade física e nutricional sobre o nível de atividade física de mulheres fisicamente ativas de 50 a 72 anos de idade. Rev Bras Med Esporte. Vol. 11, No 3 Mai/Jun, 2005 


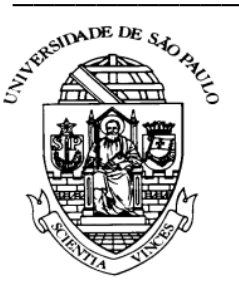

\author{
ANEXO 01 \\ Universidade de São Paulo - Escola de Enfermagem \\ Departamento de Enfermagem em Saúde Coletiva
}

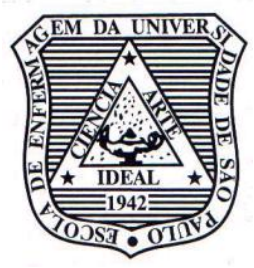

Av. Dr. Enéas de Carvalho Aguiar, 419 - Cerqueira César - CEP: 05403-000

Fone: 3061-7652 - FAX: (11) 3066-7662 - Cx. Postal: 41633 - e-mail: enssecre@edu.usp.br

\title{
TERMO DE CONSENTIMENTO LIVRE E ESCLARECIDO
}

Eu, Vitor Hugo Marques, aluno do Curso de Pós-Graduação em Enfermagem em Saúde Coletiva da Universidade de São Paulo (EEUSP), estou realizando uma pesquisa, cujo título é Caracterização do Uso da Atividade Física com fins terapêuticos com enfermeiros da Estratégia Saúde da Família do Município de São Paulo.

A pesquisa tem por finalidade fazer um levantamento sobre os conceitos de atividade física como efeito promotor da saúde junto aos enfermeiros que participam ou coordenam o programa de $\mathrm{AF}$ individual ou em grupo. Para realizá-la, conto com a orientação da Prof ${ }^{a}$ Dra. Anna Maria Chiesa, do Departamento de Enfermagem em Saúde Coletiva da EEUSP.

Sua participação é muito importante. Caso concorde em participar, você deverá assinar um este Termo de consentimento e responder a um questionário sobre o grupo de caminhada da sua UBS e se você for enfermeiro gostaríamos de caracterizar o seu perfil e avaliar o seu nível de conhecimento sobre Atividade Física.

Gostaria de ressaltar que todas as informações obtidas serão mantidas em sigilo e serão utilizadas somente para este estudo. Você poderá ter acesso, a qualquer tempo, às informações sobre o andamento e as conclusões da pesquisa. Caso não queira participar ou queira retirar sua autorização, em qualquer fase da pesquisa, não haverá nenhum prejuízo em sua relação com as suas atividades cotidianas e profissionais.

Pretende-se divulgar esta pesquisa e os resultados obtidos em publicações e eventos especializados, contudo assegurando-se o anonimato dos participantes.

Para a coleta destas informações será utilizado um questionário que se encontra em anexo. Contamos com sua importante colaboração na pronta devolução deste documento. Caso o sr.(a) decida participar, solicitamos assinar o presente termo.

Em caso de dúvidas, estou à sua disposição através do telefone do Departamento de Enfermagem em Saúde Coletiva, que é 3066-7652 ou se você quiser fazer alguma denúncia ética ou tiver outras dúvidas, pode ir até a Secretaria do Comitê de Ética em Pesquisa no endereço General Jardim, no 36 ou ligar para lá, pelo telefone 3397-2464.

Data: / /

Nome do Entrevistado:

Assinatura:

Nome do Entrevistador:

Assinatura: 


\section{ANEXO 02}

SÂOPAULO

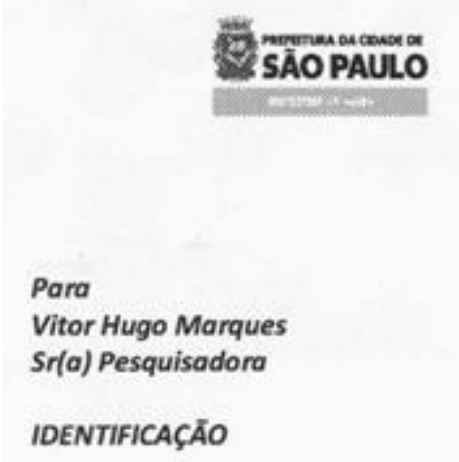

Secretaria Municipal da Saúde

Comitê de Ética em Pesquisa - CEP/SMS
São Paulo, 28 de julho de 2009.

PARECER N2 267/09-CEP/SMS

CAAE: 0120.0.162.196-09

Projeto de Pesquisa: Caracterização do Uso da Atividade Física com Fins Terapêuticos por Enfermeiros da ESF no Municipio de Săo Paula.

Pesquisador Responsável:

Instituiçāo: Escola de Enfermagem-USP

Local onde os dados serão coletados: UBS das 5 regióes do municipio de São Paulo.

\section{I-Sumário Geral do Protocolo}

OBJETIVO GERAL: caracterizar a atividade fisica, modalidade caminhada, em Unidades de Saúde da Familia e da atuaçōo do enfermeiro nessas atividades.

\section{OBJETIVOS ESPECIFICOS:}

(1) caracterizar os grupos de caminhada das Unidades de Saúde da Famillia, catalogados pela Coordenação de Atenção Básica da prefeitura municipal de Sõo Paulo (CAB-PMSP);

(2) caracterizar a atuação do enfermeiro no grupo de caminhada;

(3) Avaliar o nivel de conhecimento, para prescrição de atividade fisica, dos enfermeiros que atuam nos grupos de caminhada.

TIPO DE PESQUISA: o pesquisador designa o seu estudo como observacional, descritivo, transversal, de abordagem quantitativa. Serão aplicados questionários pelo autor do estudo, através de entrevistas, nas UBS que tenham a Estratégia Saúde da Familia e tenham grupos de caminhada, nas cinco regiōes do Municipio de São Paulo. Não há referência a amostragem.

Os critérios de inclusāo para os sujeitos da pesquisa sōo:

(1) estar diretamente envolvido com o grupo de caminhada, em açōes de supervisão, organização ou execução;

(2) atuar no grupo de caminhada, no mínimo há um mês;

(3) assinar o termo de consentimento livre e esclarecido.

Os critérios de exclusão são:

(1) não estar atuando junto ao grupo de caminhada no momento da coleta de dados;

(2) ter uma participação irregular, não continua no grupo de caminhada.

\section{II- Consideraçōes.}

\section{Apresentação do Protocolo}

A Folha de Rosto está corretamente preenchida. O curriculo do pesquisador responsável está de acordo com a proposta da pesquisa. O orçamento detalhado e o cronograma da pesquisa estäo adequados.

Está sendo proposto um estudo epidemiológico transversal (página 9 - metodologia). 0 estudo impõe mínimas condiçōes de risco ou desconforto ao sujeito da pesquisa, devidamente justificado no corpo do projeto. 
Termo de Consentimento Livre e Esclarecido (TCLE) - É conciso, objetivo, está redigido na forma de convite à participação no estudo, em linguagem adequada ao nivel sócio-cultural dos sujeitos de pesquisa. Há explicitaçõo das garantias referidas no item IV. 1 da Res.CNS 196/96.

\section{III- Parecer do CEP: Projeto APROVADO}

Antes do inicio da coleta de dados, alertamos para a necessidade de contato com o gerente da unidade quando não foi ele quem autorizou a realização da pesquiso.

Salientamos que o pesquisador deve desenvolver a pesquisa conforme delineada no protocolo aprovado. Eventuais modificaçōes ou emendas ao protocolo devem ser apresentadas ao CEP de forma ciara e sucinto, identificando a parte do protocolo a ser madificada e suas justificativas. O relatório final deve ser apresentado ao CEP, logo que o estudo estiver concluido.

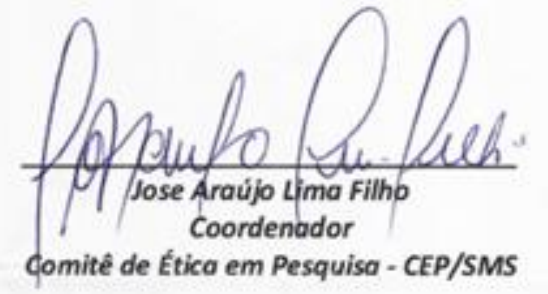

Rua General Jardim, 36 / 89-São Paulo - CEP 01223 -010 Telefone: (11) 33972464 - e-mail: smscep@gmail.com homepage: http://portal.prefeitura.sp.gov.br/secretarias/saude/cepsms 


\begin{abstract}
ANEXO 03
UBS:

Iniciais: - Idade: anos - Formado há: meses

Tempo de Trabalho no PSF: meses - Tempo de Trabalho na UBS: meses

Especialidade:
\end{abstract}

\title{
I - QUESTIONÁRIO SOBRE O NÍVEL DE CONHECIMENTO:
}

1. Para as pessoas no geral, no mínimo quantos dias da semana você acha que elas devem ser fisicamente ativas para ser bom para a saúde?

$$
\text { dia (s) por semana } \quad \text { (8) Não importa a freqüência }
$$

(9) Exercício / AF pode fazer mal (10) Não sei

2. Em cada um dos dias que alguém faz alguma atividade física, no mínimo por quanto tempo deve fazer para ser bom para a saúde?

minutos por dia

3. Essa atividade física deve ser feita em uma sessão ou pode ser dividida em períodos curtos?
(a) Uma sessão
(b) Curtos períodos
(c) Não importa
(d) Não sei

3a. Em caso da resposta anterior for a alternativa ( b ), qual é o período mínimo de tempo que a atividade deve ser executada?

$$
\text { min por sessão }
$$

4. Se alguém está fazendo atividade física para melhorar a saúde, qual das seguintes afirmações descreve melhor quanto esforço ela precisa fazer?

(1) Deve deixar a pessoa se sentir exausto

(2) Deve fazer a pessoa se sentir sem fôlego e suado

(3) Deve fazer a pessoa se sentir ligeiramente aquecido e respirando com mais dificuldade que o normal

(4) Não deve fazer a pessoa respirar mais difícil do normal

(5) Não sei 


\section{II - QUESTIONÁRIO: CARACTERIZAÇAO DO GRUPO DE CAMINHADA}

5. Há quanto tempo existe o Programa de Caminhada nesta UBS?

meses ( ) Não sei

6. Quantas vezes por semana é realizada esta atividade (CAMINHADA)?

por semana ( ) Não sei

7. Nos dias em que ocorre esta atividade (CAMINHADA) quanto tempo costuma durar?

minutos ( ) Não sei

8. Na unidade é utilizado algum protocolo clínico para diagnosticar / identificar sedentarismo dos pacientes nas suas consultas de enfermagem?

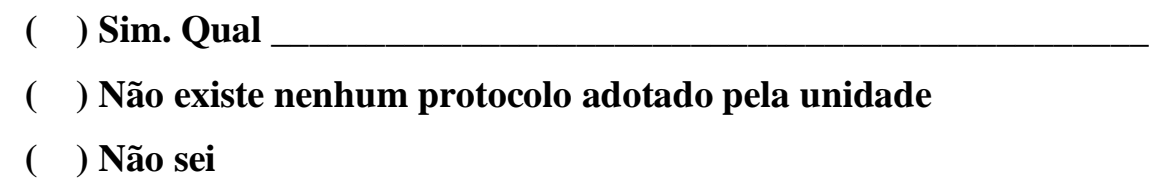

9. Os pacientes são encaminhados para o GRUPO DE CAMINHADA:

NESTA QUESTÃO, PODEM SER ASSINALADAS MAIS DE UMA RESPOSTA AFIRMATIVA

( a ) após passar em consulta individual com o enfermeiro

( b ) após passar em consulta individual com o médico

( c ) após passar em consulta individual com outro profissional de nível superior:

( d ) em qualquer momento encaminhado por auxiliares ou técnicos de enfermagem

( e ) em qualquer momento encaminhado por ACS

( $f$ ) em qualquer momento encaminhado por funcionários do setor administrativo da unidade

( g ) em qualquer momento desde que o próprio paciente solicite sua inclusão 


\section{III - QUESTIONÁRIO: ANÁLISE DE PRÁTICA PROFISSIONAL}

\section{Há quanto tempo você utiliza ou participa do GRUPO DE CAMINHADA da Unidade}

meses ( ) participa de forma contínua / ininterrupta

( ) realiza rodízio com os outros enfermeiros da unidade

\section{Sua participação no GRUPO DE CAMINHADA da unidade é:}

a) Voluntária e você acredita totalmente nos benefícios terapêuticos da caminhada

b) Voluntária e você acredita parcialmente nos benefícios terapêuticos da caminhada

c) Involuntária e você acredita totalmente benefícios terapêuticos da caminhada

d) Involuntária e você acredita parcialmente nos benefícios terapêuticos da caminhada

12. Em relação à sua participação no GRUPO DE CAMINHADA da unidade você:

a) gostaria de continuar participando desta atividade

b) gostaria de interromper por algum tempo sua participação nesta atividade

c) não gostaria de continuar participando desta atividade

d) gostaria que esta responsabilidade fosse compartilhada com os demais enfermeiros da unidade

13. Quais são as atividades executadas por você no GRUPO DE CAMINHADA da Unidade?

NESTA QUESTÃO, PODEM SER ASSINALADAS MAIS DE UMA RESPOSTA AFIRMATIVA

a ) Avaliar os pacientes para inclusão no grupo

b ) Acompanhar o grupo em sua caminhada vezes por mês

c ) Avaliar os participantes do grupo antes de iniciar as atividades no grupo de caminhada

d) Avaliar os participantes do grupo de caminhada vezes por mês

e ) Elaborar de escalas dos funcionários responsáveis por acompanhar o grupo de caminhada, define o horário, os dias de execução e a duração da atividade, etc.

f ) Participar de forma discreta oferecendo respaldo administrativo ao responsável direto pelo grupo de caminhada

g ) NÃO interfere ou NÃO participa de forma ativa do grupo de caminhada

14. Quais outros profissionais da unidade estão envolvidos nas atividades GRUPO DE CAMINHADA?

NESTA QUESTÃO, PODEM SER ASSINALADAS MAIS DE UMA RESPOSTA AFIRMATIVA
( a ) médico
( b ) ACS
(c) auxiliar / técnico de enfermagem
(d) fisioterapeuta
(e ) Educador físico
(f) Terapeuta ocupacional
( g ) outros:

$$
\text { V- voluntário } \quad F \text { - funcionário }
$$

